\section{ADVANCED STEEL CONSTRUCTION}

\section{An International Journal}

Volume 3 Number 4

December 2007

CONTENTS

Technical Papers

Flexural Behaviour of SFRC In-filled Light Gauge Steel Rectangular Box Sections S. Senthil Selvan, K. Nagamani and E. Chandrasekaran

Collapse and Rehabilitation of Steel Tanks Roof Structures

F. Turcic, I. Luketina and M. Plisic

Design of Corrugated Webs under Patch Load

Krzysztof R. Kuchta

Structures, Design and Construction of a Steel Orthotropic Bridge in Sofia D. Partov and D. Dinev

Ductility of High Performance Steel Moment Connections Ana M. Girão Coelho and Frans S. K. Bijlaard

ISSN 1816-112X

Copyright $\odot 2007$ by :

The Hong Kong Institute of Steel Construction

Website: $h t t p: / / w w w . h k i s c . o r g /$

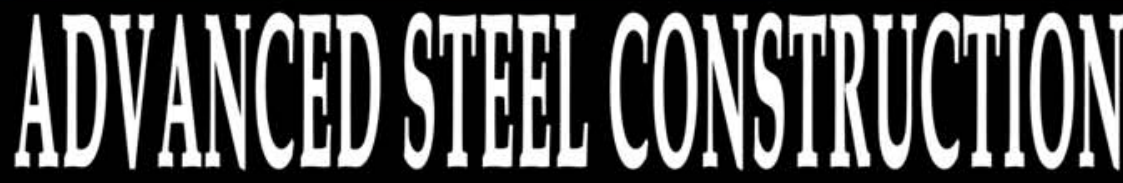

an International Jounal ISSN 1816-112X

Volume 3 Number 4

December 2007

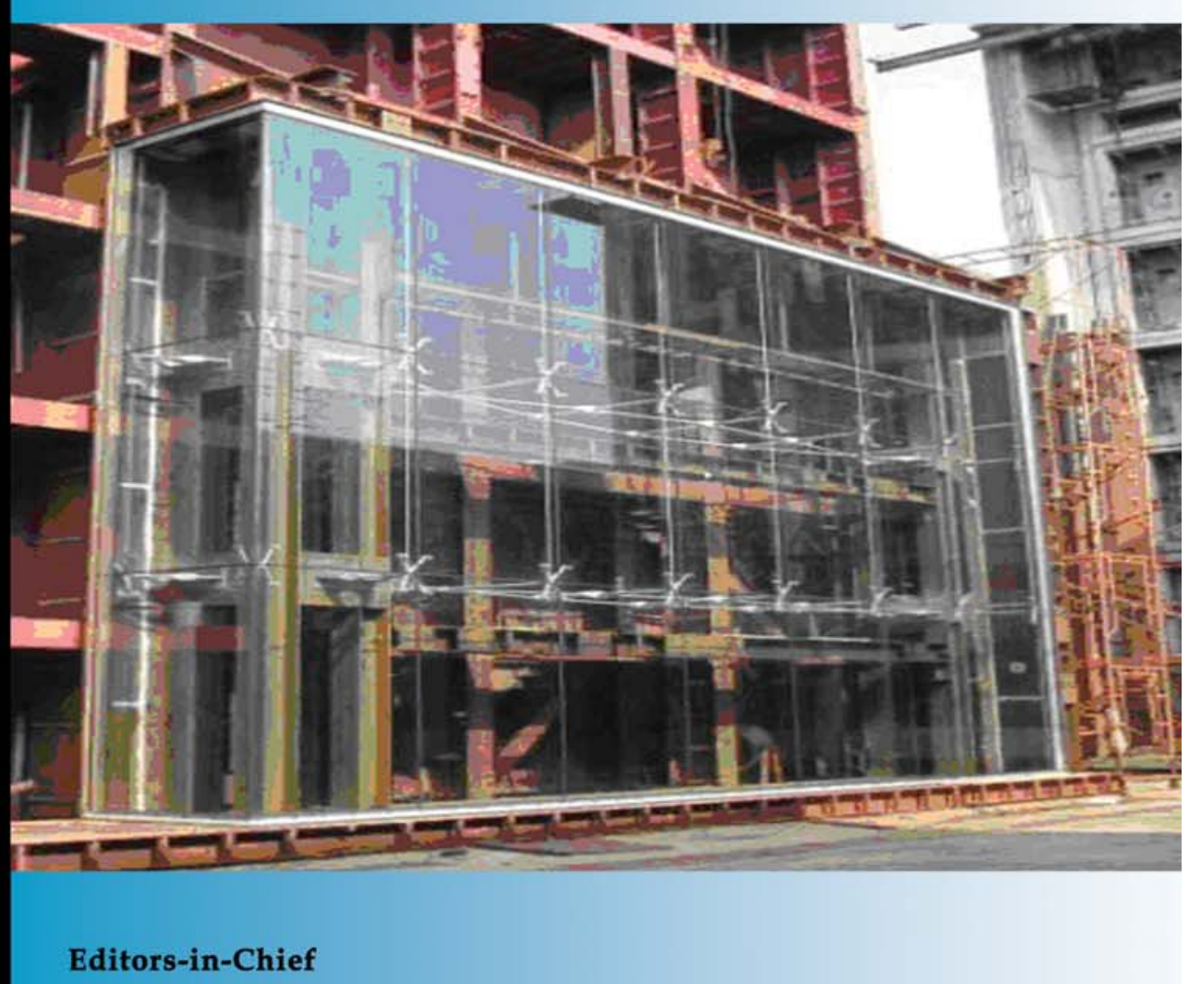

S.L. Chan, The Hong Kong Polytechnic University, Hong Kong

W.F. Chen, University of Hawaii at Manoa, USA

R. Zandonini, Trento University, Italy 


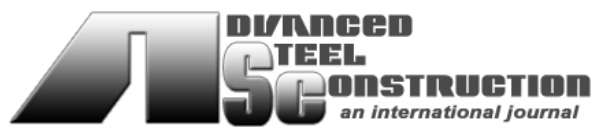

ISSN 1816-112X

\section{Advanced Steel \\ Construction an international journal}

\section{EDITORS-IN-CHIEF}

Asian Pacific, African and organizing Editor

S.L. Chan

The Hong Kong Poly. Univ., Hong Kong

\section{American Editor \\ W.F. Chen \\ Univ. of Hawaii at Manoa, USA}

\section{European Editor}

R. Zandonini

Trento Univ., Italy

\section{INTERNATIONAL} EDITORIAL BOARD

F.G. Albermani

The Univ. of Queensland, Australia

F.S.K. Bijlaard

Delft Univ. of Technology, The Netherlands

R. Bjorhovde

The Bjorhovde Group, USA

M.A. Bradford

The Univ. of New South Wales, Australia

D. Camotim

Technical Univ. of Lisbon, Portugal

C.M. Chan

Hong Kong Uni v. of Science \& Technolog Hong Kong

S.P. Chiew

Nanyang Technological Univ., Singapore

K.F. Chung

The Hong Kong Polyt. Univ., Hong Kong

G.G. Deierlein

Stanford Univ., California, USA

L. Dezi

Univ. of Ancona, Italy

D. Dubina

The Politehnica Univ. of Timosoara, Romania
R. Greiner

Technical Univ. of Graz, Austria

G.W.M. Ho

Ove Arup \& Pa rtners Hong Kon g Ltd. Hong Kong

B.A. Izzuddin

Imperial College of Science, Technology and Medicine, UK

J.P. Jaspart

Univ. of Liege, Belgium

S. A. Jayachandran

SERC, CSIR, Chennai, India

S. Kitipornchai

City Univ. of Hong Kong, Hong Kong

D. Lam

Univ. of Leeds, UK

G.Q. Li

Tongji Univ., China

J.Y.R. Liew

National Univ. of Singapore, Singapore

X. Liu

Tsinghua Univ., China

E.M. Lui

Syracuse Univ., USA

Y.L. Mo

Univ. of Houston, USA

J.P. Muzeau

CUST, Clermont Ferrand, France

$\mathrm{y}$,

D.A. Nethercot

Imperial College of Science, Technology and Medicine, UK

D.J. Oehlers

The Univ. of Adelaide, Australia

K. Rasmussen

The Univ. of Sydney, Australia

T.M. Roberts

Cardiff Univ., UK

J.M. Rotter

The Univ. of Edinburgh, UK

C. Scawthorn

Scawthorn Porter Associates, USA

P. Schaumann

Univ. of Hannover, Germany
G.P. Shu

Southeast Univ. China

J.G. Teng

The Hong Kong Polyt. Univ., Hong Kong

G.S. Tong

Zhejiang Univ., China

K.C. Tsai

National Taiwan Univ., Taiwan

C.M. Uang

Univ. of California, USA

B. Uy

The Univ. of Wollongong, Australia

M. Veljkovic

Univ. of Lulea, Sweden

F. Wald

Czech Technical Univ. in Prague, Czech

Y.C. Wang

The Univ. of Manchester, UK

D. White

Georgia Institute of Technology, USA

E. Yamaguchi

Kyushu Institute of Technology, Japan

Y.B. Yang

National Taiwan Univ., Taiwan

B. Young

The Univ. of Hong Kong, Hong Kong

X.L. Zhao

Monash Univ., Australia 


\section{General Information Advanced Steel Construction, an international journal}

\section{Aims and scope}

The International Journal of Advanced Steel Construction provides a platform for the publication and rapid dissemination of ori ginal and up-to-date research and tec hnological developments in steel c onstruction, design and anal ysis. Scope of research $p$ apers published in this journal includes but is not limite $d$ to theor etical and expe rimental research on elements, assemblages, sy stems, material, design philosophy and codification, standards, fabrication, projects of innov ative nature and computer tech niques. The journal is specifically $t$ ailored to channel the exchange of tec hnological know-ho w bet ween $r$ esearchers an $d$ practitioners. Contributions from all aspects related to the recent developments of advanced steel construction are welcome.

Instructions to authors

Submission of the manuscript. Authors may submit three double-spaced hard copies of manuscripts together with an electronic copy on a diskette or cd-rom in an editable format (MS Word is preferred). Manuscripts should be submitted to the regional editors as follows for arrangement of review.

Asian Pacific, African and organizing editor : Professor S.L. Chan

American editor :

European editor :

Professor W.F. Chen

Professor R. Zandonini

All manuscripts submitted to the journal are highl y recommended to accompany with a list of four potential reviewers suggested by the author(s). This list should include the complete name, address, telephone and fax numbers, e mail address, and at least five keywords that identify the expertise of each reviewer. This scheme will improve the process of review.

Style of manuscript

General. Author(s) should provide full postal and email addresses and fax number for correspondence. The manuscript including abstract, keywords, references, figures and tables should be in English with pages numbered and typed with double line spacing on single side of A4 or letter-sized paper. The front page of the article should contain:

a) a short title (reflecting the content of the paper);

b) all the name(s) and postal and email addresses of author (s) specifying the author to whom correspondence and proofs should be sent

c) an abstract of 100-200 words; and

d) 5 to 8 keywords.

The paper must contain an introduction and a conclusion. The length of paper should not exceed 25 journal pages (approximately 15,000 words equivalents).

Tables and figures. Tables and figures including photographs should be typed, numbered consecutively in Arabic numerals and with short titles. They should be referred in the text as Figure 1, Table 2, etc. Originally drawn figures and photographs should be provided in a form suitable for photographic reproduction and reduction in the journal.

Mathematical expressions and units. The Systeme Internationale (SI) should be followed whenever possible. The numbers identifying the displayed mathematical expression should be referred to in the text as Eq. (1), Eq. (2).

References. References to published literature should be referred in the text, in the order of citation with Arabic numerals, by the last name(s) of the author(s) (e.g. Zandonini and Zanon [3]) or if more than three authors (e.g. Zandonini et al. [4]) . References should be in English $w$ ith occasional allow ance of 1-2 e xceptional referenc es in local lang uages and $r$ eflect the curren $t$ state-of-technology. Journal titles should be abbreviated in the style of the Word List of Scientific Periodicals. References should be cited in the following style [1, 2, 3].

Journal: [1] Chen, W.F. and Kishi, N., "Semi-rigid Steel Beam-to-column Connections, Data Base and Modellin g", Journal of Structural Engineering, ASCE, 1989, Vol. 115, No. 1, pp. 105-119.

Book: [2] Chan, S.L. and Chui, P.P.T., "Non-linear Static and Cyclic Analysis of Semi-rigid Steel Frames", Elsevier Science, 2000

Proceedings: [3] Zandonini, R. a nd Zanon, P., "Experimental Analy sis of S teel Beams with Semi -rigid Joint s", Proceedings of International Conference on Advances in Steel Structures, Hong Kong, 1996, Vol. 1, pp. 356-364.

Proofs. Proof will be sent to the c orresponding author to correct an y typesetting errors. Alternations to the original manuscript at this stage will not be accepted. Proofs should be returned within 48 hours of receipt by Express Mail, Fax or Email.

Copyright. Submission of an article to "Advanced Steel Construction" implies that it presents the original and unpublished work, and not under consideration for publication nor published elsewhere. On acceptance of a manuscript submitted, the copyright thereof is transferred to th e publisher $b y$ the Transfer of $C$ opyright Agreement and upon $t$ he acceptance of publication for the $p$ apers, the corresponding author must sign the form for Transfer of Copyright.

Permission. Quoting from this journal is granted provided that the customary acknowledgement is given to the source.

Page charge and Reprints. There will be no page charges if the length of paper is within the limit of 25 journal pages. A total of 30 free offprints will be supplied free of charge to the corresponding author. Purchasing orders for additional offprints can be made on order forms which will be sent to the authors. These instructions can be obtained at the Hong Kong Institute of Steel Construction, Journal website: http://www.hkisc.org

The International Journal of Advanced Steel Construction is published quarterly by non-profit making learnt society, The Hong Kong Institute of Steel Construction, c/o Department of Civil \& Structural Engineering, The Hong Kong Polytechnic University, Hung Hom, Kowloon, Hong Kong.

Disclaimer. No responsibility is assumed for a ny injury and / or damage to per sons or property as a matter of products liability, negligence or otherwise, or from any use or operation of any methods, products, instructions or ideas contained in the material herein.

Subscription inquiries and change of address. Address all subscription inquiries and correspondence to Member Records, IJASC. Notify an address change as soon as possible. All communications should include both old and new addresses with zip codes and be accompanied by a mailing label from a recent issue. Allow six weeks for all changes to become effective.

The Hong Kong Institute of Steel Construction

HKISC

clo Department of Civil and Structural Engineering

The Hong Kong Polytechnic University,

Hunghom, Kowloon, Hong Kong, China

Tel: 852- 27666047 Fax: 852- 23346389

Email:ces/chan@polyu.edu.hk Website: http://www.hkisc.org/

ISSN 1816-112X

Copyright $\odot 2007$ by:

The Hong Kong Institute of Steel Construction. 


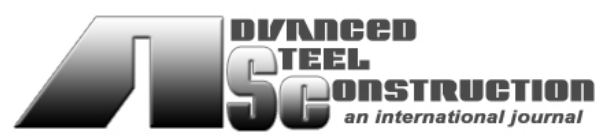

ISSN 1816-112X

\section{EDITORS-IN-CHIEF}

Asian Pacific, African and organizing Editor

S.L. Chan

The Hong Kong Polyt. Univ., Hong Kong

\section{American Editor}

W.F. Chen

Univ. of Hawaii at Manoa, USA

\section{European Editor}

R. Zandonini

Trento Univ., Italy

\section{Advanced Steel Construction an international journal}

VOLUME 3 NUMBER 4 DECEMBER 2007

Technical Papers

Flexural Behaviour of SFRC In-filled Light Gauge Steel Rectangular Box Sections

S. Senthil Selvan, K. Nagamani and E. Chandrasekaran

Collapse and Rehabilitation of Steel Tanks Roof Structures

F. Turcic, I. Luketina and M. Plisic

Design of Corrugated Webs under Patch Load

Krzysztof R. Kuchta

Structures, Design and Construction of a Steel Orthotropic Bridge

D. Partov and D. Dinev

Ductility of High Performance Steel Moment Connections Ana M. Girão Coelho and Frans S. K. Bijlaard 


\title{
FLEXURAL BEHAVIOUR OF SFRC IN-FILLED LIGHT GAUGE STEEL RECTANGULAR BOX SECTIONS
}

\author{
S. Senthil Selvan ${ }^{1, *}$, K. Nagamani ${ }^{2}$ and E. Chandrasekaran ${ }^{3}$ \\ ${ }^{1}$ Senior Lecturer, Department of Civil Engineering, B.S.A Crescent Engineering College, Chennai, India \\ *(Corresponding author: E-mail: ssenthils@gmail.com) \\ ${ }^{2}$ Professor, Structural Engineering Division, College of Engineering, Anna University, Chennai, India \\ ${ }^{3}$ Professor, Department of Civil Engineering, B.S.A Crescent Engineering College, Chennai, India
}

Received: 4 December 2006; Revised: 10 April 2007; Accepted: 20 April 2007

\begin{abstract}
This paper presents an experimental study on the flexural behaviour of plain cement concrete (PCC) and steel fiber reinforced concrete (SFRC) in-filled light gauge steel rectangular box sections under pure bending. Concrete in-fill provides internal support to the section and delays local buckling. It also contributes to the inertia of the section which increases the flexural strength and stiffness of the member. A reference hollow beam, plain concrete in-filled and SFRC in-filled (with three different volume fraction of fibers) beams are tested up to failure in pure bending with respect to their principal axes. Extensive strain and deformation measurements are taken at compression and tension zones. It is found that the SFRC in-filled sections take more load than hollow and plain concrete in-filled beams when it is subjected to loads about their major and minor axes. In this experimental study, it is observed that SFRC in-filled beams with $1 \%$ volume fraction of fibers have enhanced structural properties much more than other types of beams. The moment - strain plots show, a good ductility performance by the hollow and SFRC in-filled beams compared to the plain concrete in-filled beams. A comparison of the observed moment capacities and flexural stiffnesses is made, with the values calculated using the expressions recommended by the various codes of practice such as AIJ, BS 5400, Eurocode 4 \& LRFD. It was found that the values predicted by the AIJ code agree reasonably well with the experimental results. The codes developed for ordinary cement concrete in-filled beams require modifications when they are applied to high performance concretes such as SFRC in-filled composite beams.
\end{abstract}

Keywords: Hollow; PCC and SFRC in-filled beams; pure bending; flexural stiffness; flexural strength; ductility

\section{INTRODUCTION}

Hybrid structures such as concrete-filled or Steel Fiber Reinforced Concrete (SFRC) in-filled steel hollow sections are very effective in special types of applications such as piles, poles, highway overhead sign structures, bridge components, etc. Concrete-filled steel hollow section (CFSHS) columns are widely used in the construction industry for the past few years owing to the advantages of combining two materials. The steel hollow sections in-filled with concrete have higher strength and greater stiffness than the conventional structural steel sections and reinforced concrete sections. Concrete being a brittle material, has low tensile strength and low ductility. Steel fiber reinforced concrete, a two phase composite material, having randomly distributed steel fibers, has higher resistance against cracking, improved strength in shear, tension, compression and flexure with better toughness and ductility as compared to plain concrete. The addition of randomly distributed fibers improves many properties of concrete such as fracture strength, toughness, impact resistance, flexural strength and fatigue resistance. Both ductility and structural performance factors depend on the structural form selected and the materials used. One of the suggestions often made to improve the failure strain of concrete is by effectively confining concrete and inclusion of fibers in concrete matrix, which improves the ductility of concrete elements. Hence, SFRC in-filled steel sections provide excellent seismic resistance in two orthogonal directions and higher load carrying capacities. Furthermore, the Hyogoken-Nanbu Great Earthquake in Japan, 1995 [1], showed the merits of CFSHS beams which had demonstrated better ductility performance and larger energy absorption capacity than the conventional reinforced concrete and steel beams. Therefore, CFSHS columns and beams are considered to be more favourable structural component for use in earthquake sensitive regions. The main advantage of CFSHS columns and beams are attributed to 
the confining effect of core concrete by the steel hollow sections. The volume increase of the core concrete due to the development of cracks is constrained by the steel hollow section. As a result, the strength and the ductility performance of the core concrete are enhanced. It is also noted that more advantages can be achieved for CFSHS columns and beams with high strength in-filled material. High strength in-fill like SFRC provides better strength, greater confinement effect and ductility performance than ordinary in-fill. In spite of these advantages, the use of SFRC in-fill columns and beams in the construction industry is till scarce owing to the lack of understanding on their structural behaviour. Design codes such as AIJ [2], BS 5400 [3], Eurocode 4 [4] \& LFRD [5] are applicable only to the design of normal strength CFSHS beams. Hence, there is a need for extensive investigations of the behaviour of SFRC in-filled beams under various types of loading so that guidelines and recommendation can be developed for design.

\section{PREVIOUS RESEARCH}

Composite members consisting of steel hollow sections filled with concrete are extensively used in structures, which are subjected to large applied moments, particularly in zones of high seismicity. Composite square or rectangular concrete-filled tubes have been used increasingly as columns and beam columns in braced and un-braced framed structures [6]. Their use has ranged from low rise compression members, open floor plan construction using cold formed steel circular or rectangular tubes filled with concrete to large diameter cast-in-situ members used as the primary lateral resistant columns in multi storied buildings. In addition, concrete fillings are often used in retrofitting of damaged steel bridge piers after the 1994 Northridge earth quake in USA [7].

In spite of the bulk literature written over the last four decades on the technique of concrete filling of steel hollow sections, only a little of it was devoted to the study of flexural behaviour of these members. A set of pure bending tests on twelve circular concrete filled steel hollow sections (CFSHS) with diameters vary from 34 to $110 \mathrm{~mm}$ and wall thickness between $1 \mathrm{~mm}$ and $3 \mathrm{~mm}$ were conducted by Elchalakani et al. [8]. The test results revealed that filling of the voids in steel tube enhances the strength, ductility and energy absorption capacities of the thinner sections than the thicker sections. A simplified formula to determine the ultimate bending capacity of circular concrete filled tubes was also developed in this paper. Twelve rectangular CFSHS beams were tested under pure bending mode by Gho and Liu [9]. The test results show that all the specimens demonstrated favourable post-yield behaviour with good ductility performance. The test results were also compared with the values obtained using the formulae given in various codes. These codes considerably underestimate the moment capacities of the beams. The flexural behaviour of concrete -filled fiber-reinforced polymer circular tubes was studied by Fam and Rizkalla [10]. 20 beams were tested to study the flexural behaviour of concrete-filled glass fiber reinforced polymer tubes (GFRP). The concrete filled pultruded GFRP tubes show higher stiffness than concrete-filled filament-wound tubes of the same thickness. The load deflection behaviour of concrete-filled GFRP was almost linear. The cracking load was significantly less compared to the ultimate load. The stiffness after cracking was mainly governed by the laminate structure of the tube and the diameter-to-thickness ratio. Han [11] conducted a series of tests on the flexural behaviour of CFSHS beams. The parameters varied in these tests were depth to width ratio from 1 to 2 and tube depth to wall thickness ratio from 20 to 50. Due to the presence of the in-fill, the beams behaved in a ductile manner. The predicted load versus lateral deflection curves for the composite beams by AIJ [2], BS5400 [3], Eurocode 4 [4] and LRFD [5] codes have been found in good agreement with experimental values. The flexural behaviour of self-consolidating concrete in-filled steel tubes was studied by Han et al [12]. A total of 36 composite beams filled with self-consolidating concrete were tested to study their flexural behaviour. The test parameters were sectional types, steel yield strength, the ratio of tube diameter to wall thickness and the ratio of shear span to depth. The test 
results were compared with the values predicted by the existing codes AIJ [2], BS5400 [3], Eurocode 4 [4] and LRFD [5]. The results revealed that the beams filled with self-consolidating concrete are very similar to those of the composite beams filled with normal concrete. It was also found that the shear span to depth ratio has a very little influence on the behaviour of the concrete in-filled steel tubular beams with circular and square sections. The Eurocode 4 [4] recommendations are found to be closest to the experimental values. Helena and Knight [13] studied the flexural behaviour of normal and high strength concrete in-filled light gauge steel beams. The test results showed that the non-linearity in strain started at $75 \%$ and $95 \%$ of the ultimate load in compressive and tensile strains of the beams respectively.

The behaviour of SFRC in-filled light gauge steel columns were experimentally studied by Senthil et al [14]. In this paper a total of 18 slender columns were tested on three different cross sectional shapes under axial and eccentric loads with $1 \%$ volume fraction of steel fibers on concrete. It was concluded in this paper that SFRC in-filled columns have better load carrying capacity and ductility than the plain concrete in-filled columns and the plain concrete in-filled columns are found to have higher stiffness than the SFRC in-filled columns. Mursi and Uy [15] presented a comprehensive experimental study of thin walled steel sections utilizing high strength steel of a thin walled nature and filled with normal strength concrete. A numerical model was also developed to study the behaviour of slender concrete filled high strength steel columns incorporating material and geometric non-linearties. The behaviour of concrete filled steel slender columns affected by elastic or inelastic local buckling was also investigated. Liu [16] experimentally investigated the strength of 12 high strength rectangular concrete-filled steel hollow columns subjected to eccentric loading. The primary test parameters were the cross sectional aspect ratio, slenderness ratio and load eccentricity. The experimental ultimate capacities of the specimens were compared with the design strengths predicted by the codes. In the comparison, Eurocode 4 [4] over estimates the results by $3 \%$ whereas the LFRD [5] conservatively predicted the failure loads. The ultimate capacity of high strength rectangular concrete filled steel hollow section stub columns were experimentally investigated by Liu, Gho and Yuan [17]. 22 rectangular concrete filled steel hollow sections specimen with cross sectionals aspect ratio of $1,1.50$ and 2 were tested to failure under axial concentrated loading. In this paper, the ultimate loads obtained from the experiment were compared with the values calculated from the design codes, Eurocode 4 [4], LFRD [5] \& ACI [18]. The comparison of results showed that Eurocode 4 [4] closely predicts with a difference of $6 \%$ while LFRD [5] and ACI [18] underestimated the critical loads by $16 \%$ and $14 \%$, respectively. It was also noted that the strength of specimens decreases with the increase of cross-sectional aspect ratios. The behaviour of circular concrete filled steel tubes with various concrete strength under axial load was presented by Giakoumelis and Lam [19]. In this paper the effect of steel tube thickness, the bond strength between concrete and steel tube and the confinement of concrete were examined. It was concluded that the effect due to concrete shrinkage is critical for high strength and negligible for normal strength concrete.

From the above review, it is clear that there were only a few significant research works have been reported on the flexural behaviour of concrete in-filled light gauge steel hollow beams and there exist the following areas that require further investigations: The flexural behaviour of SFRC in-filled rectangular steel hollow section beams with respect to its major and minor axes, the differences of the predicted moment carrying capacity and flexural stiffness using the existing codes such as AIJ [2], BS 5400 [3], Eurocode 4 [4] \& LRFD [5] and the bond - slip behaviour of SFRC in-filled rectangular steel hollow sections. 
Hence the objectives of this paper are

1. To study the bond slip behaviour of plain cement concrete and SFRC in- filled light gauge steel hollow sections,

2. To study the flexural behaviour of hollow, plain cement concrete and SFRC in-filled beams

3. To illustrate the difference between the predicted beam capacities and flexural stiffness with the existing codes such as AIJ [2], BS 5400 [3], Eurocode 4 [4] \& LRFD [5].

\section{EXPERIMENTAL PROGRAMME}

\subsection{Test Specimens}

A total of 10 specimens are prepared to study the flexural behaviour of light gauge steel hollow rectangular sections with and without in-fill. The details of experiments conducted are presented in Figure 1. The dimension of the steel hollow sections are $100 \times 50 \times 2 \mathrm{~mm}$. All the specimens are $1474 \mathrm{~mm}$ long and it was tested to the failure under pure bending about its major and minor axes.

\subsection{Material Properties}

\subsubsection{Rectangular steel hollow sections}

The hollow sections are made from light gauge steel sheets, continuously welded at the middle of the $100 \mathrm{~mm}$ face along its length. In order to determine the actual material properties, four steel coupons are cut from the four faces of these sections and tested to failure under tension according to the requirement of American Society for Testing and Materials Standard (ASTM) [20]. The following average values are obtained Yield stress $f_{y}=270 \mathrm{~N} / \mathrm{mm}^{2}$; Ultimate stress $\mathrm{f}_{\mathrm{u}}=415 \mathrm{~N} / \mathrm{mm}^{2}$; Percentage of elongation $=13 \%$; and the Modulus of Elasticity $=2.05 \times 10^{5} \mathrm{~N} / \mathrm{mm}^{2}$. To prevent the local buckling failure of the specimens, the allowable $\mathrm{B} / \mathrm{t}$ ratio of the steel hollow sections is given by $\mathrm{B} / \mathrm{t} \leq 52(235 / \mathrm{fy})^{1 / 2}$ prescribed by Eurocode 4 [4] has been used. The chosen specimen satisfies the above requirements and therefore all the specimens could be classified as compact sections. The $\mathrm{B} / \mathrm{t}$ limits specified in Eurocode 4 [4] is conservative as it is derived without taking in to account the stability enhancement of the steel hollow section due to the in-fills.

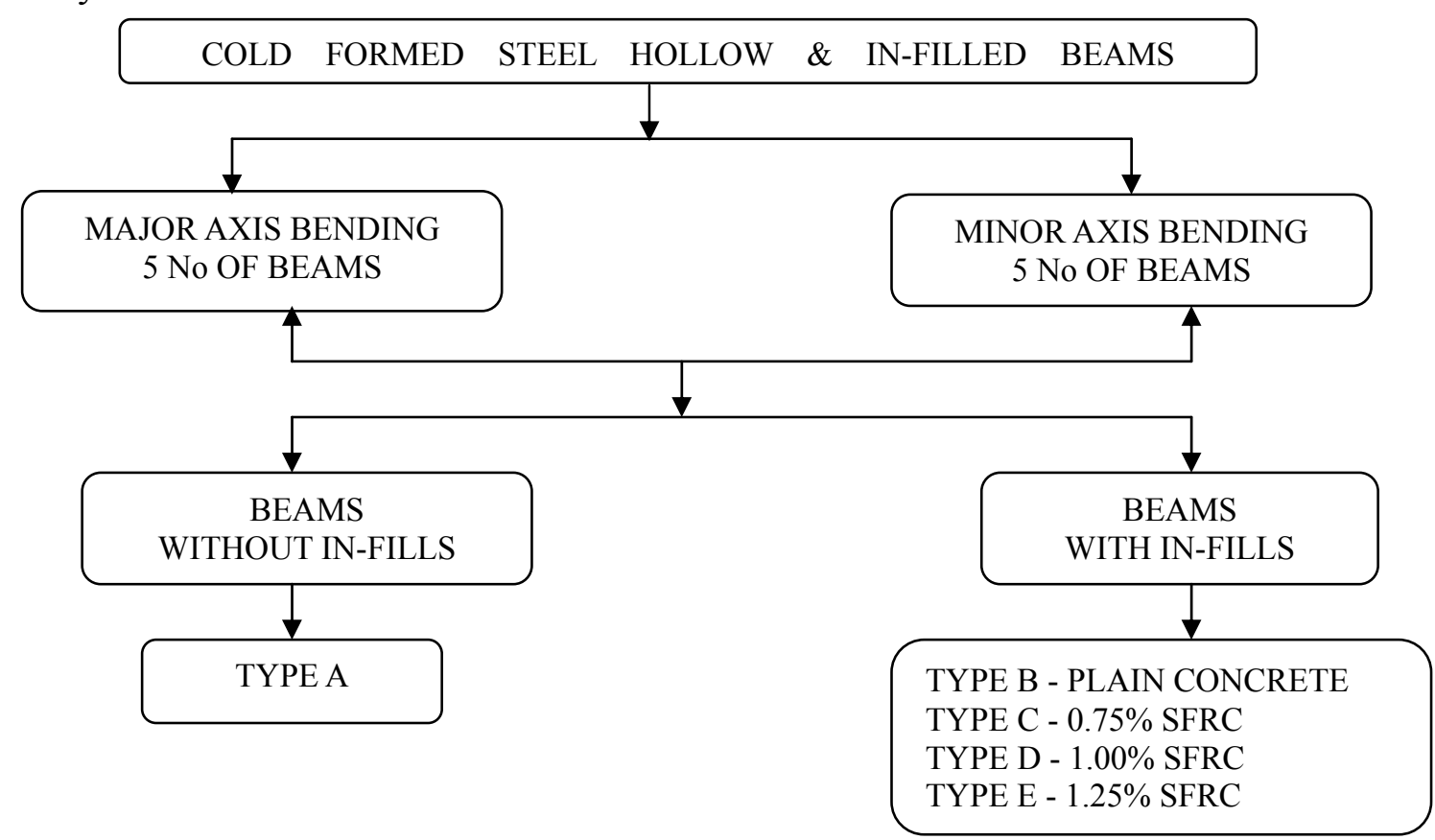

Figure 1. Details of Experiments Conducted 


\subsubsection{Plain Cement Concrete (PCC) and Steel Fiber Reinforced Concrete (SFRC)}

The concrete mix is designed for a cube compressive strength $\left(\mathrm{f}_{\mathrm{ck}}\right)$ of $20 \mathrm{MPa}$ at 28 days. The designed mix proportion is 1:2.09:2.25 with $10 \mathrm{~mm}$ size (max) coarse aggregate and $2.36 \mathrm{~mm}(\max )$ size fine aggregate with a water-cement ratio of 0.4875 based on ACI committee 211.1-1991 recommendations. Crimped steel fibers having an aspect ratio of $70\left(l_{\mathrm{f}}=30.80 \mathrm{~mm}\right.$ and $\left.\mathrm{d}_{\mathrm{f}}=0.44 \mathrm{~mm}\right)$ are used to prepare SFRC. The concrete for the eight rectangular SHS beams is mixed in four batches. The remaining two SHS beams are tested as hollow beams. Two SHS beams are filled with plain cement concrete prepared as per the above mix proportion. The remaining six beams are in-filled with SFRC having three different volume fractions of steel fibers viz. $0.75 \%, 1.00 \%$ and $1.25 \%$. $8 \mathrm{~mm}$ thick flat plates are welded on to the base of the steel hollow sections to support the wet concrete. The concrete is poured vertically in to the steel hollow section in four layers and each layer is compacted well by raising the specimen about $30 \mathrm{~cm}$ and suddenly placing it on a rubber sheet. The specimens are cured for 28 days. Subsequently $8 \mathrm{~mm}$ thick flat plates are welded at the top of the sections to complete the specimen. Table 1 shows the material properties of plain cement concrete (PCC) and steel fiber reinforced concrete (SFRC).

Table 1. Material Properties Concrete

\begin{tabular}{|c|c|c|c|c|c|c|}
\hline \multirow{2}{*}{$\begin{array}{c}\text { Specimen } \\
\text { label }\end{array}$} & \multirow[t]{2}{*}{ Type of in-fill } & \multirow{2}{*}{$\begin{array}{c}\text { Cube } \\
\text { compressive } \\
\text { strength }\left(\mathrm{f}_{\mathrm{ck}}\right) \\
\left(\mathrm{N} / \mathrm{mm}^{2}\right) \\
\end{array}$} & \multicolumn{2}{|c|}{$\begin{array}{l}\text { flexural strength } \\
\left(\mathrm{N} / \mathrm{mm}^{2}\right)\end{array}$} & \multicolumn{2}{|c|}{$\begin{array}{l}\text { Young's Modulus }\left(\mathrm{E}_{\mathrm{c}}\right) \\
\left(\mathrm{N} / \mathrm{mm}^{2}\right)\end{array}$} \\
\hline & & & test & $\begin{array}{c}\text { IS:456 } \\
{[21]}\end{array}$ & test & $\begin{array}{c}\text { IS: } 456 \\
{[21]}\end{array}$ \\
\hline Type A & $\begin{array}{l}\text { Hollow } \\
\text { (without } \\
\text { in-fill) }\end{array}$ & --- & --- & --- & --- & --- \\
\hline Type B & P.C.C & 32.44 & 4.24 & 3.99 & $2.968 \times 10^{4}$ & $2.848 \times 10^{4}$ \\
\hline Type C & $0.75 \%$ SFRC & 41.78 & 4.94 & --- & $3.230 \times 10^{4}$ & --- \\
\hline Type D & $1.00 \%$ SFRC & 57.78 & 5.86 & --- & $3.800 \times 10^{4}$ & --- \\
\hline Type E & $1.25 \%$ SFRC & 38.60 & 4.40 & --- & $3.109 \times 10^{4}$ & --- \\
\hline
\end{tabular}

\subsubsection{Push out test procedure}

Push out tests are carried out to study the bond strength between the steel sections and the in-fill. The test specimen for these test is $550 \mathrm{~mm}$ in length and the concrete is poured to $500 \mathrm{~mm}$ length leaving a $50 \mathrm{~mm}$ gap in which a groove of $7 \mathrm{~mm}$ in the form of a equilateral triangle is made at the end for relieving the air during testing [13]. The test set-up is shown in Figure 2. The load is applied through a steel plate, which rests directly on concrete in small increments and the slip is observed using a deflectometer as shown in the test set-up. The slip is very minimal indicating high bond - strength up to the ultimate load. Beyond the ultimate load, there is a rapid increase in slip, indicating the sudden decrease of bond. Due to increased characteristic compressive strength, the bond strength is high for SFRC in-filled specimens when compared to PCC in-filled specimens. Tested specimens are shown in the Figure 3 and the load - slip characteristic of the in-filled specimens are shown in Figure 4. The bond strength is found to be $0.282 \mathrm{~N} / \mathrm{mm}^{2}, 0.389 \mathrm{~N} / \mathrm{mm}^{2}$, $0.461 \mathrm{~N} / \mathrm{mm}^{2}$ and $0.318 \mathrm{~N} / \mathrm{mm}^{2}$ respectively for PCC, $0.75 \%$ SFRC in-fill, $1 \%$ SFRC in-fill and $1.25 \%$ SFRC in-fill. When compared to PCC in-filled specimens, SFRC in-filled specimens takes about $63 \%$ more load before slip. 


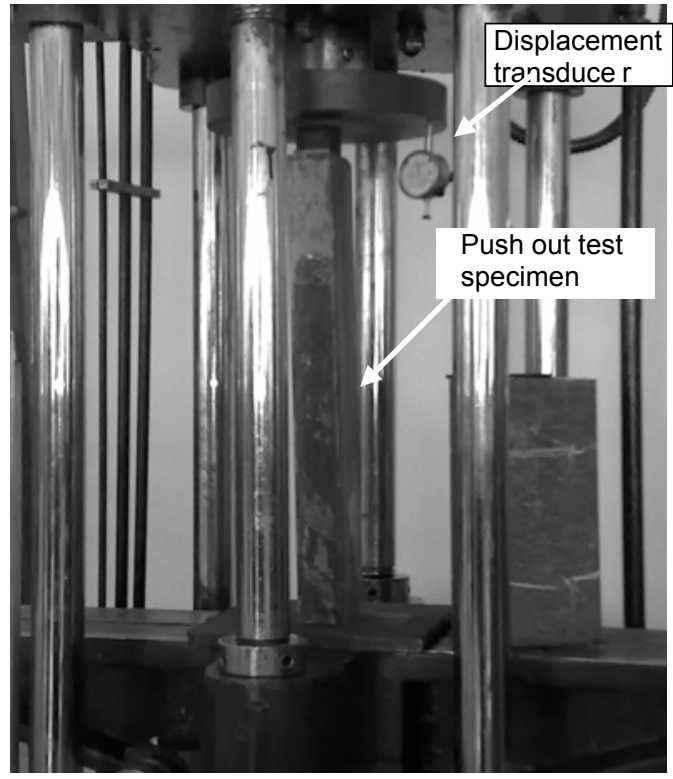

Figure 2. Test Set Up for Push Out Test

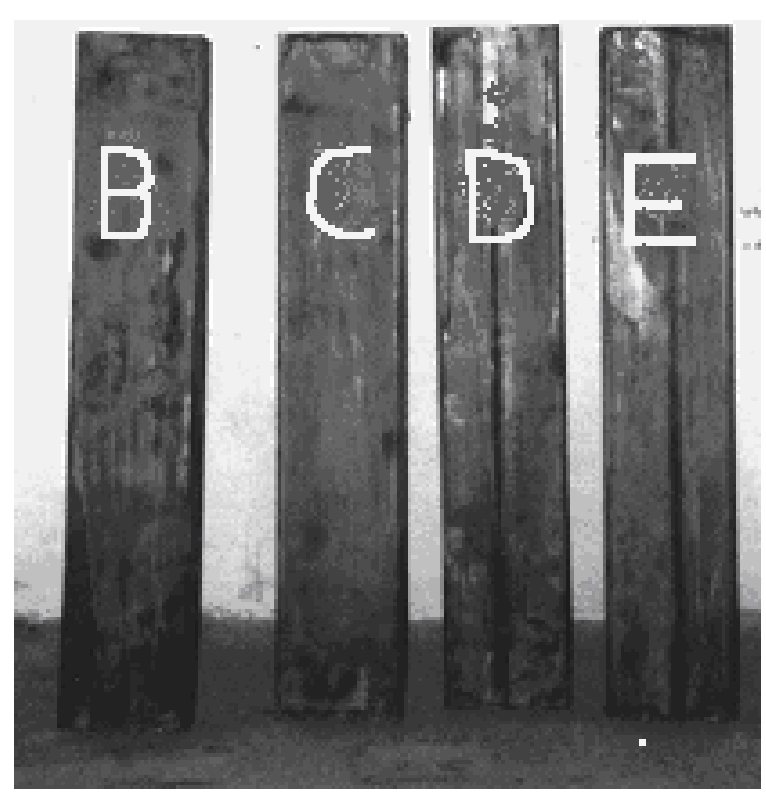

Figure 3. Tested Specimens of Push Out Test

\subsection{4} Flexural stiffness $\left(K_{e}\right)$

The experimental flexural stiffness $\left(\mathrm{K}_{\mathrm{ee}}\right)$ determined for the 10 tested beams are compared with the theoretical flexural stiffnesses $\left(\mathrm{K}_{\mathrm{e}}\right)$ calculated from the expressions given in the codes and listed in Table 2. The expressions for the flexural stiffness by the different codes are given in the Eqn. 1 to Eqn. 4.

1. AIJ [2]

2. BS $5400[3]$
Flexural Stiffness $\mathrm{K}_{\mathrm{e}}=\mathrm{E}_{\mathrm{s}} . \mathrm{I}_{\mathrm{s}}+0.20 \mathrm{E}_{\mathrm{c}} . \mathrm{I}_{\mathrm{c}}$ where $\mathrm{Es}=205,800 \mathrm{MPa} ; \mathrm{E}_{\mathrm{c}}=21,000\left(\mathrm{fc}^{\prime} / 19.60\right)^{1 / 2} \mathrm{MPa}$

3. Eurocode 4 [4] Flexural Stiffness $K_{e}=E_{s} . I_{s}+0.60 E_{c} \cdot I_{c}$ where Es = 206,000 MPa; $E_{c}=9500\left(f_{c k}+8\right)^{1 / 3} \mathrm{MPa}$

4. LRFD [5]

Flexural Stiffness $\mathrm{K}_{\mathrm{e}}=\mathrm{E}_{\mathrm{s}} . \mathrm{I}_{\mathrm{s}}+0.80 \mathrm{E}_{\mathrm{c}} . \mathrm{I}_{\mathrm{c}}$ where Es = 199,000 MPa; $E_{c}=4733\left(f_{c}^{\prime}\right)^{1 / 2} \mathrm{MPa}$

Table 2 also shows the mean and standard deviation of the ratio $\left(\mathrm{K}_{\mathrm{e}} / \mathrm{K}_{\mathrm{ee}}\right)$ obtained from different design codes. The results clearly show that the codes over estimate the flexural stiffness of the beams in general. The flexural stiffness predicted by AIJ [2] is around 6\% higher than the experimental value about the major axis loading and $0.80 \%$ lower than the experimental value about the minor axis loading for in-filled beams. Eurocode 4 [4], BS 5400 [3] and LRFD [5] gave a flexural stiffness about $45 \%$ higher than the experimental flexural stiffness values about the major axis loading and $15 \%$ higher than the experimental flexural stiffness about the minor axis loading for in-filled beams. The AIJ [2] method gives a mean value of 1.056 and standard deviation of 0.022 and predicts a slightly higher stiffness than the test results and is found to be the best predictor. This clearly shows that the flexural stiffness for the in-filled beams are less than the theoretical prediction. Due to this less flexural stiffness, the specimens show high ductile behaviour. Comparing the flexural stiffness of all the in-filled beams, 1\% SFRC in-filled beams shows less flexural stiffness about the major and the minor axes. 


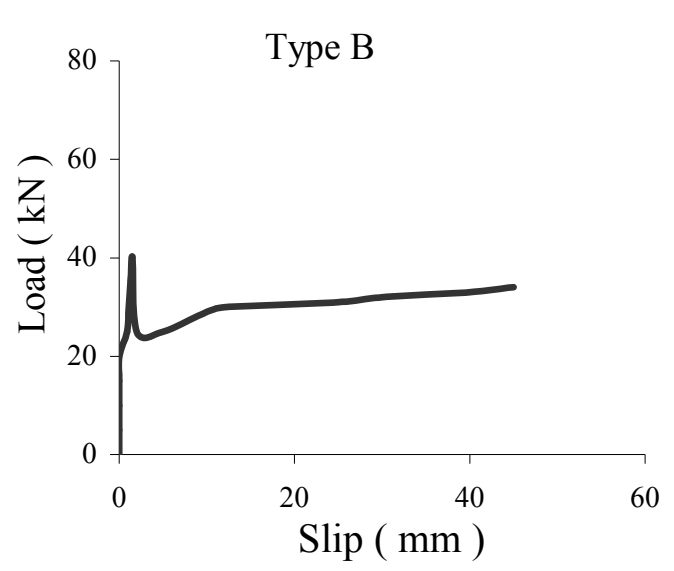

a) PCC In-filled Specimen

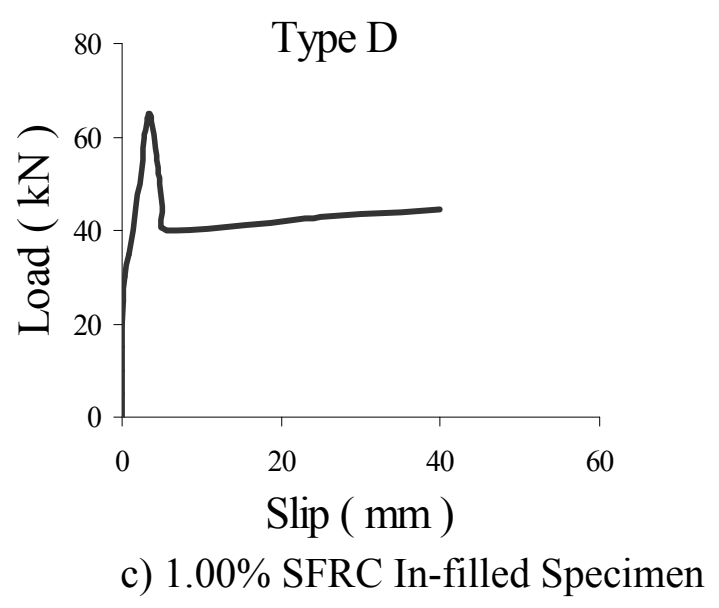

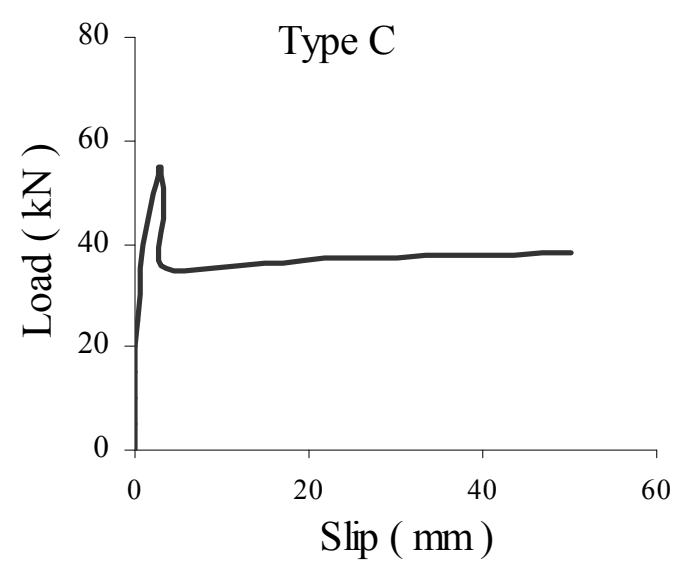

b) $0.75 \%$ SFRC In-filled Specimen

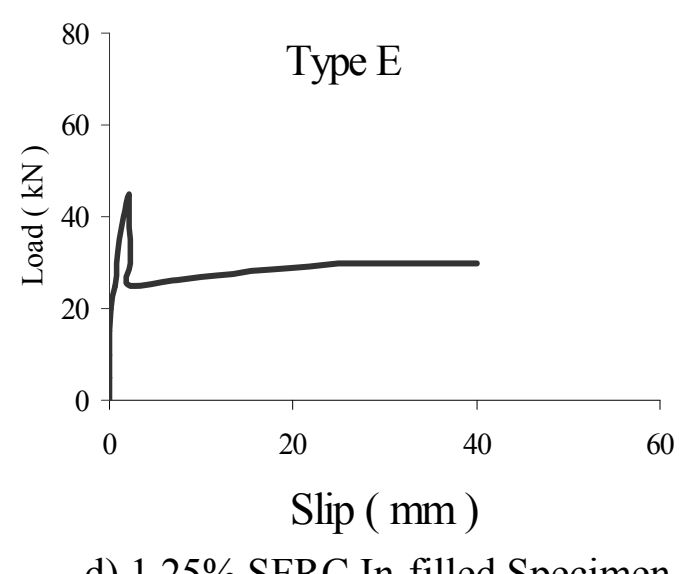

d) $1.25 \%$ SFRC In-filled Specimen

Figure 4. Load - Slip Characteristics of In-filled Specimens

\subsection{Test Procedure}

Rectangular hollow and SFRC in- filled beams are tested in the beam loading frame of $1000 \mathrm{kN}$ capacity in the Advanced Structural Engineering Laboratory of B.S.A. Crescent Engineering College, Chennai, India. The beams are tested up to failure, five with longer side vertical (about major axis) and five with shorter side vertical (about minor axis). The objective is to find the ultimate moment of the beam along the stronger and weaker axes. Loading arrangements are made such that two point loads are applied at one-third spans. Above this loading arrangement a $1000 \mathrm{kN}$ proving ring is placed and the load from the jack is applied through the proving ring. Strain gauges are fixed at six different test locations, three at top fiber of the beam and three at bottom fiber of the beam. Deflectometers are placed at the bottom at three different points to measure the vertical deflections, two deflectometer at $1 / 3{ }^{\text {rd }}$ span points and one at mid span. Two more deflectometers are also placed at the two ends on sides to check whether the load is applied vertically without any lateral translation of the beam. The loading pattern and positions of the strain gauges and deflectometers are shown in Figure 5. The load is applied at equal intervals of $0.50 \mathrm{kN}$ in the elastic 
range and at shorter intervals in the inelastic range. Deflectometer readings and strain gauge readings are taken for every increment of load. Figure 6 shows the failure modes of the tested beams about major and minor axes.

Table 2. Comparison between Predicted Initial Section Flexural Stiffness and Test Results

\begin{tabular}{|c|c|c|c|c|c|c|c|c|c|c|c|c|c|c|c|c|c|c|c|}
\hline \multirow{3}{*}{$\begin{array}{l}\text { Sl. } \\
\text { No. - }\end{array}$} & \multirow{3}{*}{$\begin{array}{l}\text { speci } \\
\text { men } \\
\text { ype }\end{array}$} & \multirow{2}{*}{\multicolumn{2}{|c|}{$\begin{array}{l}\text { Experiment } \\
(\mathrm{Kee}) \\
\mathrm{kN} \mathrm{m}^{2}\end{array}$}} & \multicolumn{4}{|c|}{ AIJ [2] } & \multicolumn{4}{|c|}{ BS 5400 [3] } & \multicolumn{4}{|c|}{ Eurocode 4 [4] } & \multicolumn{4}{|c|}{ LRFD [5] } \\
\hline & & & & \multicolumn{2}{|c|}{$\begin{array}{c}\text { Theoretical } \\
(\mathrm{Ke}) \\
\mathrm{kN} \mathrm{m}^{2}\end{array}$} & \multicolumn{2}{|c|}{$\begin{array}{c}\text { Theoretical / } \\
\text { Experimental } \\
\text { (Ke/Kee) }\end{array}$} & \multicolumn{2}{|c|}{$\begin{array}{l}\text { Theoretical } \\
(\mathrm{Ke}) \\
\mathrm{kN} \mathrm{m}^{2}\end{array}$} & \multicolumn{2}{|c|}{$\begin{array}{c}\text { Theoretical / } \\
\text { Experimental } \\
\text { (Ke/ Kee) }\end{array}$} & \multicolumn{2}{|c|}{$\begin{array}{l}\text { Theoretical } \\
(\mathrm{Ke}) \\
\mathrm{kN} \mathrm{m}^{2}\end{array}$} & \multicolumn{2}{|c|}{$\begin{array}{c}\text { Theoretical / } \\
\text { Experimental } \\
\text { (Ke/Kee) }\end{array}$} & \multicolumn{2}{|c|}{$\begin{array}{c}\text { Theoretical } \\
(\mathrm{Ke}) \\
\mathrm{kN} \mathrm{m}^{2}\end{array}$} & \multicolumn{2}{|c|}{$\begin{array}{c}\text { Theoretical / } \\
\text { Experimental } \\
\text { (Ke / Kee) }\end{array}$} \\
\hline & & $\begin{array}{l}\text { Major } \\
\text { Axis }\end{array}$ & $\begin{array}{l}\text { Minor } \\
\text { Axis }\end{array}$ & $\begin{array}{l}\text { Major } \\
\text { Axis }\end{array}$ & $\begin{array}{l}\text { Minor } \\
\text { Axis }\end{array}$ & $\begin{array}{c}\text { Major } \\
\text { Axis }\end{array}$ & $\begin{array}{c}\text { Minor } \\
\text { Axis }\end{array}$ & $\begin{array}{c}\text { Major } \\
\text { Axis }\end{array}$ & $\begin{array}{l}\text { Minor } \\
\text { Axis }\end{array}$ & $\begin{array}{l}\text { Major } \\
\text { Axis }\end{array}$ & $\begin{array}{l}\text { Minor } \\
\text { Axis }\end{array}$ & $\begin{array}{c}\text { Major } \\
\text { Axis }\end{array}$ & $\begin{array}{l}\text { Minor } \\
\text { Axis }\end{array}$ & $\begin{array}{c}\text { Major } \\
\text { Axis }\end{array}$ & $\begin{array}{l}\text { Minor } \\
\text { Axis }\end{array}$ & $\begin{array}{l}\text { Major } \\
\text { Axis }\end{array}$ & $\begin{array}{l}\text { Minor } \\
\text { Axis }\end{array}$ & $\begin{array}{l}\text { Major } \\
\text { Axis }\end{array}$ & $\begin{array}{c}\text { Minor } \\
\text { Axis }\end{array}$ \\
\hline 1 & $\mathrm{~A}$ & 139.53 & 46.05 & 150.06 & 51.65 & 1.075 & 1.122 & 150.06 & 51.65 & 1.075 & 1.122 & 150.06 & 51.65 & 1.075 & 1.122 & 150.06 & 51.65 & 1.075 & 1.122 \\
\hline 2 & B & 149.25 & 56.82 & 152.50 & 51.93 & 1.022 & 0.914 & 239.36 & 61.68 & 1.604 & 1.086 & 229.09 & 66.44 & 1.535 & 1.169 & 248.91 & 62.75 & 1.668 & 1.104 \\
\hline 3 & $\mathrm{C}$ & 144.23 & 54.04 & 152.08 & 51.88 & 1.054 & 0.960 & 209.72 & 58 & 1.454 & 1.080 & 220.51 & 64.83 & 1.529 & 1.200 & 230.86 & 60.72 & 1.601 & 1.124 \\
\hline 4 & $\mathrm{D}$ & 141.11 & 51.37 & 151.91 & 51.86 & 1.077 & 1.010 & 200.20 & 57.28 & 1.419 & 1.115 & 217.26 & 64.22 & 1.540 & 1.250 & 224.13 & 59.97 & 1.588 & 1.167 \\
\hline 5 & E & 144.93 & 54.35 & 152.17 & 51.88 & 1.050 & 0.955 & 214.63 & 58.90 & 1.481 & 1.084 & 222.08 & 65.13 & 1.532 & 1.198 & 234.12 & 61.09 & 1.615 & 1.124 \\
\hline \multicolumn{6}{|c|}{ Mean } & 1.056 & 0.992 & & & 1.407 & 1.097 & & & 1.442 & 1.188 & & & 1.510 & 1.12 \\
\hline \multicolumn{6}{|c|}{ Standard Deviation } & 0.022 & 0.080 & & & 0.198 & 0.020 & & & 0.206 & 0.047 & & & 0.245 & 0.023 \\
\hline
\end{tabular}

Table 3. Comparison between Predicted Beam Strength and Test Results

\begin{tabular}{|c|c|c|c|c|c|c|c|c|c|c|c|c|c|c|c|c|c|c|c|}
\hline \multirow{3}{*}{$\begin{array}{l}\text { S1. } \\
\text { No }\end{array}$} & \multirow{3}{*}{$\begin{array}{l}\text { Specimen } \\
\text { Type }\end{array}$} & \multicolumn{6}{|c|}{ AIJ [2] } & \multicolumn{4}{|c|}{ BS 5400 [3] } & \multicolumn{4}{|c|}{ Eurocode 4 [4] } & \multicolumn{4}{|c|}{ LRFD [5] } \\
\hline & & \multicolumn{2}{|c|}{$\begin{array}{l}\text { Experiment } \\
\text { (Mee) } \\
\mathrm{kN}-\mathrm{m}\end{array}$} & \multicolumn{2}{|c|}{$\begin{array}{c}\text { Theoretical } \\
(\mathrm{Me}) \\
\mathrm{kN}-\mathrm{m}\end{array}$} & \multicolumn{2}{|c|}{$\begin{array}{c}\text { Theoretical / } \\
\text { Experimental } \\
\text { (Me / Mee) }\end{array}$} & \multicolumn{2}{|c|}{$\begin{array}{c}\text { Theoretical } \\
(\mathrm{Me}) \\
\mathrm{kN}-\mathrm{m}\end{array}$} & \multicolumn{2}{|c|}{$\begin{array}{l}\text { Theoretical / } \\
\text { Experimental } \\
\text { (Me / Mee) }\end{array}$} & \multicolumn{2}{|c|}{$\begin{array}{c}\text { Theoretical } \\
(\mathrm{Me}) \\
\mathrm{kN}-\mathrm{m}\end{array}$} & \multicolumn{2}{|c|}{$\begin{array}{l}\text { Theoretical / } \\
\text { Experimental } \\
\text { (Me / Mee) }\end{array}$} & \multicolumn{2}{|c|}{$\begin{array}{l}\text { Theoretical } \\
(\mathrm{Me}) \\
\mathrm{kN}-\mathrm{m}\end{array}$} & \multicolumn{2}{|c|}{$\begin{array}{c}\text { Theoretical / } \\
\text { Experimental } \\
\text { (Me / Mee) }\end{array}$} \\
\hline & & $\begin{array}{l}\text { Major } \\
\text { Axis }\end{array}$ & $\begin{array}{l}\text { Minor } \\
\text { Axis }\end{array}$ & $\begin{array}{l}\text { Major } \\
\text { Axis }\end{array}$ & $\begin{array}{c}\text { Minor } \\
\text { Axis }\end{array}$ & $\begin{array}{c}\text { Major } \\
\text { Axis }\end{array}$ & $\begin{array}{l}\text { Minor } \\
\text { Axis }\end{array}$ & $\begin{array}{l}\text { Major } \\
\text { Axis }\end{array}$ & $\begin{array}{l}\text { Minor } \\
\text { Axis }\end{array}$ & $\begin{array}{c}\text { Major } \\
\text { Axis }\end{array}$ & $\begin{array}{l}\text { Minor } \\
\text { Axis }\end{array}$ & $\begin{array}{c}\text { Major } \\
\text { Axis }\end{array}$ & $\begin{array}{l}\text { Minor } \\
\text { Axis }\end{array}$ & $\begin{array}{c}\text { Major } \\
\text { Axis }\end{array}$ & $\begin{array}{l}\text { Minor } \\
\text { Axis }\end{array}$ & $\begin{array}{l}\text { Major } \\
\text { Axis }\end{array}$ & $\begin{array}{l}\text { Minor } \\
\text { Axis }\end{array}$ & $\begin{array}{c}\text { Major } \\
\text { Axis }\end{array}$ & $\begin{array}{c}\text { Minor } \\
\text { Axis }\end{array}$ \\
\hline 1 & A & 2.457 & 1.474 & 3.953 & 2.721 & 1.609 & 1.846 & 4.946 & 3.146 & 2.013 & 2.134 & 3.953 & 2.721 & 1.609 & 1.846 & 3.953 & 2.721 & 1.609 & 1.846 \\
\hline 2 & B & 6.550 & 3.439 & 5.713 & 2.880 & 0.872 & 0.837 & 5.427 & 3.318 & 0.829 & 0.965 & 5.266 & 2.767 & 0.804 & 0.805 & 5.123 & 3.542 & 0.782 & 1.030 \\
\hline 3 & $\mathrm{C}$ & 7.370 & 4.422 & 6.460 & 2.989 & 0.877 & 0.676 & 5.527 & 3.345 & 0.750 & 0.756 & 5.594 & 3.268 & 0.759 & 0.739 & 6.068 & 3.660 & 0.823 & 0.828 \\
\hline 4 & $\mathrm{D}$ & 7.861 & 5.405 & 7.694 & 3.173 & 0.979 & 0.587 & 5.671 & 3.379 & 0.721 & 0.625 & 6.150 & 3.540 & 0.782 & 0.655 & 6.978 & 3.774 & 0.888 & 0.698 \\
\hline 5 & $\mathrm{E}$ & 6.592 & 3.931 & 6.054 & 2.941 & 0.918 & 0.748 & 5.009 & 3.336 & 0.760 & 0.849 & 4.942 & 3.216 & 0.750 & 0.818 & 5.798 & 3.627 & 0.880 & 0.923 \\
\hline \multicolumn{6}{|c|}{ Mean } & 1.051 & 0.939 & & & 1.015 & 1.066 & & & 0.941 & 0.973 & & & 0.996 & 1.065 \\
\hline \multicolumn{6}{|c|}{ Standard Deviation } & 0.315 & 0.515 & & & 0.560 & 0.610 & & & 0.374 & 0.492 & & & 1.129 & 0.424 \\
\hline
\end{tabular}

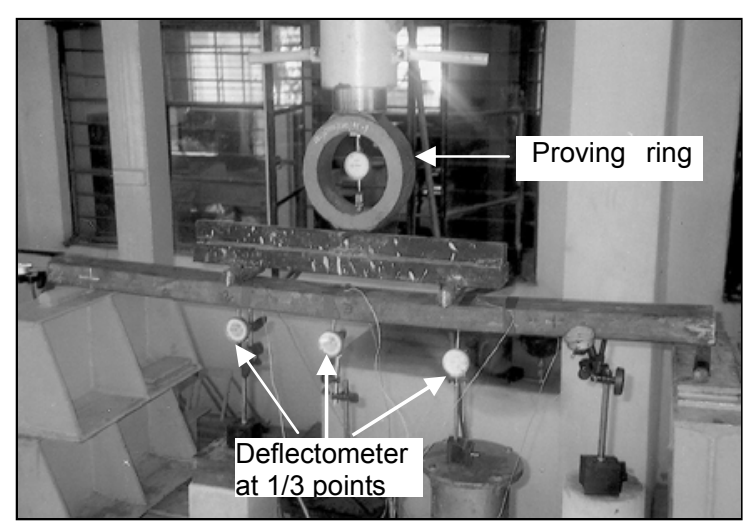

Figure 5. Test Set Up

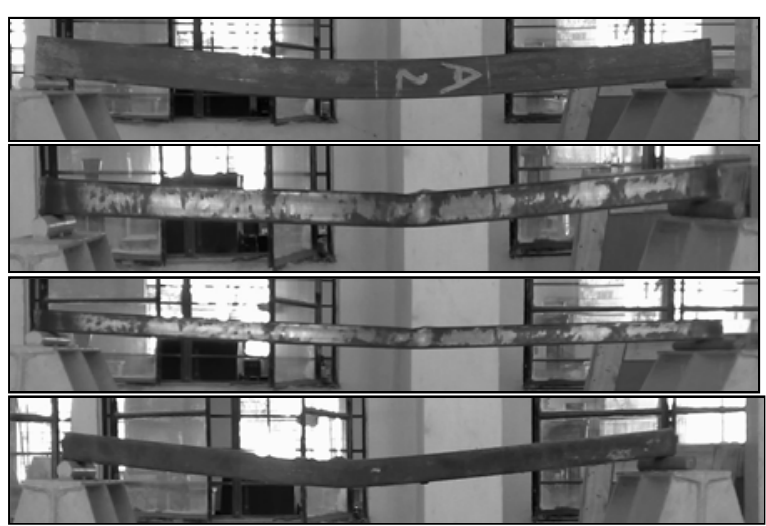

Figure 6. Failure Modes of the Tested Beam Specimen 


\section{RESULTS AND DISCUSSION}

\subsection{Ultimate Load}

All the specimen are tested up to failure under pure bending about their major and minor axes. For each load interval, the loading is paused for a minute to allow for the plastic deformation of steel and for the concrete to crack. The cracking sound of concrete are heard at loads around 2 $\mathrm{kN}$ and $1.50 \mathrm{kN}$ for hollow beams and around $10 \mathrm{kN}$ and $6 \mathrm{kN}$ for beams with in-fills for loads applied about their major and minor axes respectively. All the in-filled beams failed only due to overall bending. After attaining the ultimate load levels the beams deflected more without any significant increase in the load. This shows the crushing of concrete at the point of maximum bending tensile stress and rapid yielding of outer steel section. The SFRC in-filled beams carried around 3 times more load than the hollow beams about their major axis loading and 3.66 times more load than the hollow beams about their minor axis loading. When compared with PCC in-filled beams the SFRC in-filled beams carried 1.20 times more load about their major axis and 1.55 times more load about their minor axis.

\subsection{Provisions in Different Codes for the Determination of Moment Capacities}

The expressions for determining the moment capacity of in-filled beams by the various codes are illustrated through Eqn. 5 to Eqn. 16. These equations are theoretically analysed for the present study of SFRC in-filled beams. The notations used in this paper for the expressions are the same as that used in the original code.

\subsection{1 $\quad A I J[2]$}

This AIJ [2] code predicts the theoretical moment based on the combined effect of steel and concrete taking into account of the plastic section modulus and angular location of the neutral axis. The property of the steel is fully utilized by taking into account the plastic section modulus of the steel tube. The ultimate confined concrete strength is considered here which will give the true value of the in-filled beams.

Ultimate moment of CFT cross section $\mathrm{M}_{\mathrm{u}}={ }_{\mathrm{s}} \mathrm{M}_{\mathrm{u}}+{ }_{\mathrm{c}} \mathrm{M}_{\mathrm{u}}$

Ultimate moment due to steel tube $\left({ }_{\mathrm{s}} \mathrm{M}_{\mathrm{u}}\right)={ }_{\mathrm{s}} \mathrm{Z}_{\mathrm{p}} \sigma_{\mathrm{y}}$

Ultimate moment due to concrete $\quad\left({ }_{\mathrm{c}} \mathrm{M}_{\mathrm{u}}\right)=\frac{1}{12}\left({ }_{\mathrm{c}} \mathrm{r}_{\mathrm{o}} \mathrm{f}_{\mathrm{c}}\right) \mathrm{d}^{3} \sin ^{3} \theta$

\subsubsection{BS $5400[3]$}

This code predicts the flexural behaviour by taking the average compression stress in the concrete at failure to the design yield strength of steel considering the composite action between steel and concrete. It also gives more importance to steel section rather than concrete core. So the theoretical moment calculated for SFRC in-filled beams will not exhibit the true moment.

Ultimate moment $=0.91 \mathrm{f}_{\mathrm{y}}\left[\mathrm{A}_{\mathrm{s}} \frac{\mathrm{h}-\mathrm{d}_{\mathrm{c}}}{2}+\mathrm{b}_{\mathrm{f}} \mathrm{t}_{\mathrm{f}}\left(\mathrm{t}_{\mathrm{f}}+\mathrm{d}_{\mathrm{c}}\right)\right]$

\subsubsection{Eurocode 4 [4]}

The moment resistance of the CFT beams are calculated based on the plastic stress distribution and full strain compatibility of the cross section for the both steel and concrete. Here the strength of concrete in tension was omitted in the calculation and this code was applicable to the design of CFT 
beams with concrete cylinder strength and steel yield stress of not higher than 50 and $355 \mathrm{MPa}$ respectively.

Ultimate flexural capacity of CFT section $\quad M_{\text {pl.Rd }}=M_{\max } R_{d}-M_{n} R_{d}$

The maximum resistance about major axis $M_{\max } R_{d}=w_{p a} \cdot f_{y d}+w_{p s} \cdot f_{s d}+w_{p c} \cdot F_{c d} / 2$

Combined plastic section modulus of structural steel reinforcement and concrete parts

$\mathrm{M}_{\mathrm{n}} \mathrm{R}_{\mathrm{d}}=\mathrm{w}_{\mathrm{pan}} \cdot \mathrm{f}_{\mathrm{yd}}+\mathrm{w}_{\mathrm{psn}} \cdot \mathrm{f}_{\mathrm{sd}}+\mathrm{w}_{\mathrm{pcn}} \cdot \mathrm{F}_{\mathrm{cd}} / 2$

Plastic section modulus of the concrete core $\quad \mathrm{w}_{\mathrm{pcn}}=(\mathrm{d}-2 \mathrm{t}) \mathrm{h}_{\mathrm{n}}{ }^{2}$

Plastic section modulus of the steel tube

$$
\mathrm{w}_{\mathrm{pan}}=\mathrm{bh}_{\mathrm{n}}{ }^{2}-\mathrm{w}_{\mathrm{pcn}}-\mathrm{w}_{\mathrm{psn}}
$$

Neutral axis depth

$$
h_{n}=\frac{N_{p m \cdot R d}-A_{s n}\left(2 f_{s d}-f_{c d}\right)}{2 b f_{c d}+4 t\left(2 f_{y d}-f_{c d}\right)}
$$

Plastic section modulus of the steel reinforcement $\mathrm{w}_{\mathrm{psn}}=0$ (for CFT beams)

The compression resistance of the whole and concrete $\mathrm{N}_{\mathrm{pm} \cdot \mathrm{Rd}}=\mathrm{A}_{\mathrm{c}} \mathrm{f}_{\mathrm{cd}}$

\subsubsection{LRFD [5]}

This code predicts the strength of CFT beams by the plastic stress distribution in the cross section for both steel and concrete as like Eurocode 4 [4]. However the flexural strength of the CFT columns were determined based on the steel hollow section. The AISC - LRFD method was limited to CFT beams with concrete cylinder strength and steel strength less than 55 and $380 \mathrm{MPa}$ respectively. Ultimate moment of composite cross section is given by,

$\mathrm{M}_{\mathrm{n}}=Z \mathrm{Z}_{\mathrm{y}}+\frac{1}{3}\left(\mathrm{~h}_{2}-2 \mathrm{C}_{\mathrm{r}}\right) \mathrm{A}_{\mathrm{r}} \mathrm{f}_{\mathrm{yr}}+\left(\frac{\mathrm{h}_{2}}{2}-\frac{\mathrm{A}_{\mathrm{w}} \cdot \mathrm{f}_{\mathrm{y}}}{1.7 \mathrm{f}_{\mathrm{c}} \mathrm{h}_{1}}\right) \mathrm{A}_{\mathrm{w}} \mathrm{f}_{\mathrm{y}}$

The moment capacities $\left(\mathrm{M}_{\mathrm{e}}\right)$ using the above expressions are computed for all the 10 specimens and compared with the experimental results $\left(\mathrm{M}_{\mathrm{ee}}\right)$ in Table 3. It also shows the mean and the standard deviation of the ratio $\left(\mathrm{M}_{\mathrm{e}} / \mathrm{M}_{\mathrm{ee}}\right)$ for different design codes. These results clearly indicate that all the codes are conservative. The moment capacities predicted by AIJ [2] and Eurocode 4 [4] are around $11 \%$ lower than the experimental values, with respect to their major axis and around $30 \%$ lower than the experimental values with respect to their minor axis for SFRC in-filled beams. Similarly the moment capacities predicted by BS 5400 [3] and LRFD [5] are around 16\% lower than the experimental moment values about their major axis and around $19 \%$ lower than the experimental moment values about their minor axis for SFRC in-filled beams. AIJ [2] method gives a mean value of 1.051 and a COV of 0.315 and predicts $11 \%$ lower capacity than the corresponding test results and is the best predictor and thus are acceptable for the calculation of moment capacities of SFRC in-filled steel beams.

\subsection{Load - Deflection}

The load - deflection characteristics for all the beams tested are shown in Figure 7. The in-filled beams in general exhibit significant yield plateau with good ductility performance in the post yield region. In the initial stages of loading, all the beams exhibit almost the same load-deflection 
behaviour. Rapid deformations started first for type A beams followed by type B beams and type E beams. The low characteristic strength of concrete in type E beams has an impact on the load deflection plots also. In general the type $\mathrm{D}$ beams show better ductility performance compared with other specimens. The mid span deflection became larger for type D beam when the load crossed 16 $\mathrm{kN}$ about major axis and $11 \mathrm{kN}$ about minor axis. The $1 / 3^{\text {rd }}$ span deflection became rapid for type $\mathrm{D}$ beam when the load crossed $15 \mathrm{kN}$ about major axis and $10.50 \mathrm{kN}$ about minor axis. In the PCC in-filled beams, rapid deflection point started at lower load levels, which clearly show the brittle behaviour of concrete. In the SFRC in-filled beams, the rapid deflection started at higher load levels which show less stiffness compared to the PCC in-filled beams. Due to the in-fill, the lateral deflections have reduced and the moment capacities have increased. Thus longer span concrete in-filled specimens will show less deflections and greater safety against permissible lateral deflections. Beams with plain concrete in-fill are stiffer than other types of beams.

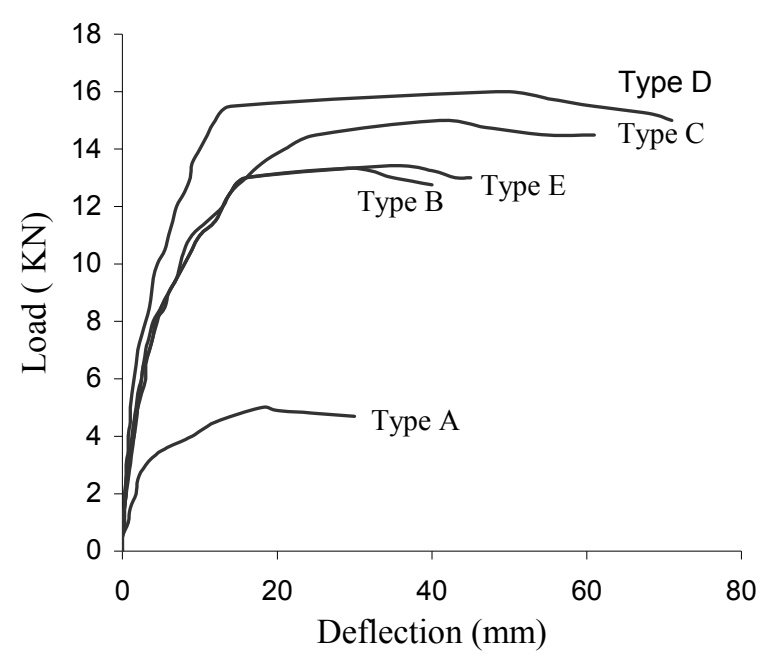

i) Load versus mid span deflection (major axis)

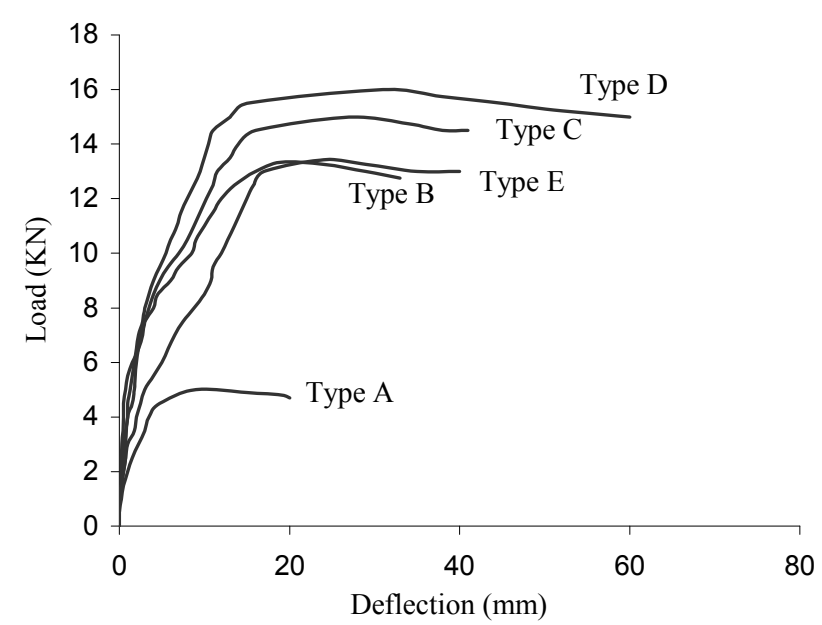

ii) Load versus $1 / 3$ span deflection ( major axis) 


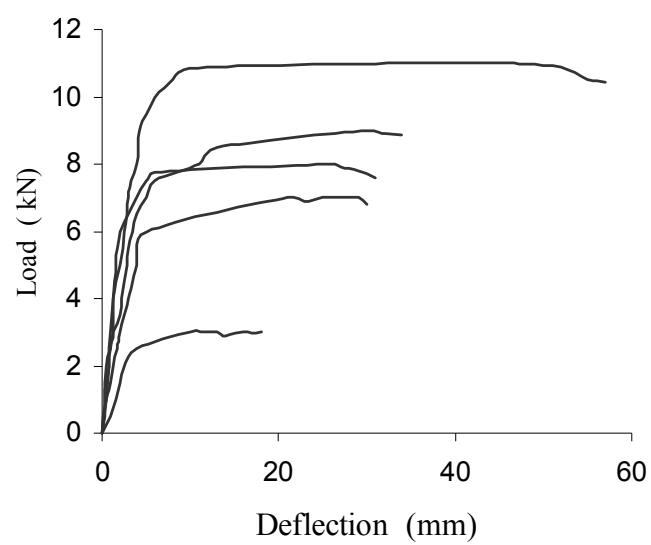

iii) Load versus mid span deflection (minor axis)

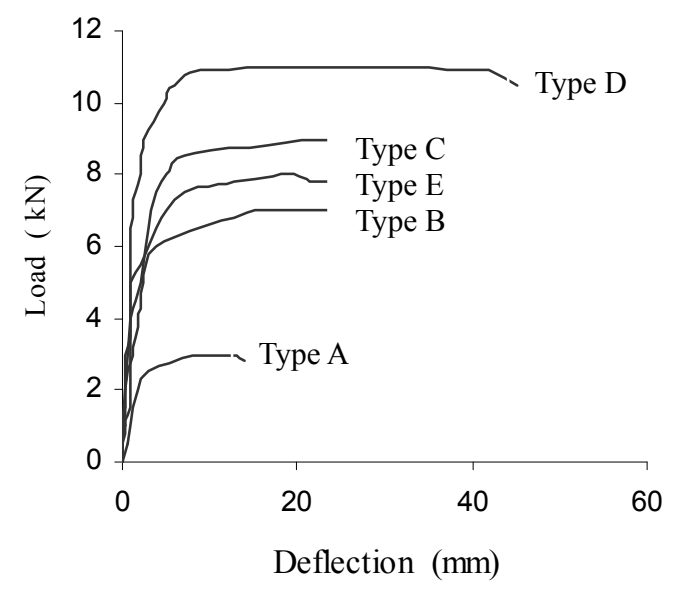

iv) Load versus $1 / 3$ span deflection ( minor axis)

Figure 7. Load - Deflection Plots of Hollow and In-filled Beams

\subsection{Moment - Strain}

Figure 8 \& Figure 9 show the Moment - Micro strain behaviour of hollow and concrete in-filled beams under pure bending about major and minor axes respectively. Compressive strains are recorded from the top strain gauges and tensile strains are recorded from the bottom strain gauges. The Moment - Micro strain plots show an early elastic response and in-elastic behaviour with gradually decreasing stiffness thereafter, until the ultimate moments are reached asymptotically. For all practical considerations the moment corresponding to the maximum fiber strain of $0.20 \%$ is taken as the moment capacity of the composite beam as it is found that when the maximum fiber strain reach $0.20 \%$, the moments tend to stabilize. The moment capacities of the test specimen are listed in Table 3. As illustrated in the Figures 8 and 9, both the compressive and tensile strains of the specimens are higher than $0.20 \%$ at the yield plateau, which indicates that both flanges of the specimen have yielded prior to their moment capacities. The non-linearity in strains starts at $85 \%$ and $95 \%$ of the ultimate load for compressive and tensile strains respectively. The failure of the beams is identified by the overall bending of the beam followed by the localized buckling under the concentrated load in the case of hollow beam and by overall bending in the case of in-filled beams. 
After comparing the moment strain plots of all the beams, the type D beams (1\% SFRC in-filled) show a significant yield plateau beyond the yield point indicating good ductility performance than other type of beams about the major and minor axes.

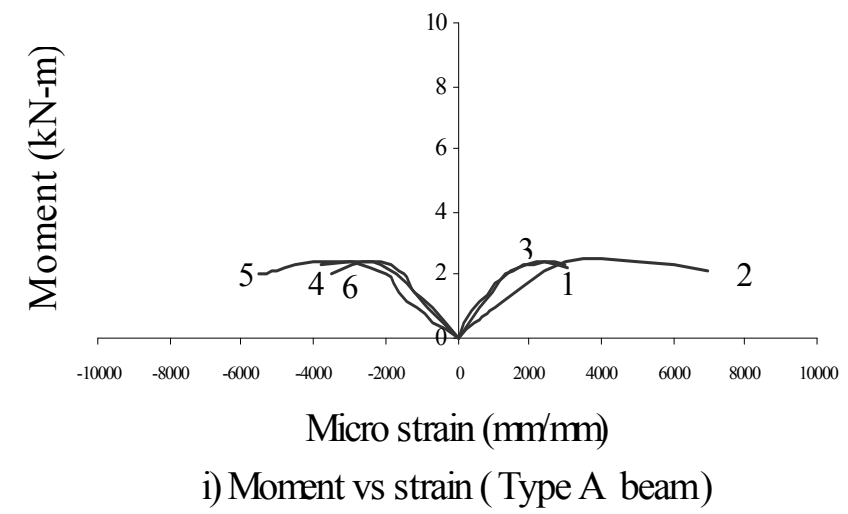

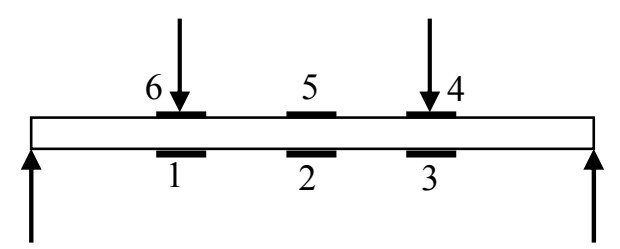

ii) Strain gauge arrangement

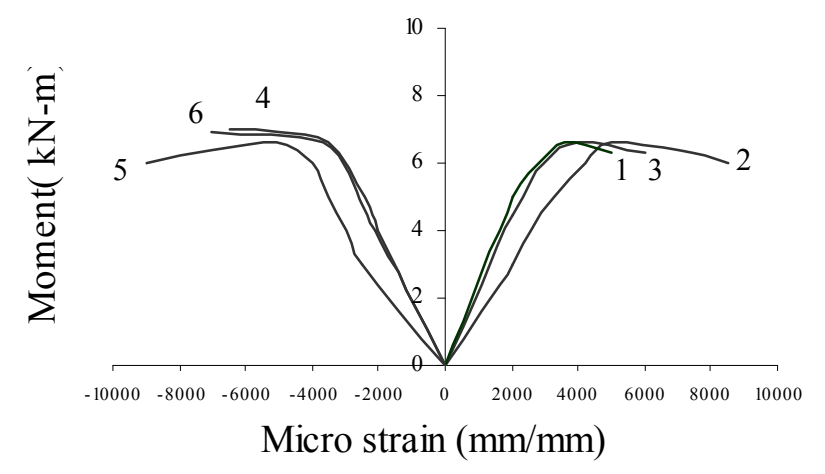

iii) Moment vs strain (Type B beam)

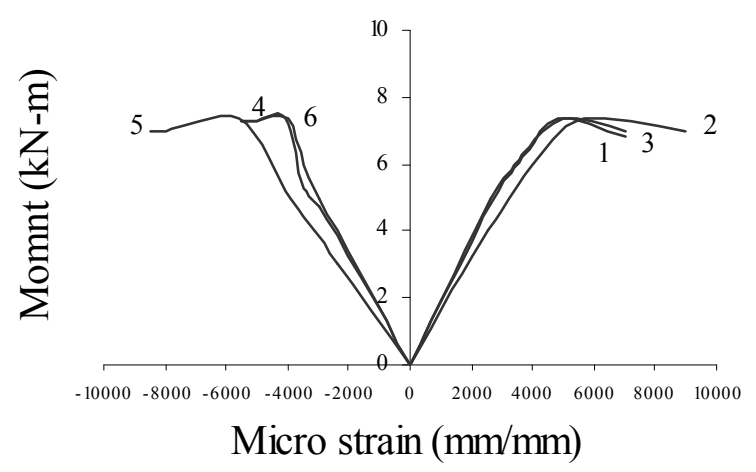

iv) Moment vs strain (Type $\mathrm{C}$ beam)

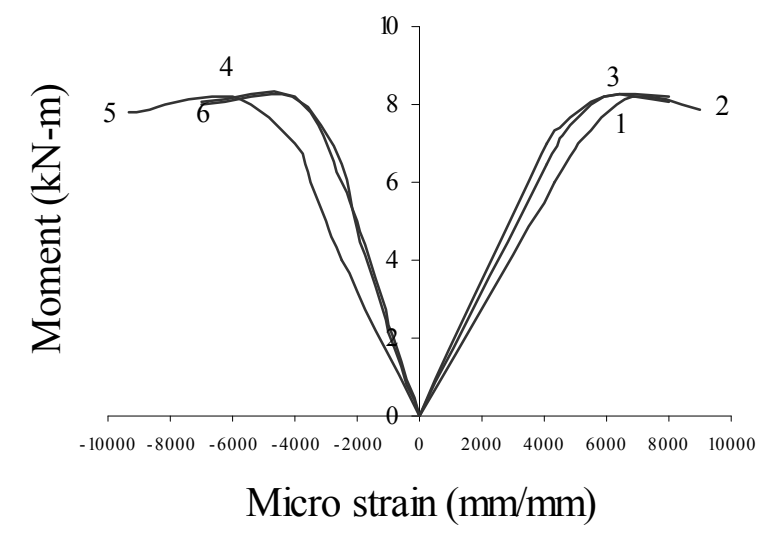

v) Moment vs strain (Type D beam)

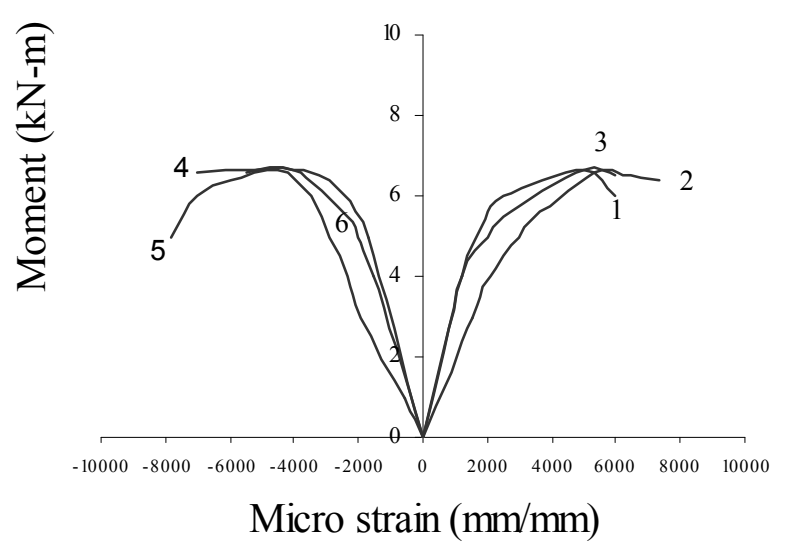

vi) Moment vs strain ( Type E beam)

Figure 8. Moment vs Micro Strain Plots (About Major Axis) 


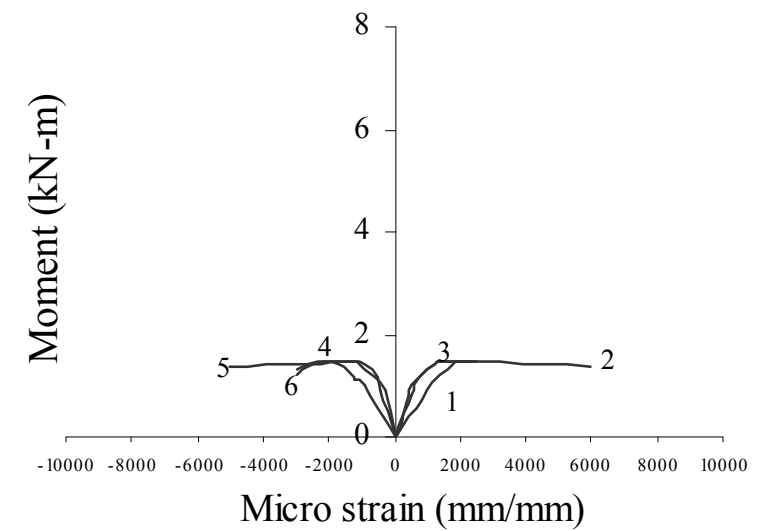

i) Moment vs strain (Type A beam)

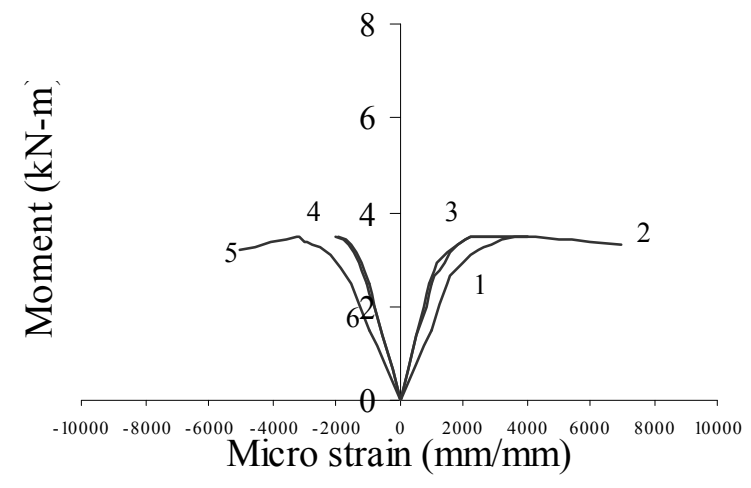

iii) Moment vs strain ( Type B beam)

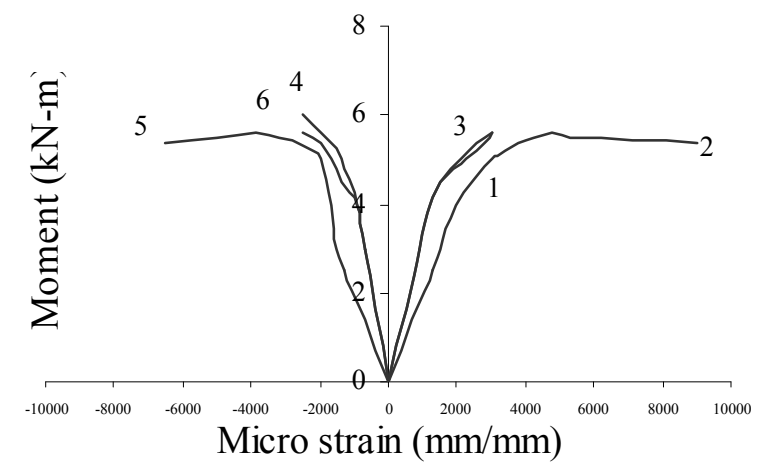

v) Moment vs strain ( Type D beam)

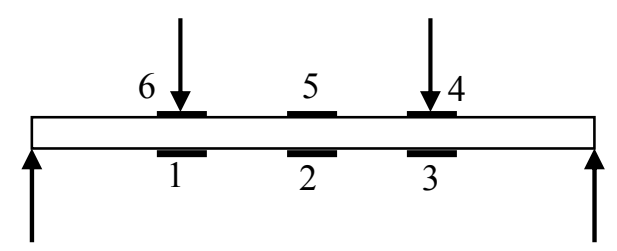

ii) Strain gauge arrangement

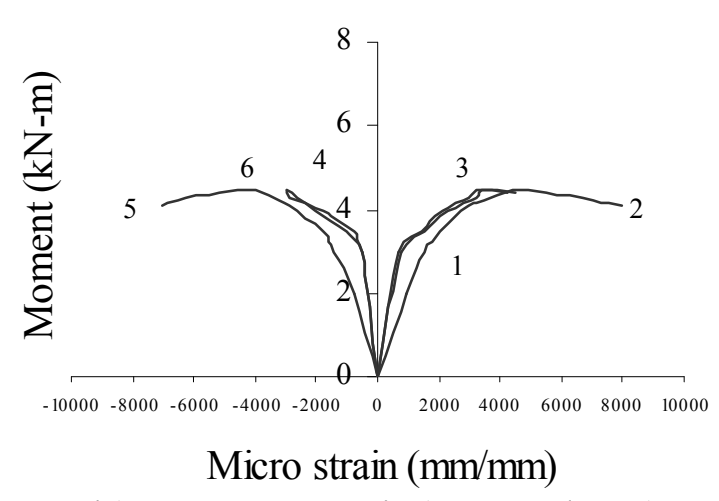

iv) Moment vs strain ( Type $\mathrm{C}$ beam)

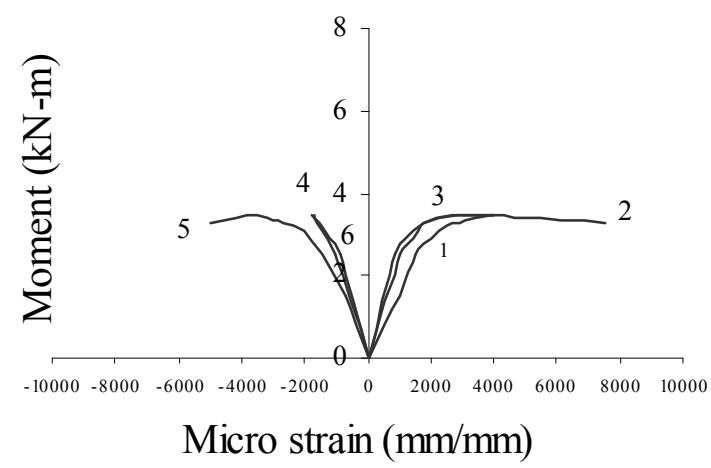

vi) Moment vs strain (Type E beam)

Figure 9. Moment vs Micro Strain Plots (About Minor Axis) 


\section{CONCLUSIONS}

The following observations and conclusions are drawn based on the present study on hollow and in-filled light gauge steel sections.

Due to the plain cement concrete in-fill and the SFRC in-fill, the light gauge steel hollow sections exhibit enhanced flexural performances of the beams compared to hollow beams. The bond strength of SFRC in-filled specimens is higher than PCC in-filled specimen. The SFRC in-filled specimen takes $63 \%$ more load than the PCC in-filled specimens before the slip. Because of the SFRC in-fill, the tested in-filled beams behaved in a relatively ductile manner. The enhanced ultimate load and ductility of the beams are due to the "composite action" between the steel tube and the concrete core. The theoretical flexural stiffness predicted based on the codes, AIJ [2], BS 5400 [3], Eurocode 4 [4] and LRFD [5] are compared with the experimental flexural stiffness. In general, all the codes predicted slightly higher values for the flexural stiffness. The AIJ [2] code shows closer values of the experimental results and can be accepted for calculation of the flexural stiffness of SFRC in-filled beams.

The SFRC in-filled beams show lesser deflection than the hollow and PCC in-filled beams and exhibit significant yield plateau. The moment capacities of the hollow, PCC \& in-filled beams are experimentally calculated. The SFRC in-filled beams carry around 3 times more load than the hollow beams with respect to the major axis and 3.66 times more load than the hollow beams with respect to the minor axis. When compared with PCC in-filled beams, the SFRC in-filled beams carry about 1.20 times more load with respect to the major axis and 1.55 times more load with respect to the minor axis. The SFRC in-filled beams with $1 \%$ volume fraction of fiber is found to have higher flexural strength and less stiffness than the other two volume fraction of fibers $(0.75 \%$ and $1.25 \%$ ) studied and can be taken as optimum percentage of volume fraction fibers in the SFRC in-filled beams. The validity of different codes for determining the strength and stiffness of PCC in-filled beams and their applicability to SFRC in-filled beams have been discussed. The experimental moment capacities of the beams and the theoretical moment capacities calculated based on the codes AIJ [2], BS 5400 [3], Eurocode 4 [4] and LRFD [5] are compared. The AIJ [2] and Eurocode 4 [4] gave a moment capacity around $11 \%$ lesser than the experimental values, with respect to the major axis and $30 \%$ lesser than the experimental value with respect to the minor axis for SFRC in-filled beams. BS 5400 [3] and LRFD [4] gave a moment capacity about 16\% lower than the experimental moment values about the major axis and 19\% lower than the experimental moment values about the minor axis for SFRC in-filled specimens. The code provisions indicate plain cement concrete in-filled light gauge beams cannot be used directly for SFRC in-filled light gauge steel beams. Hence new provisions are required for composite beams with high performance concrete in-fills such as SFRC. 


\section{NOMENCLATURE}

$\mathrm{A}_{\mathrm{c}} \quad$ concrete cross - sectional area

$\mathrm{A}_{\mathrm{s}} \quad$ steel cross - sectional area

$\mathrm{A}_{\mathrm{sn}} / \mathrm{A}_{\mathrm{r}} \quad$ area of the reinforcement

$\mathrm{A}_{\mathrm{w}} \quad$ web area of the encased steel

B width of rectangular steel tube

$\mathrm{b}_{\mathrm{f}} \quad$ external dimension of rectangular section

$\mathrm{C}_{\mathrm{r}} \quad$ average distance to the reinforcement

D depth of rectangular steel tube

$\mathrm{d} / \mathrm{b} \quad$ out side diameter of steel tube

$\mathrm{d}_{\mathrm{c}} \quad$ distance of neutral axis from the most compressed face of concrete

$\mathrm{d}_{\mathrm{f}} \quad$ diameter of fiber

$\mathrm{E}_{\mathrm{c}} \quad$ concrete modulus of elasticity

$\mathrm{E}_{\mathrm{s}} \quad$ steel modulus of elasticity

$\mathrm{f}_{\mathrm{c}} \quad$ concrete cylinder strength

$\mathrm{f}_{\mathrm{c}} \quad$ characteristic concrete cylinder strength

$f_{c d} \quad$ design yield strength of the concrete

$\mathrm{f}_{\mathrm{ck}} / \mathrm{f}_{\mathrm{cu}} \quad$ characteristic concrete strength

$\mathrm{f}_{\mathrm{sd}} / \mathrm{f}_{\mathrm{yr}} \quad$ design yield strength of steel reinforcement

$f_{y} / \sigma_{y} / f_{y d} \quad$ yield strength of the steel tube

$\mathrm{h} \quad$ depth of concrete in-fill

$\mathrm{h}_{1} \quad$ width of the member perpendicular to the plane of bending

$\mathrm{h}_{2} \quad$ width of the member parallel to the plane of bending

$\mathrm{I}_{\mathrm{c}} \quad$ moment of inertia of concrete core

$\mathrm{I}_{\mathrm{S}} \quad$ moment of inertia of steel tube

$\mathrm{K}_{\mathrm{e}} \quad$ theoretical flexural stiffness of composite beam

$\mathrm{K}_{\mathrm{ee}} \quad$ experimental flexural stiffness of composite beam

$1_{\mathrm{f}} \quad$ length of fiber

$\mathrm{M}_{\mathrm{e}} \quad$ theoretical moment of composite beam

$\mathrm{M}_{\mathrm{ee}} \quad$ experimental moment of composite beam

${ }_{\mathrm{c}} \mathrm{r}_{\mathrm{o}} \quad$ outer radius of the concrete tube

$\mathrm{t} \quad$ thickness of the steel tube

${ }_{s} Z_{p} / Z \quad$ plastic section modulus of the steel tube 


\section{REFERENCES}

[1] Kas, S., Ge, H. and Usami, T.A., "Capacity Prediction Procedure for Concrete-filled Steel Columns", Journal of Earth quake Engineering, 2001, Vol. 4, No. 5, pp. 483-520.

[2] Architectural Institute of Japan, "Recommendations for Design and Construction of Concrete Filled Steel Tubular Structures", Architectural Institute of Japan, Tokyo, 1997.

[3] BS 5400. Part 5, "Concrete and Composite Bridges", British Standard Institution, 1979.

[4] Eurocode 4, "Deign of Composite Steel and Concrete Structures, Part 1.1: General Rules and Rules for Buildings (Together with United Kingdom National Application Document), DD ENV 1994-1-1: 1994 London W1A2BS”, British Standard Institution, 1994.

[5] AISC-LRFD, "Load and Resistance Factor Design Specification for Structural Steel Buildings", American Institute of Steel Construction Inc., 1999.

[6] Hajjar, J., "Concrete-filled Steel Tube Columns under Earthquake Loads", Journal of Progress Structural Engineering Materials, 2000, Vol. 2, No. 1, pp. 1-10.

[7] Fukumoto, Y. "Structural Stability Design, Steel and Composite Structures", Oxford: Pergamon, 1997.

[8] Elchalakani, M., Zhao, X.L. and Grzebieta, R.H., "Concrete-filled Circular Steel Tubes Subjected to Pure Bending”, Journal of Constructional Steel Research, 2001, Vol. 57, No. 11, pp. 1141-1168.

[9] Gho, W.M. and Liu, D., "Flexural Behaviour of High-strength Rectangular Concrete-filled Steel Hollow Sections", Journal of Constructional Steel Research, 2004, Vol. 60, No. 11, pp 1681-1696.

[10] Fam, A.Z. and Rizkalla, S.H., "Flexural Behaviour of Concrete-filled Fiber-reinforced Polymer Circular Tubes", Journal of Composites for Construction, 2002, Vol. 6, No. 2, pp. 123-132.

[11] Han, L.H., "Flexural Behaviour of Concrete-filled Steel Tubes", Journal of Constructional Steel Research, 2004, Vol. 60, No. 2, pp. 313-337.

[12] Han, L.H, Lu, H., Yao, G.H. and Liao, F.Y., "Further Study on the Flexural Behaviour of Concrete-filled Steel Tubes”, Journal of Constructional Steel Research, 2006, Vol. 62, No. 6, pp. 554-565.

[13] Helena, J.H. and Knight, S.G..M., Behaviour of Cold-formed Steel In-filled Columns", Journal of Steel and Composite Structures, 2005, Vol. 5, No. 1, pp. 35-47.

[14] Senthil, S. S., Chandrasekaran, E., Srinivasaraghavan, R. and Nagamani, K., "Post Buckling Strength of Steel Fiber Reinforced Concrete In-filled Light Gauge Steel Box Sections - An Experimental Study", Proceedings of the 2005 Annual Stability Conference, 2005, Structural Stability Research Council, University of Missouri - Rolla, Canada Vol. 1, pp, 389-407.

[15] Mursi, M. and Uy, B., "Strength of Slender Concrete Filled High Strength Steel Box Columns", Journal of Constructional Steel Research, 2004, Vol. 60, No. 12, pp. 1825-1848.

[16] Liu, D., "Behaviour of High Strength Rectangular Concrete-filled Steel Section Columns under Eccentric Loading", Journal of Thin Walled Structures, 2004, Vol. 42, No. 12, pp. 1631-1644.

[17] Liu, D., Gho, W.M. and Yuan, J, "Ultimate Capacity of High Strength Rectangular Concrete Filled Steel Hollow Section Stub Columns", Journal of Constructional Steel Research, 2003, Vol. 59, No. 12, pp. 1499-1515.

[18] Standard Practice for Selecting Proportions for Normal, Heavyweight, and Mass Concrete. ACI 211.1-91. ACI Manual of Concrete 1991, Part 1, Materials and General Properties of Concrete. Detroit, Michigan: American Concrete Institute.

[19] Giakoumelis, G and Lam, D., "Axial Capacity of Circular Concrete-filled Tube Columns", Journal of Constructional Steel Research, 2004, Vol. 60, No. 7, pp. 1049-1068.

[20] ASTM, "American Society for Testing and Materials. Test Methods for Tension Testing of Metallic Materials", West Conshohocken, PA, 1997.

[21] IS: 456 - 2000, "Indian Standard Code of Practice for Plain and Reinforced Concrete (Fourth Revision)", Bureau of Indian Standards, 2000. 


\title{
COLLAPSE AND REHABILITATION OF STEEL TANKS ROOF STRUCTURES
}

\author{
F. Turcic ${ }^{1, *}$, I. Luketina, M. Plisic \\ ${ }^{1}$ Civil Engineering Institute of Croatia, Zagreb, Croatia \\ Department of Steel structures \\ *(Corresponding author: E-mail: franjo.turcic@igh.hr)
}

Received: 10 November 2006; Revised: 3 May 2007; Accepted: 15 May 2007

\begin{abstract}
Steel roof structures of two identical cylindrical heating oil tanks, located in Zagreb, Croatia, suffered great deformations and partly collapsed in 1993 and 1994, after two decades of continuous use. The tanks are each 20,000 cubic meters in volume, $45.7 \mathrm{~m}$ in diameter, $12.5 \mathrm{~m}$ in sheathing height, and each of them has a central column in the middle. The cause of damages has been analyzed. An account is given to poor original design, with respect to relevant influences: all types of loads, adequate static system and boundary conditions for individual load types. Necessary additional calculations have been performed and described. The mechanism of the activation and development of the damages are explained. Solutions implemented in the rehabilitation works are also presented. The results and analyses are presented in detail, as they are deemed highly instructive and of interest to a variety of professionals. The tank type analyzed in this paper can be considered as an internationally typical structure as it has been widely used in many locations worldwide. The authors believe that some of similar failures occurred also in the other locations, but, according to available literature, the corresponding reports have proven to be scarce.
\end{abstract}

Keywords: Steel tanks, roof structures, collapse, damage, rehabilitation

\section{INTRODUCTION}

Steel roof structures of two identical heating oil tanks, each 20,000 cubic meters in capacity, located in Zagreb, Croatia, partly collapsed in 1993 and 1994, after two decades of continuous use.

According to design information, the load-bearing roof structure consisted of 16 fan trusses, which are supported on the one side by tank sheathing and by the central column on the other, purlins, rafters and metal sheet covering.

The followings are described in the paper: original structure, structural damage, cause of damage, and rehabilitation conducted in 1993 and 1994 on R5 and R6, and once again in 1996, only on R6. No difficulties have been reported since the last rehabilitation work.

Part of this article was published in Europe 2006. [1]

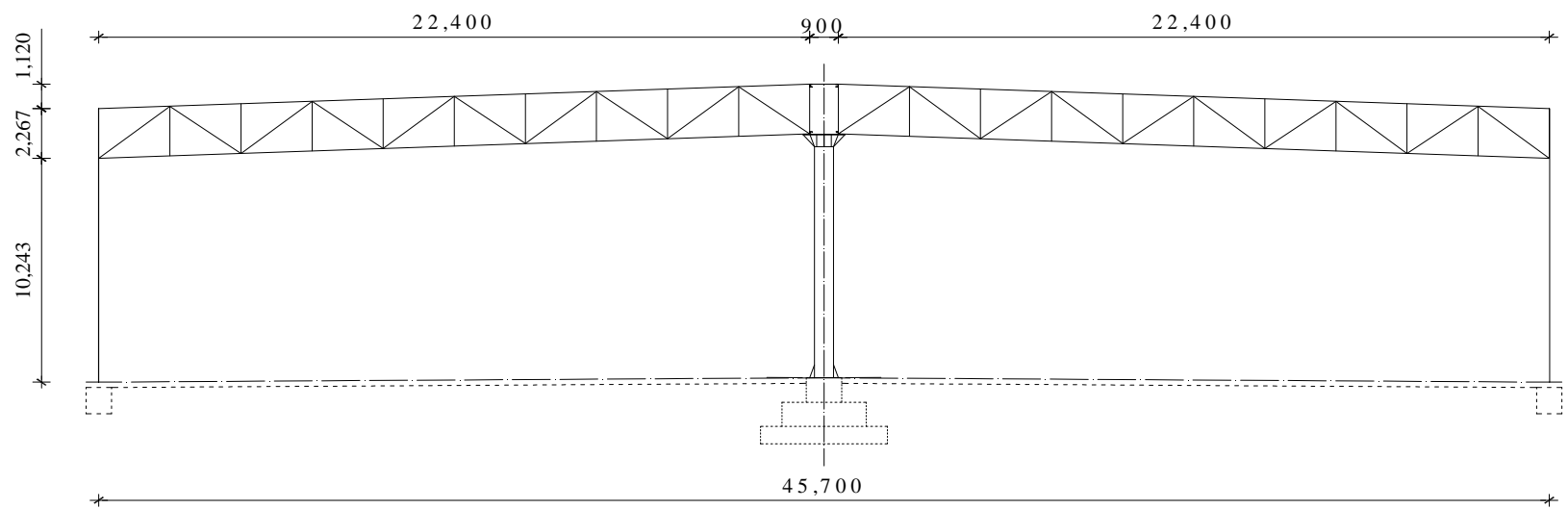

Figure 1. Tank Cross Section and Dimensions (mm) 


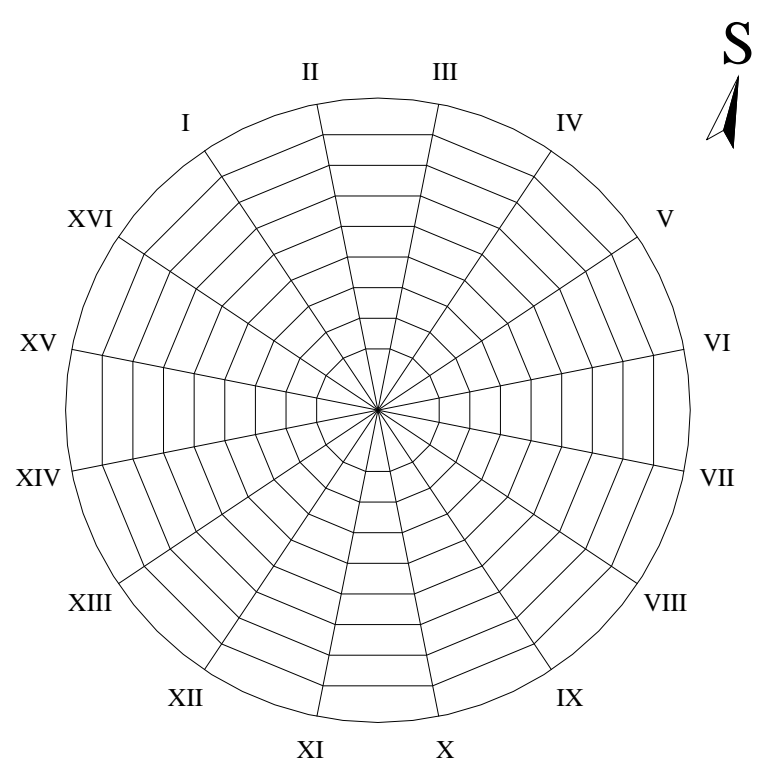

Figure 2. Plan View of Roof Trusses and Purlins

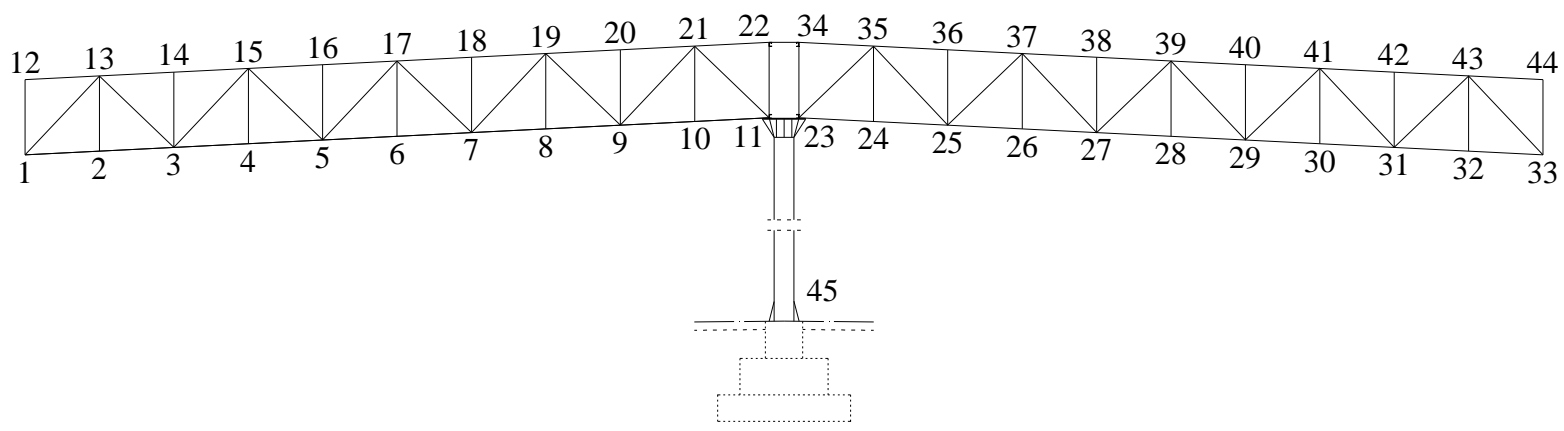

Figure 3. Roof Truss and Central Column Node Designations

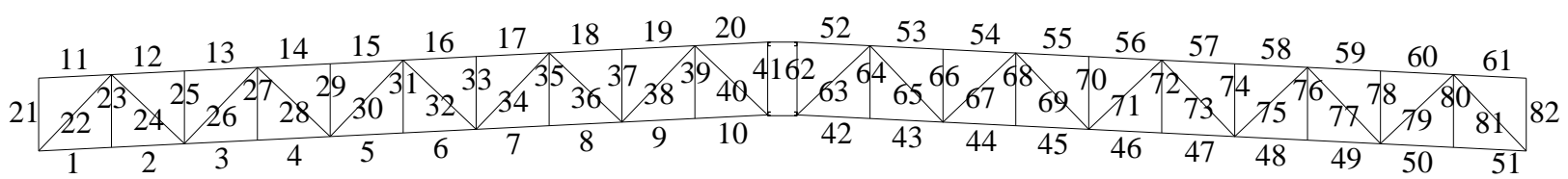

Figure 4. Roof Truss Member Designations

\section{PRESENTATION OF THE INITIALLY DESIGNED AND BUILT ROOF STRUCTURE}

The steel sheet cover of $5 \mathrm{~mm}$ in thickness was locally welded onto the top surface of roof trusses. Purlins are made of steel IPE profiles: 18, 18, 16, 14, 12, 10, 10 and 10 supported in nodes 13 through 20. Steel sheet thicknesses at the tank sheathing level are: 22, 15, 15, 13, 10, 8 and $7 \mathrm{~mm}$. At top, the sheathing is stiffened with the steel angle L100x100x10. Roof trusses are connected to the sheathing and the central column in the following nodes: 1, 12, 33, 34, 11, 22, 23 and 44 shown in Figure 3 above. These connections are rigid and no relative movement is allowed. 
The central column is a hollow cylindrical tube $600 \mathrm{~mm}$ in diameter and $8 \mathrm{~mm}$ in wall thickness. At node 45 , this column was not firmly linked with the steel sheet at the base or with the foundations, and hence a vertical upward movement was enabled.

At nodes 2 to 7, the lower chord of roof trusses was laterally attached to purlins by means of inclined struts. However, such lateral support was not provided for in nodes 8, 9 and 10 of the lower chord.

\section{DESCRIPTION OF DAMAGE TO TANK R5}

The damage to the roof of the tank R5 was registered in September 1993.

After the tank was emptied and washed, the following internal and external damage was observed:

(1) About 40 percent of the roof area caved in through shell penetration, including also the roof trusses XIII, XIV, XV, XVI and I. Thus a depression in form of an ellipse shaped basin $(1.75 \mathrm{~m}$ in maximum depth, with ellipse axes 35 and $15 \mathrm{~m}$ in length) was created on the roof surface.

(2) Last two envelopes of the sheathing, together with edge bracing and railing on about $1 / 3$ of the perimeter (about $45 \mathrm{~m}$ ) are heavily deformed and damaged.

(3) The following roof truss members failed either due to axial tensile forces or bending action along nodes (Table 1):

Table 1. Failure due to Axial Tensile Forces or Bending

\begin{tabular}{|l|l|l|}
\hline Truss No. & Element No. & Place of failure \\
\hline \multirow{5}{*}{ I } & 2 & next to node 2 \\
\cline { 2 - 3 } & 11 & next to node 12 \\
\cline { 2 - 3 } & 12 & next to node 14 \\
\cline { 2 - 3 } & 24 & in the middle \\
\hline XIII & 9 & next to node 9 \\
\hline XIV, XV & 2 & next to node 3 \\
\hline \multirow{2}{*}{ XVI } & 12 & next to node 13 and 14 \\
\cline { 2 - 3 } & 24 & in the middle \\
\hline
\end{tabular}

(4) The following roof truss members were buckled plastically within or outside the truss plane (Table 2):

Table 2. Plastically Buckled Roof Truss Members

\begin{tabular}{|l|l|l|}
\hline Truss No. & Element No. & Place of failure \\
\hline XIII & 14 & in the plane \\
\hline $\begin{array}{l}\text { I, II, IX, X, XI, } \\
\text { XIII, XIV, XV, } \\
\text { and XVI }\end{array}$ & $7,8,9$ and 10 & outside of the plane \\
\hline $\begin{array}{l}\text { I, XIII, XIV, } \\
\text { XV and XVI }\end{array}$ & 36,37 and 40 & outside of the plane \\
\hline
\end{tabular}


(5) The foot of the central column moved from the initial position by $105 \mathrm{~mm}$, approximately in the direction of the truss no. XI.

(6) In the zone of roof collapse, the first bearing member to collapse was the purlin INP 18 which is connected to truss no. I in node 13 . This was followed by failure of several elements of the rafters L65-65-6.

The above described damage can be seen in Figures 5, 6, 7 and 8.

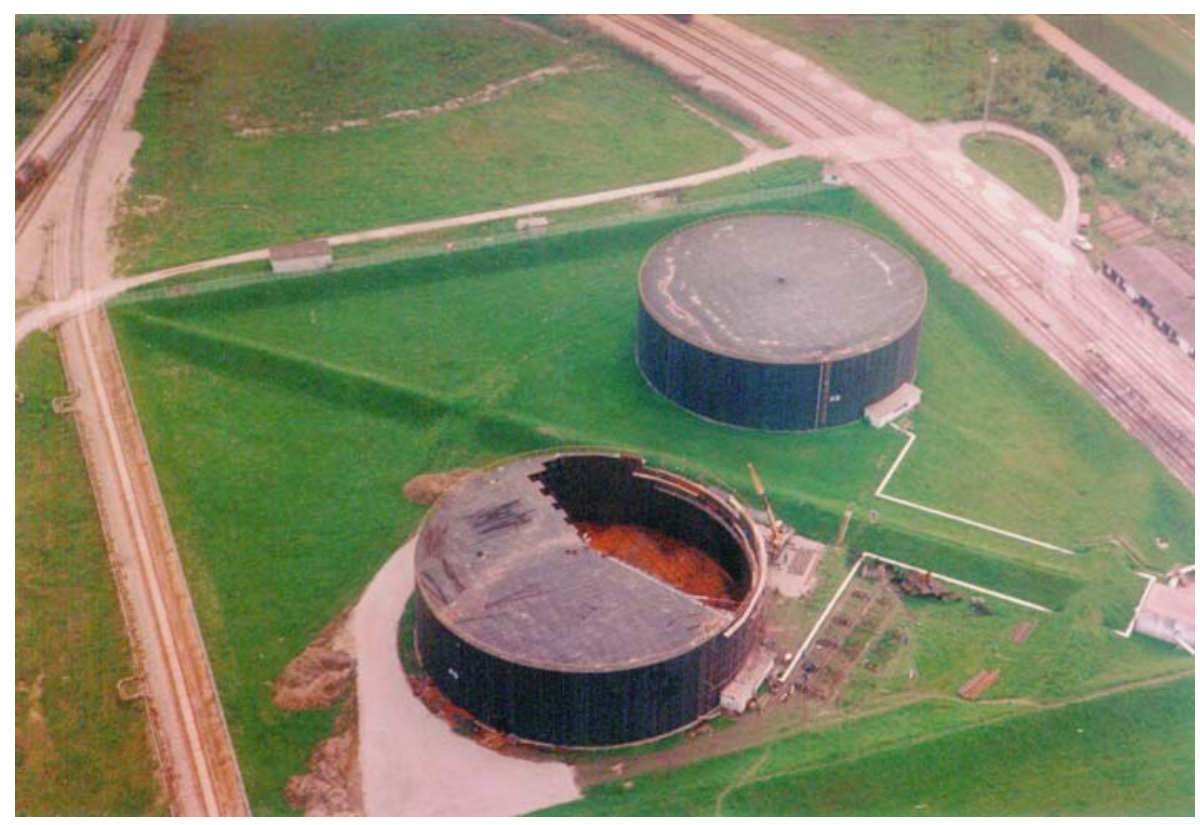

Figure 5. View of Tanks R5 and R6 (R5 during the Rehabilitation Stage)

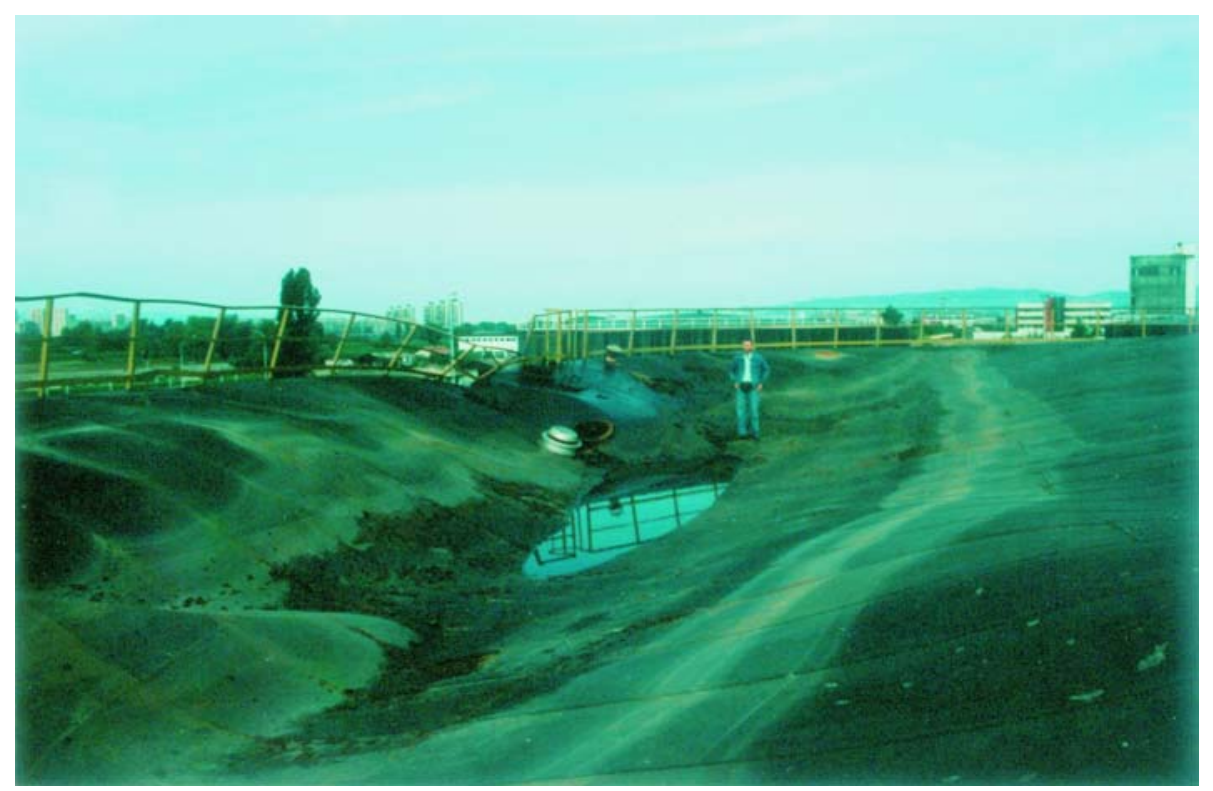

Figure 6. Form of Depression on the Roof Surface 


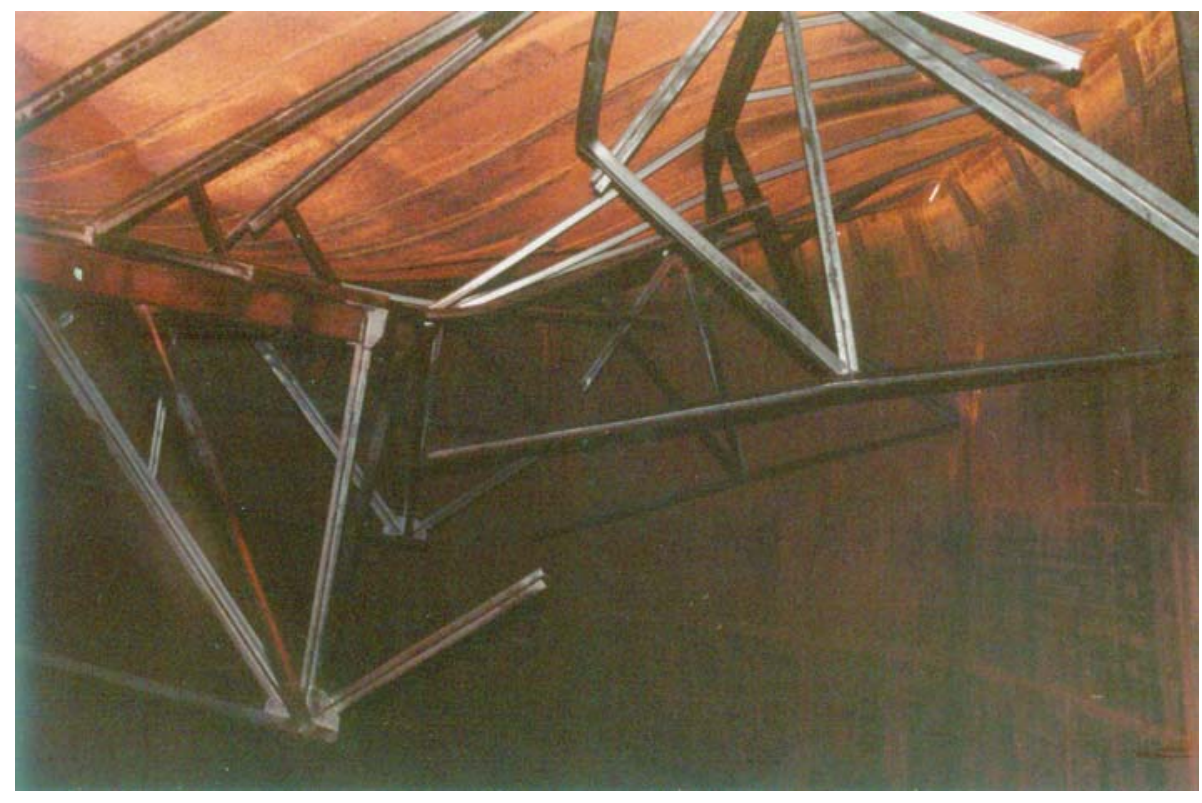

Figure 7. Broken Roof Trusses

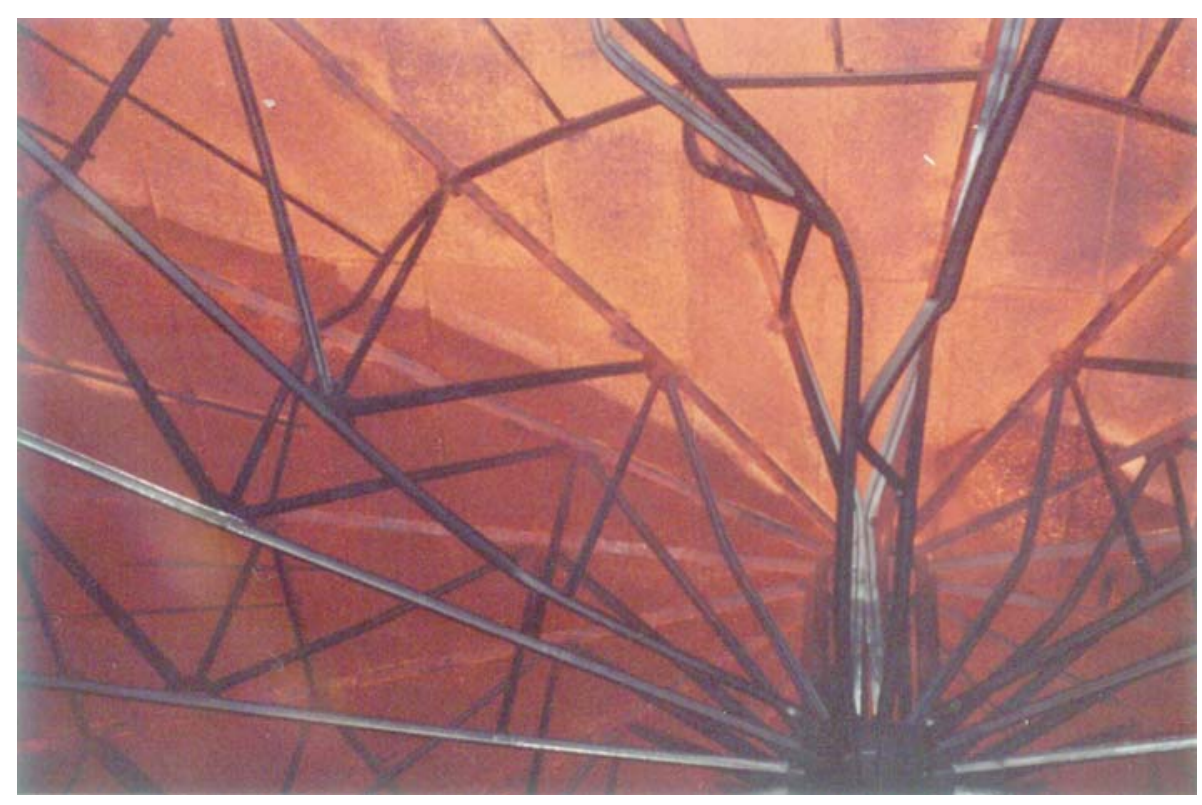

Figure 8. Deformed Roof Trusses in the Vicinity of the Central Column

\section{COLLAPSE CAUSE ANALISYS OF THE TANK R5}

The initial design was inspected in the first step of the analysis. It was established that the roof truss was dimensioned as the simple-supported beam in the length from the envelope to the central column ( $\mathrm{L}=22,400 \mathrm{~mm}$ ) for the following loads: self weight, uniform snow $0.75 \mathrm{kN} / \mathrm{m}^{2}$, and uniform wind: $-1.3 \times 0.60=-0.78 \mathrm{kN} / \mathrm{m}^{2}$.

The roof members were designed quite correctly for the assumed static system and for the assumed load. 
The following deficiencies in analysis, and differences between the design assumptions and actual realization of the structures, were noted.

(1) The central column in node 45 is not fixed to the base or to the foundations. Therefore a vertical upward displacement is activated. The continuity of roof trusses is ensured via rigid connections to the central column and via the roof sheeting. Thus, the real static system differs from the system assumed in the original design.

(2) The influence of the sudden change in temperature at the cover and at a portion of the envelope (above the level of the partly filled tank) during summer rain, particularly when combined with the wind, was not taken into account.

(3) The value of $0.75 \mathrm{kN} / \mathrm{m}^{2}$ assumed as superimposed load in the design is too small. According to API standard [2], such load should amount to at least $1.22 \mathrm{kN} / \mathrm{m}^{2}$. In Zagreb, the value of 1.25 $\mathrm{kN} / \mathrm{m}^{2}$ of snow load is normally used for light steel structures.

(4) The possibility of negative pressure was not taken into account as vents installed on the roof of the tank R5 become activated only when the negative pressure (vacuum) during service exceeds 0.22 bars. Here it should however be noted that, unlike tank R5, tank R6 had a free opening so that vacuum could not be created in the tank.

During the analysis of causes of the collapse on R5 the main cause could not be determined with a high level of certainty, because of the extent of damage. This became possible only in 1994 when permanent deformations were recorded on the roof of the neighbouring tank R6.

\section{DESCRIPTION OF DAMAGE TO TANK R6}

In August 1994, during rehabilitation and strengthening of the tank R5, the identical tank R6 was visually inspected and local deformations (depressions) were found in the roof area around nodes 13 and 14, almost along the entire perimeter.

After the tank was emptied and washed, the following damage was recorded.

(1) The footing of the central column (node 45) deviated from design position by $11 \mathrm{~cm}$.

(2) The following roof truss members were damaged (Table 3):

Table 3. Damaged Roof Truss Members

\begin{tabular}{|l|l|l|}
\hline Truss No. & Element No. & Type of damage \\
\hline I to XVI & 24 & plastic buckling \\
\hline I to XVI & 2 and 12 & plastic deformations \\
\hline IV, V and VI & 11 & plastic buckling \\
\hline VIII & 23 & plastic buckling \\
\hline
\end{tabular}

(3) The deflections on the roof surface are such that rainwater remains on the roof despite the roof slope. Typical appearance of roof girder deformations on R6 is shown in Figures 9, 10 and 11. Figure 9 shows the appearance of damaged roof truss members, Figure 10 indicates the deflection with water pools on the roof and Figure 11 depicts the displacement of the central column footing. 


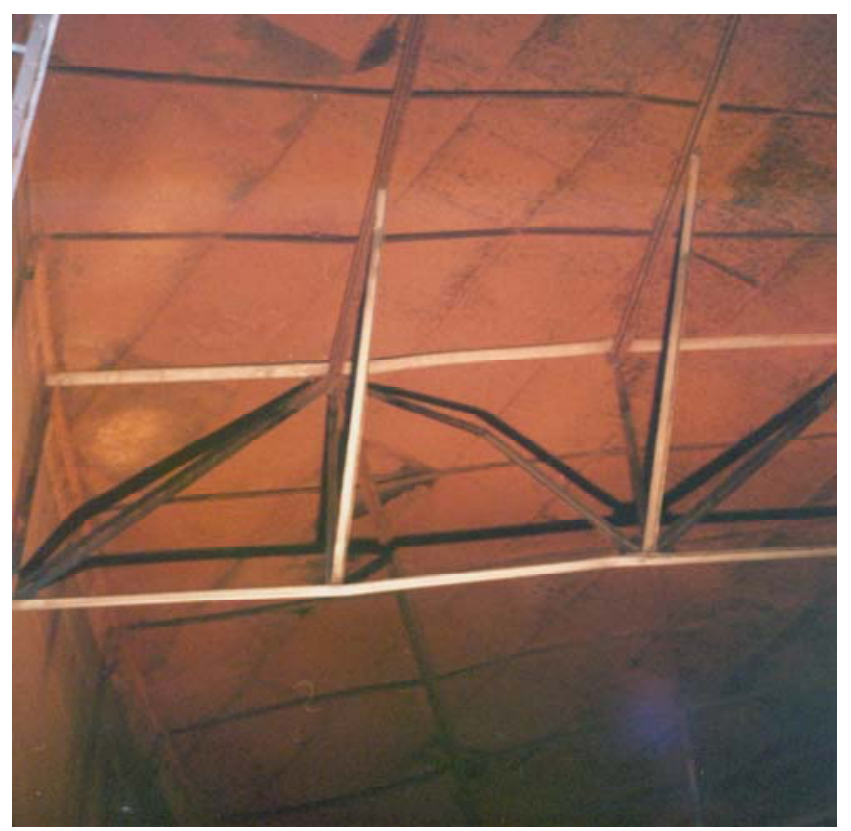

Figure 9. Damaged Roof Truss Members

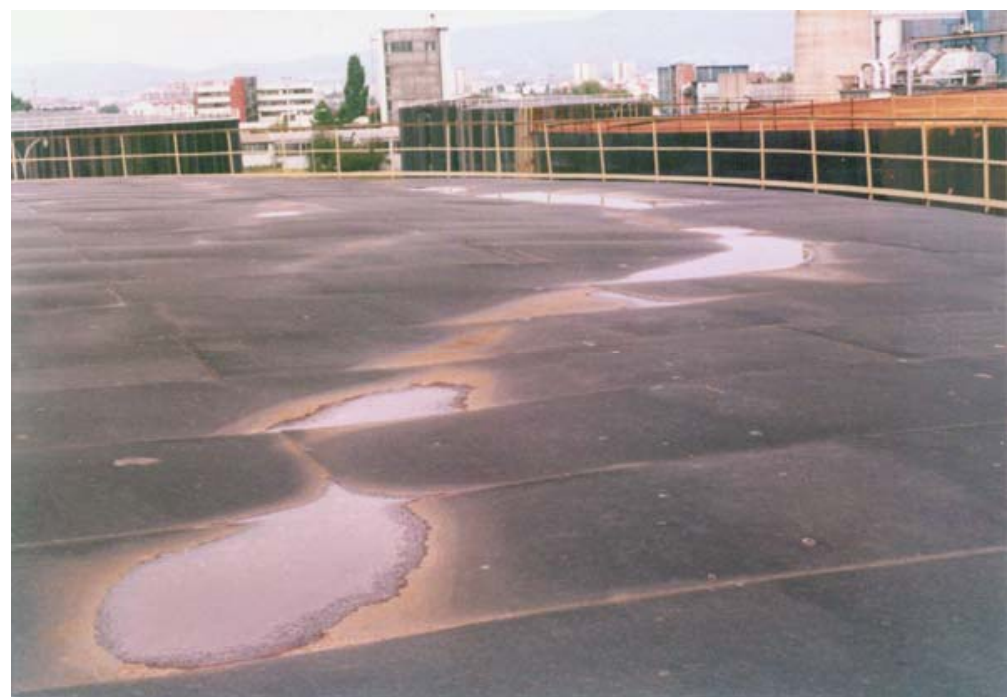

Figure 10. Depressions on the Roof Surface

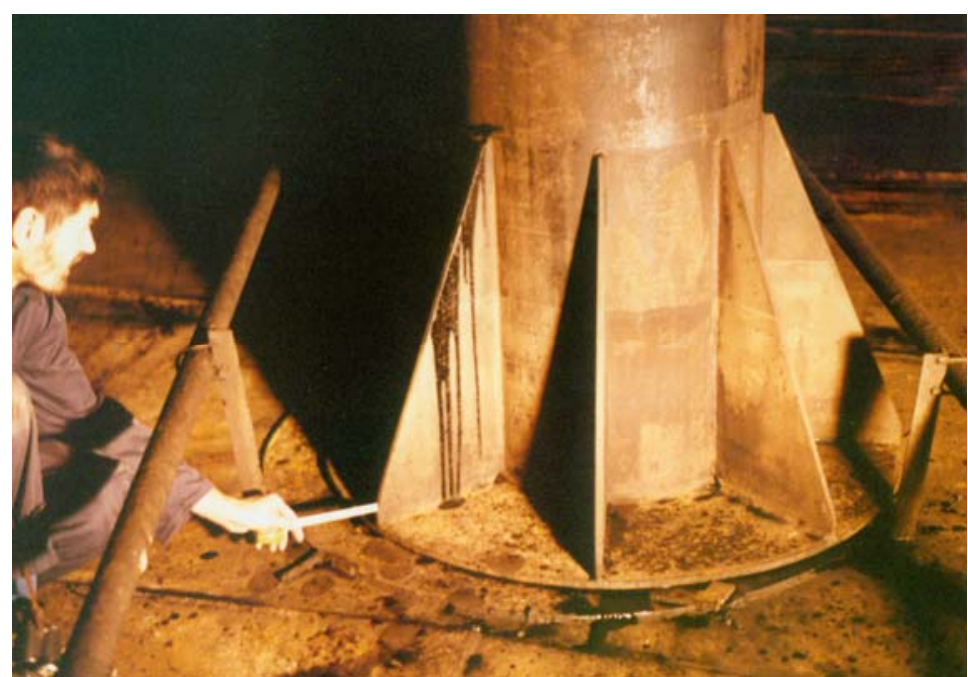

Figure 11. Central Column Footing Displacement 


\section{DAMAGING CAUSES OF TANKS R5 AND R6}

Once the type of damage to R6 was defined, it was possible to determine, with a relatively high level of certainty, basic causes of initial damage to R5 and R6, and to prove them by calculations. It became clear that the critical event was the insufficient compressive capacity of the member 24 .

If appropriate load combinations are analyzed using adequate static systems, then this can also be confirmed in numerical form.

Axial force results for studied roof truss members are presented in Table 4 under the following conditions.

(1) The self-weight of the cover and roof structure on the truss of $22.4 \mathrm{~m}$ in span, fixed at the points of connection with the central column, and with restrained displacement in the direction of the bottom chord in nodes 1 and 33 (column 2) is assumed.

(2) Uniform wind, $-1.3 \times 0.6 \mathrm{kN} / \mathrm{m}^{2}$ in intensity, plus buoyant force in the direction of the hollow central column in case of full tank, minus self-weight of the roof structure and central column, on the roof truss $45.7 \mathrm{~m}$ in span, with an unrestrained vertical displacement above the central column is assumed. Unrestrained displacement of nodes 1 and 33 was noted in the direction of the bottom chord. Restrained displacement in nodes 12 and 44 in the direction of the top chord (column 3).

(3) In case of summer rainfall, the temperature at the metal sheet cover and at a part of the tank sheathing falls by temperature change as $30^{\circ} \mathrm{C}$, at the roof truss $45.7 \mathrm{~m}$ in span.

The calculated free vertical displacement (uplift) at the central column amounts to $17 \mathrm{~mm}$ for the load combination case (2).

It can be seen from the preceding description that boundary conditions at the sheathing support were defined for individual design models (i.e. load or combination) based on the direction of node deformation. The displacement is restrained if the deformation of nodes 1, 12, 33 and 44 in the direction of the top or bottom chord is outside of the tank perimeter, while the displacement is unrestrained if the deformation occurs within the tank perimeter.

Table 4. Axial Forces in the Truss Members $(\mathrm{kN})$

\begin{tabular}{|c|c|c|c|c|c|c|c|c|}
\hline \multirow{3}{*}{$\begin{array}{l}\text { Element } \\
\text { No. }\end{array}$} & \multicolumn{4}{|c|}{ Single or combined loads } & \multicolumn{2}{|c|}{ Combinations } & \multirow{2}{*}{\multicolumn{2}{|c|}{$\begin{array}{c}\text { Compressive bearing } \\
\text { capacity }\end{array}$}} \\
\hline & \multirow{2}{*}{$\begin{array}{l}\text { Self } \\
\text { weight }\end{array}$} & \multirow{2}{*}{$\begin{array}{l}\text { Self weight } \\
\text { + wind } \\
\text { +buoyancy }\end{array}$} & \multicolumn{2}{|c|}{$\Delta \mathrm{T} 30^{\circ} \mathrm{C}$} & \multirow{2}{*}{$\begin{array}{l}\Sigma \\
2+4+5\end{array}$} & \multirow{2}{*}{$\begin{array}{l}\Sigma \\
3+4\end{array}$} & & \\
\hline & & & roof & sheathing & & & Allowable & Critical \\
\hline 1 & 2 & 3 & 4 & 5 & 6 & 7 & 8 & 9 \\
\hline 1 and 2 & -4 & -10 & 52 & -108 & -60 & 42 & -58 & -88 \\
\hline 9 and 10 & -44 & -20 & -49 & -13 & -106 & -69 & -58 & -88 \\
\hline 11 & 0 & 44 & -133 & 31 & -102 & -89 & -128 & -192 \\
\hline 20 & 32 & 62 & -7 & -88 & $\begin{array}{l}-63 \\
\end{array}$ & 55 & -128 & -192 \\
\hline 24 & 31 & -10 & -17 & 16 & 30 & -27 & -20 & -30 \\
\hline
\end{tabular}

The following conclusions can be derived from the calculations results:

According to local conditions in Zagreb area, the load combination $3+4+5$ is quite realistic, i.e. the load combinations as : self-weight of the cover, roof trusses and central column, + strong summer 
wind, + sudden fall in temperature at the metal sheet cover and tank sheathing (assumed in our calculations to be $\Delta \mathrm{T}=30^{\circ} \mathrm{C}$ ) due to a summer shower, positive buoyant force on central column. It should however be noted, comparing results from the columns 6 and 9, that the compressive strength of members in the bottom chord of roof trusses 9 and 10 would be exceeded in the case of the load combination $2+4+5$.

Members 9 and/or 10 will buckle elastically or plastically first, but the load bearing system continued to function, until buckling of the diagonal 24 of the roof truss occurred.

The difference in pressure (values in excess of the bottom chord capacity) due to fall in sheathing temperature was fully assumed by top chord elements of the roof truss, and thus we come to the relevant load combination $3+4$, as given in column 7 (the maximum prescribed design wind value was included).

In this combination, the member 24 will buckle (after elastic buckling of members 9 or 10), even if the maximum prescribed design wind intensity is not attained. This is because the forces in column 7 are less than the forces in member 24.

(4) Presence of the additional pressure is exerted by sheathing onto the top chord after buckling of members 9 and 10. The force generated in the diagonal caused by temperature change could be released only after failure of the top chord members,

(5) The wind load at the roof level may not be uniform, i.e. the wind resultant was assumed to move from the centre to the side which attracts a larger wind pressure.

This field of the truss, after buckling of the member 24, acts as a frame, resulting in deformation of chord members 2 and 12 due to bending along nodes. At this time, initial downward deflections begin to form in the area around nodes 13 and 14. Rainwater gradually accumulates in these deformed zones.

It is at this stage of roof deformations that such occurrences were recorded in tank R6.

The occurrence of first deformations, and their gradual increase ultimately to failure, was a time dependent process that might spread over several years, during which the area was probably affected by several events characterized by repeated superposition of a variety of negative load combinations.

No one noted nor understood unfavourable or warning signs that formed on the load bearing structure of tank R5 in the initial stage.

In this respect, it can be seen from documents about maintenance of the tank $\mathrm{R} 5$ that great deflections from linearity were registered and repaired 1986. At the level of members 9 and 10 of the roof truss bottom chord, no abnormality was noted, analyzed, commented or explained.

As to tank R5, it can be concluded that chord members 2 and 12 were no longer able to withstand negative load combinations from self-weight, snow and possibly suction wind present in the newly formed frame-shaped static system after buckling of the diagonal member 24, which resulted in the deformation and bending ruptures of the members. After this, the roof failed in the vicinity of nodes 13 and 14 on a part of the perimeter. The rainwater started to accumulate in the valley formed by this failure and the volume of the valley gradually increased because of the water weight, and hence the diagonal member 24 was converted into a tensile member. Once the volume of the valley and the 
quantity of the accumulated rainwater reached the critical level, this new tensile member 24 failed and the part of the roof around the valley caved in.

It is only at this stage that this phenomenon was noted at the tank R5 in 1993.

The failure stages are shown in Figure 12.
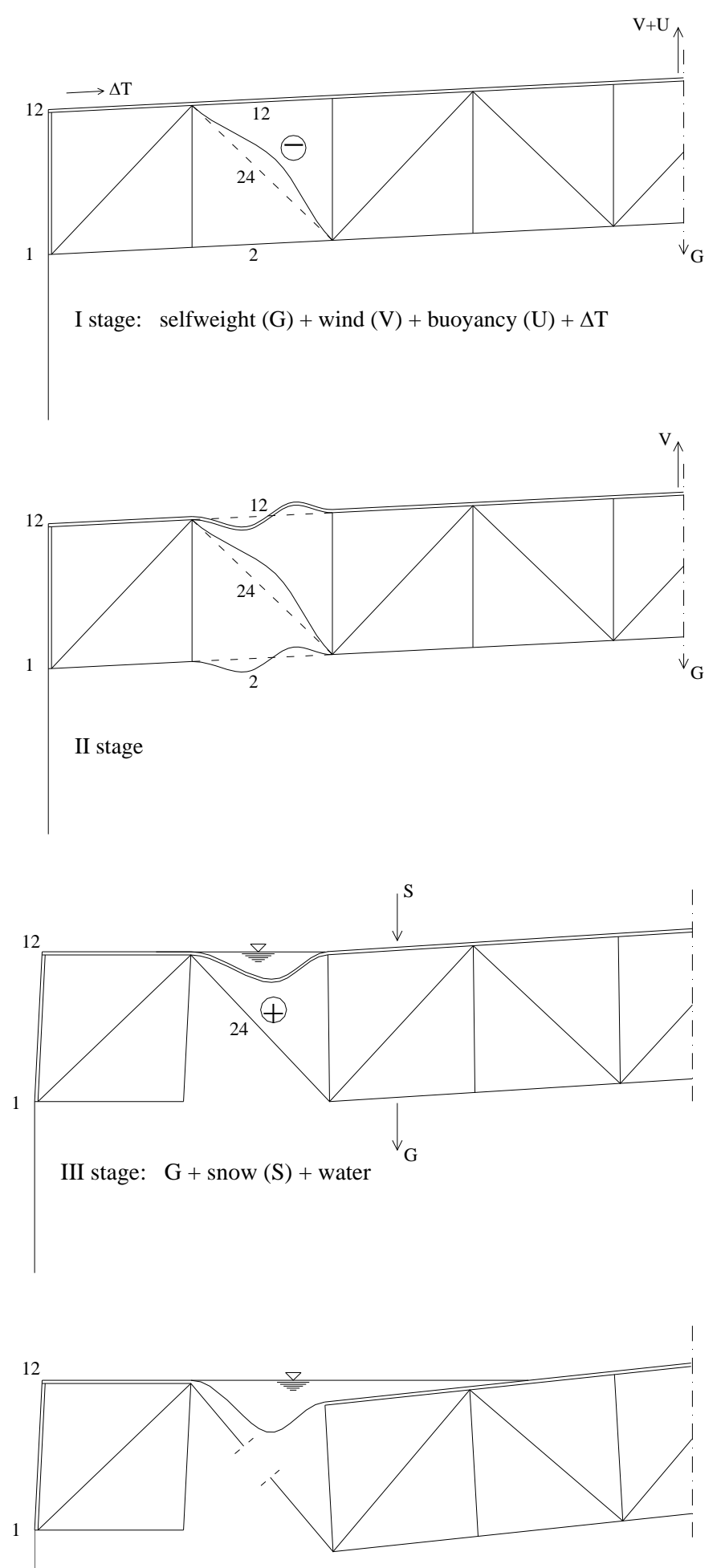

IV final stage: collapse after breakdown of D24

Figure 12. Stages of Damage Development 
It can be seen from the photograph of the roof metal sheet area in the valley that the process lasted for some time. The mud and corrosion isohypse traces show several valley filling levels, and point to longer periods of rainwater deposition and evaporation.

The question should now be put as to why and when the central column footing in node 45 were displaced at tank R6 (i.e. in initial phase of damage development and again in 1996.), and at tank R5 (registered after final collapse).

As already stated in the introductory section of the paper, no connection was required or planned between the central column footing and the base or foundations. Some sort of makeshift connection was nevertheless realized in form of "chairs" i.e. L-shaped upright metal sheets weakly welded onto the tank base (Figure 13). Their form was such that they enabled free vertical movement, but prevented lateral movements. This connection can be seen in photographs. The number and dimensions of such chairs/supports were not registered or figured in the design documents. It seems that these chairs were used as a temporary means of support during assembly work.

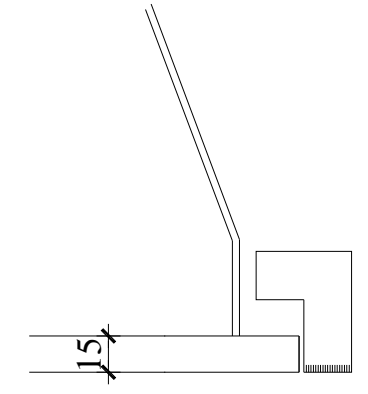

Figure 13. Lateral Support of the Central Column Footing

It can be seen in photographs the situation during inspection that the column footing failed such restraints during the lateral displacement.

Roof trusses are characterized by structural continuity in the zone above the central column. In case of sudden loss of stability of compressed members 9 and/or 10 of the bottom chord in a group of roof trusses (which are due to unsymmetrical wind load subjected to maximum load, or are geometrically weaker than others), the connection at the top of the central column rotates and moves the central column footing in the lateral direction. This movement is instantaneous and strong, resulting in the breakdown of weak restrainers.

The followings were determined during analysis of the sudden fall in temperature at the level of the metal sheet cover and sheathing:

(6) Rapid cooling of the metal sheet cover generates pressure in the entire top chord, in members 7 , 8,9 and 10 of the bottom chord, and in the diagonal 24.

(7) Rapid cooling of the sheathing results in compression in the bottom truss chord and in tension in the diagonal 24, but due to rapid overstepping of compressive strength of lower chord members 9 and 10 the difference is registered, as the compression affecting top chord members which in turn increases compression in members 24.

Obviously, the rapid cooling of the cover and sheathing cannot by itself endanger the safety, bearing capacity and stability of roof trusses, regardless of the temperature change, as the load due to temperature change is released already during elastic bending of members. This behaviour, however, does not hold true for the diagonal member 24 in combination with other loads, because the influence 
of temperature change can be released only after the compressive strength of members in the top chord of the truss is exceeded.

\section{STRENGTHENING AND REPAIR MEASURES TAKEN IN 1993 AND 1994}

The following major works were undertaken in the scope of tank rehabilitation activities on tanks R5 and R6:

(1) All roof truss parts or elements at sheet metal and sheathing levels, that either collapsed or were affected by plastic deformation, were replaced. Central column was corrected in designed position.

(2) All roof truss members were strengthened so as to be able to withstand the service load of 1.25 $\mathrm{kN} / \mathrm{m}^{2}$, which were defined as necessary through calculations.

(3) The hollow steel-made central column was filled with concrete.

(4) Four latticed bracings were added on the tank R6 in order to further stabilize the top chord of roof trusses at the roof level.

(5) The central column footing was fillet-welded along the circular perimeter to the sheet metal at the tank bottom level.

(6) Node 9 at the bottom chord was laterally linked to purlins by diagonal bracing.

\section{NEW PROBLEMS WITH TANK R6 IN 1996 - ADDITIONAL REPAIRS ONLY ON R6}

In 1996, it was observed that the heating oil leaked from the tank R6. A crack of $1300 \mathrm{~mm}$ in length was discovered at a weld situated at the tank base, about $80 \mathrm{~mm}$ away from the central column footing. The cause of the cracking was related to the functional use of the roof bearing structure.

In addition to this cracking at the base level, some new deformations were recorded at the roof structure:

(1) Large local and plastic deformations of the member 10 at the bottom chord on roof trusses X, XI, XII, and XIII (i.e. buckling in the truss plane).

(2) Elastic and plastic deformations on the bottom chord on roof trusses IV, VIII and IX.

The causes of the above deformations and phenomena are similar to those explained above.

After the investigation in 1996, the tank R6 was subjected to the following additional repairs:

(1) The fillet weld, by which the central column footing was linked to the base, was removed.

(2) Roof truss supported on the central column, in nodes 11 and 23, were converted from fixed supports to movable supports. 
(3) The top part of the central column head at R6 was radially anchored with 8 inclined anchors to the tank sheathing above the base (This intervention was probably unnecessary but considered as an additional safety measure, because weight of the concrete in central column was sufficient to prevent vertical movement).

(4) The lateral displacement of the central column footing was prevented via lateral restraints situated at the tank base.

(5) Members 9 and 10 were adjusted to improve their linearity.

\section{REHABILITATION WORKS WITH TANK R5}

Making reference to the case for R6, it was recommended to the Client (Report IGH No 25-602/1996, from 22 Nov. 1996.) to undertake the same rehabilitation works on tank R5 as it was carried out for R6 described under section 8 of this paper to prevent similar collapse.

The completed works reported from the Client indicates the followings.

a) Recommended rehabilitation on tank R5 has not been completed. Only the vents on the roof (see section 4 (4)) have been removed and replaced with free openings.

b) Both tanks since then have been in continuous use. No major discrepancies have been reported.

Authors of this paper have not seen the tank R5 since 1994. Our presumptions are as follows.

a) Member 10 plastically buckled, because the theoretical critical compressive capacity will be exceeded already due to self weight of the structure plus $50 \%$ of the prescribed snow load, or for load described under b).

b) Also, buckled bottom chords of some trusses along the whole length (elastically or plastically), because the theoretical critical compressive capacity will be exceeded due to fall in sheathing temperature (see table 4 and explanation in section 6 (3)).

c) We assume the central column footing is not displaced, because it is welded to the tank bottom. It seams quite obvious that the inclinations of the column, caused by buckling of the trusses elements, did not result in the cracking of tank bottom sheathing metal welds. If it happens, the heating oil leaks would have been observed.

\section{CONCLUSIONS}

The causes of damage to roof structures of two identical heating oil tanks are analyzed. The failure causes are accounted to poor original design under Section 4, with respect to relevant factors as types of loads, adequate static system and boundary conditions for individual load types.

The causes of the damages on tanks R5 and R6, and also the mechanism of the beginnings and development of the damages are described in detail under Section 6, which corresponds to the professional reports submitted to the Client (in Croatian). 
Strengthening and repair measures, taken in 1993, 1994 and 1996, are described under Section 7 and 8.

The results and analyses made during this appraisal are presented in detail, as they are deemed highly instructive and of interest to the engineering, building and construction professionals.

In this respect, it should be noted that the tank type analyzed in this paper can be considered as an internationally typical structure, as it has been widely used in many locations worldwide. The authors believe that similar failure occurred in the other locations, although failure reports in literature were scarce.

\section{REFRENCES}

[1] Turcic, F., Luketina, I. and Plisic, M., "The Cause of Collapse and Rehabilitation of Steel Tanks Roof Structures”, In: Gizejowski, Kozlowski, Sleczka \& Ziolko (eds), Progress in Steel, Composite and Aluminium Structures, 2006, pp. 729-736. Taylor \& Francis 2006. Used with permission.

[2] API STANDARD 650: 1980, "Welded Steel Tanks for Oil Storage” 


\title{
DESIGN OF CORRUGATED WEBS UNDER PATCH LOAD
}

\author{
Krzysztof R. Kuchta \\ Ph. D., Faculty of Civil Engineering, Cracow University of Technology \\ ul. Warszawska 24, 31-155 Cracow, Poland \\ "(Corresponding author: E-mail: ikk@poczta.fm)
}

Received: 19 October 2006; Revised: 2 May 2007; Accepted: 13 June 2007

\begin{abstract}
Corrugated webs, in spite of their small thickness, are characterized by relatively high patch load carrying capacity. Some formulae for estimating patch load carrying capacity can be found in specialist literature. They were derived from different web failure mechanical models and values of patch load carrying capacity calculated from these formulae differ from one to another. Shaping of web folds in form of sinusoidal wave cause increase of web patch load carrying capacity in comparison with web with other shapes of folds. In experimental tests and numerical simulations it has been shown that, as well as in plate webs, in corrugated webs their patch load carrying capacity is dependent on the width of patch load application.
\end{abstract}

Keywords: Ultimate strength; thin-walled structures; corrugated web; patch load

\section{INTRODUCTION}

Web of optimally shaped classical bended steel plate girder includes about $50 \%$ of the material and carries shear force and only $15 \%$ of bending moment. For this reason possibility of using slender webs in order to decrease share of web weight in plate girder total weight was researched for a long time. The idea of applying thin corrugated sheet for plate girder web appeared in the $30 \mathrm{~s}$ of $20^{\mathrm{th}}$ century, but the high cost of welds between web and flange made the construction of this kind of profiles uncommon. The situation changed in the end of the $80 \mathrm{~s}$ of $20^{\text {th }}$ century when the automatical flange to web welding process line made the production of a new generation of steel girders with corrugated web possible. These girders consist of flanges made of hot-rolled plates (in general from steel of higher strength) and webs made of sinusoidally profiled sheets (in general from steel of lower strength).

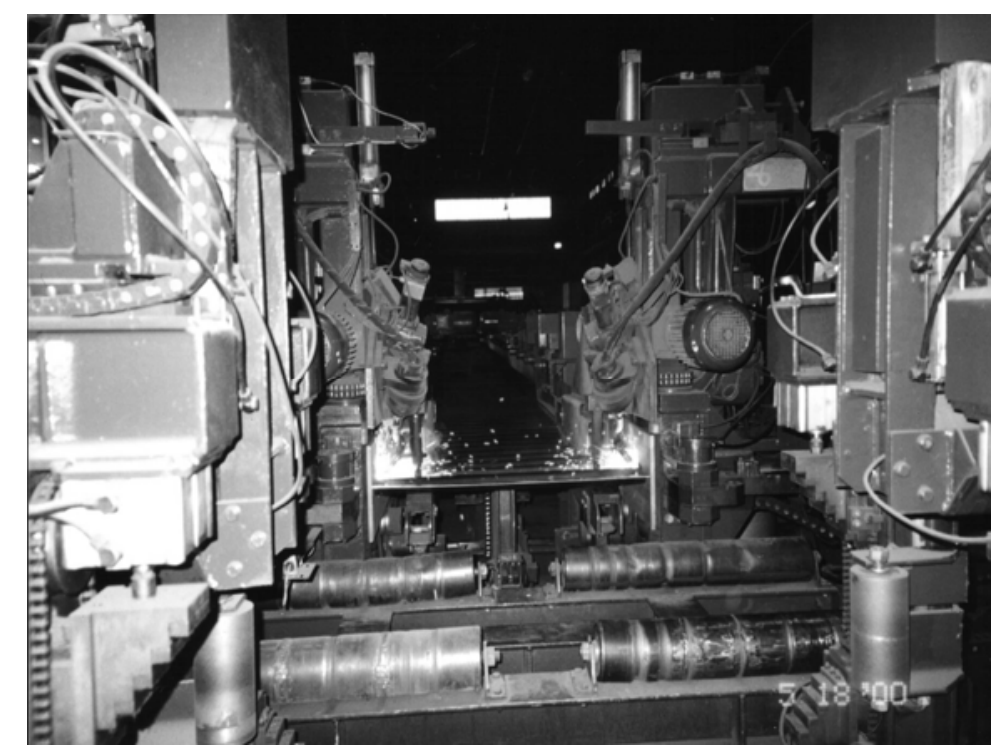

Figure 1 Automatic Welding of Web to Flanges of the Girder 
Geometrical parameters of web waves are selected in such a way that web instability does not occur before shear stresses reach yield point. Flanges of this web thickness do not exceed $3 \mathrm{~mm}$ even with web depth equal to $1500 \mathrm{~mm}$. In comparison to girders with plate web proportion of mass distribution is changed (see Figure 2).

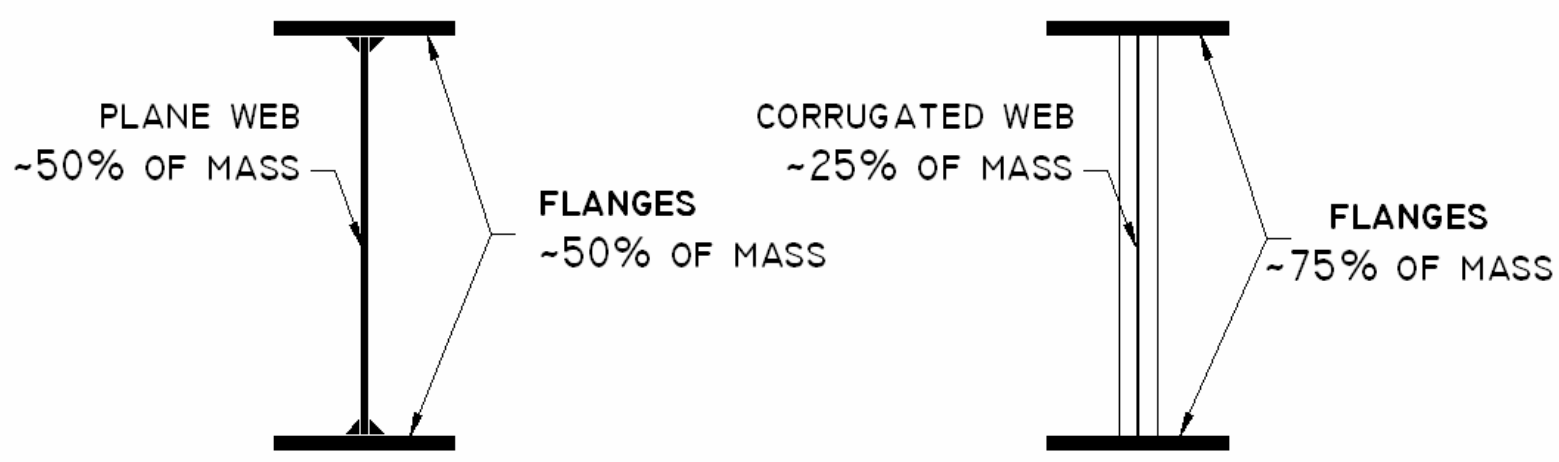

Figure 2 Mass Distribution in Girders with Plane and Corrugated Web

Moving of part of the web mass into flanges makes the girder with corrugated web $30 \%$ lighter than girder with plate web with the same elastic load capacity.

Girders with corrugated web are mainly used in one-floor halls with light roof and walls covering (Figure 3).

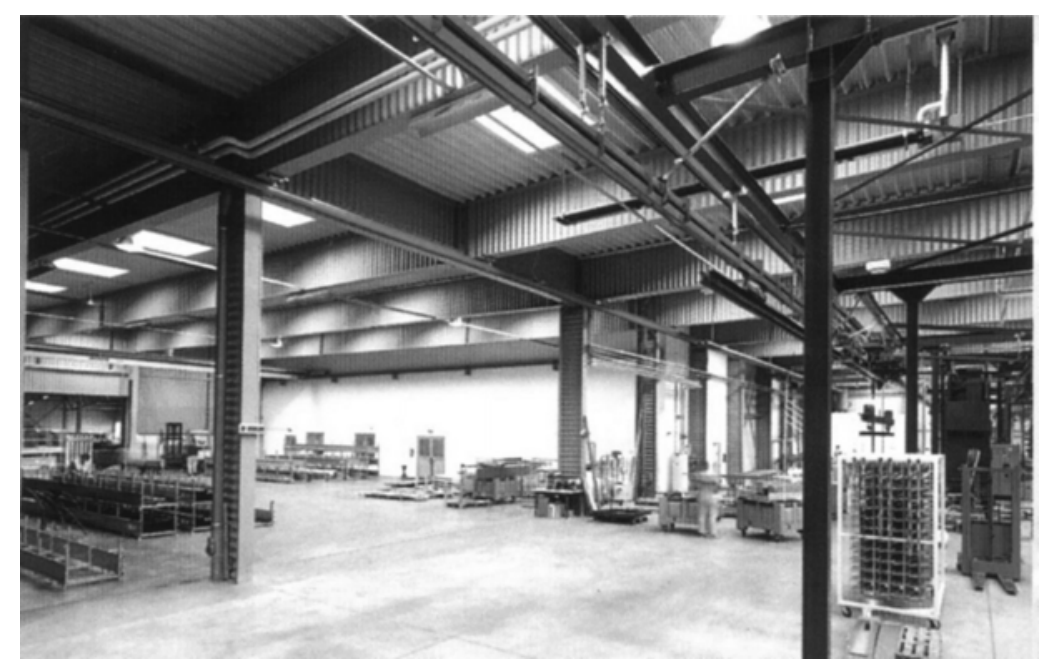

Figure 3 Industrial Hall Made of Girders with Corrugated Web

One of the advantages of girders with corrugated web is that no web stiffeners are needed (with the exception of locations under large concentrated forces, for example, over supports). The problem of proper determination of unstiffened web carrying capacity under patch load is of great practical importance, because stiffeners are hand-welded with considerable increase in costs of construction.

In the case when patch load must be transferred to upper flange of the girder, designer may not use the stiffeners under this load, provided that condition of patch load carrying capacity of the web is fulfilled. Additionally, if in the considered cross section both bending moment and shear force are large in comparison with the appropriate carrying capacities, interaction of patch load and compressing force from bending in flanges must be taken into consideration. 


\section{DESIGN FORMULAE OF CORRUGATED WEBS UNDER PATCH LOAD}

According to Eurocode 3 [1] in case of unstiffened webs of welded girders, loaded in their own plane by patch load, three forms of failure may occur:

(1) plastification of the web in the contact zone near the flange,

(2) web crippling - local elastic-plastic instability of the web involved in plastic deformations of the loaded flange,

(3) web buckling on the major part of the web depth.

Large moment of inertia of corrugated web in direction perpendicular to wave generator leads to one third of the above mentioned forms of failure in this type of girder practically non-existent.

Taking into consideration the first form of failure design patch load carrying capacity of a plane web may be described as follows

$$
\begin{gathered}
P_{R d}=c_{0} \cdot t_{w} \cdot f_{d}, \\
c_{0}=c+k \cdot\left(t_{f}+a\right),
\end{gathered}
$$

where: $c_{0}$ - effective width of patch load distribution on the web,

$c$ - width of patch load application on the girder flange,

$k$ - coefficient depending on deformability of loading element $(k=2-5)$,

$t_{f}$ - thickness of loaded flange,

$a$ - thickness of weld connecting web with flange,

$t_{w}$ - web thickness,

$f_{d}-$ design resistance of web steel.

Patch load carrying capacity of corrugated web may be calculated from (1) with effective width of applied load equal to wave development length on segment $c_{0}$ according to (2) (Siokola [2]). This method gives safe, but overestimated (even more than 200\%), values of patch load carrying capacity of corrugated web, what has been confirmed by experimental tests (Ramberger [3], Pasternak and Brańka [4], Kuchta [5]).

If loading element is stiff and insensitive to deformations, effective width of patch load distribution on the web $c_{0}$ can be written in the following form (Broude [6]):

$$
c_{0}=\eta \cdot \sqrt[3]{\frac{I_{x f}}{t_{w}}}+c
$$

where: $\eta$-dimensionless coefficient depending on web to flange clamping rigidity (for welded girders $\eta=3,26$ ), $I_{x f}$-moment of inertia of loaded flange.

Determination of patch load carrying capacity of corrugated web according to (1) with effective width of patch load distribution on the web $c_{0}$ according to (3) (assuming $\eta=3,75$ as for riveted girders) gives safe load close to experimental tests (Kuchta [5]). It must be noticed that this is only 
quantitative conformity, because formula (3) has been derived for failure mechanism due to plastification of the web in contact zone. This mechanism is characteristic for girders with stocky web. In girder with thin $(2-3 \mathrm{~mm})$ web under action of patch load there appears local loss of stability connected with web crippling and plastic deformation of loaded flange. Since the end of the $60 \mathrm{~s}$ of the $20^{\text {th }}$ century the above mentioned form of failure has been subjected to many experimental tests and theoretical studies concerning plate webs (i.e. Bergfeld [7], Roberts and Rockey [8], Oxfort and Gauger [9]).

Slender plate web patch load carrying capacity formula recommended by DASt 015 [10] is based on the mechanism of failure proposed by Oxfort and Gauger [9]. In the moment of reaching the limit strength, plastic hinges in flanges and plastic lines in web occur in the same time (Figure 4). Plastic lines in web were assumed to be a circular arc.

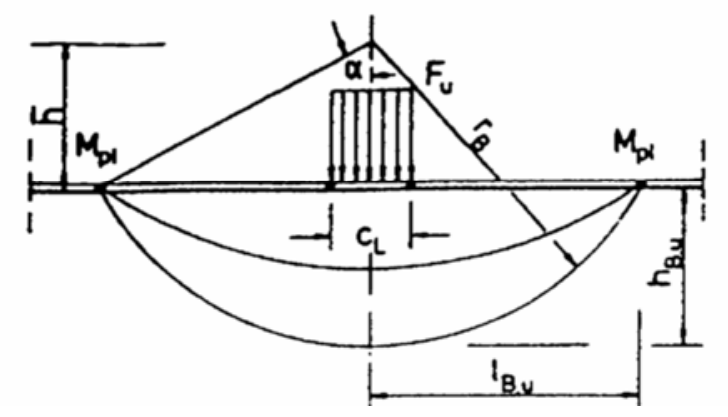

Figure 4 Oxfort and Gauger Web Mechanism of Failure (Oxfort and Gauger [9])

Taking into consideration the influence of membrane stresses in web on reduction of plastic moment in web plastic lines, formula for patch load carrying capacity of plate web has been derived as,

$$
P_{R}=\frac{40 M_{p l} f_{y w} t_{w}^{2}}{M_{p l}+20 f_{y w} t_{w}^{3}},
$$

where: $M_{p l}-$ web plastic moment,

$f_{y w}-$ web steel yield point.

It should be noticed that Oxfort-Gauger formula (4) assumed that width of applied load does not influence patch load carrying capacity.

Different approach was applied by Kähönen [11]. He treated loaded flange of the girder as beam on elastic foundation, where parameters of foundation depend on the elastic-plastic properties of trapezoidally corrugated web. Kähönen formula [5] is quite complicated because it uses deformed structure equilibrium conditions, so carrying capacity depends on web as well as flange effort.

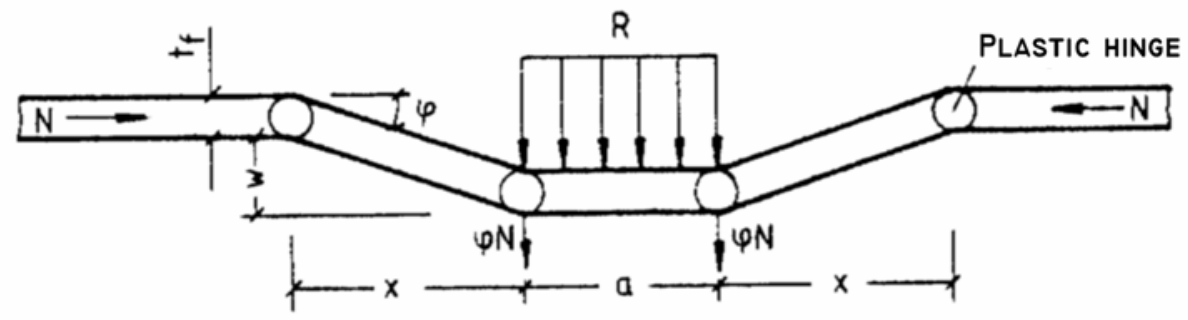

Figure 5 Mechanism of Failure According to Kähönen [11] 
Patch load design carrying capacity of corrugated web according to Kähönen [11] has the following form

$$
P_{R d}=\left(R_{d 1}+R_{d 2}+R_{d 3}\right) \frac{k_{0} k_{r}}{\gamma_{M}},
$$

where: $R_{d 1}-$ web reaction force,

$R_{d 2}$ - additional force due to flange bending moment carrying capacity,

$R_{d 3}$ - force increasing pressure due to normal force acting in flange (see Figure 5),

$\gamma_{M}$ - safety factor for material,

$k_{r}, k_{0}$ - dimensionless corrective factors.

Equation (5) depends on many design variables and empirical factors and therefore is not convenient in design practice. Exact description of parameters in Equation (5) can be found in Kähönen [11].

Luo and Edlund ([12] and [13]) in their numerical analyses proved that patch load carrying capacity of corrugated web strongly depends on the width of applying load (see Figure 6).

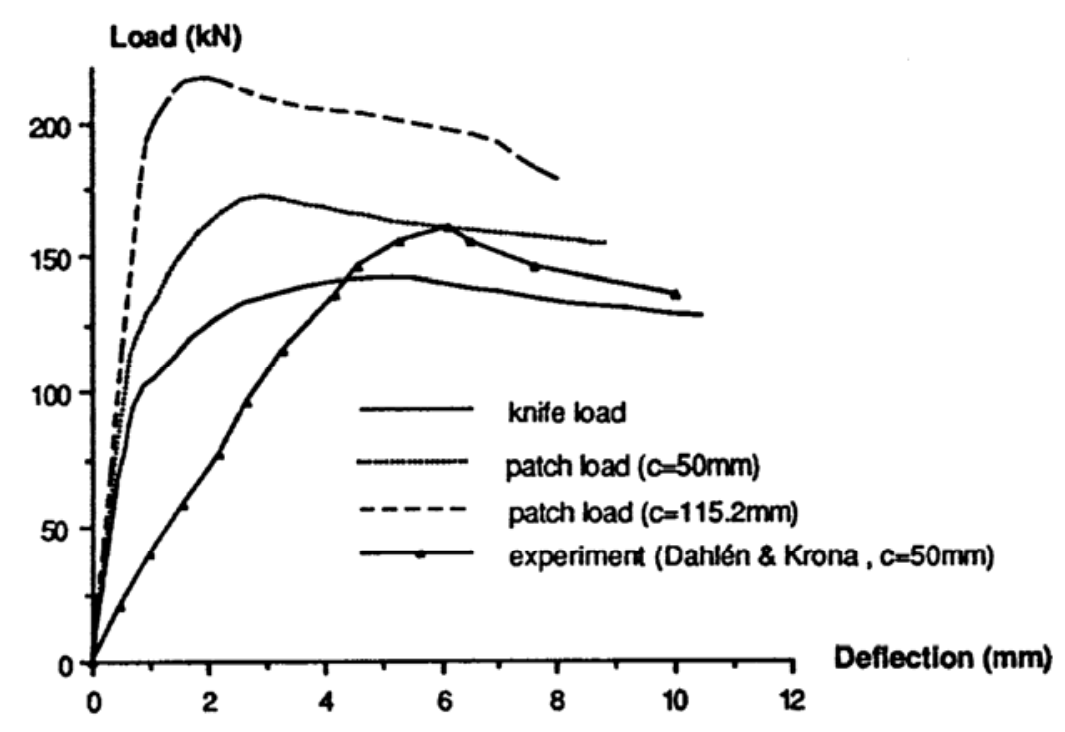

Figure 6 Equilibrium Paths of Girder with Different Width of Applied Load (Luo and Edlund [12])

On the basis of the obtained analysis results, they proposed the following empirical formula for carrying capacity of trapezoidally corrugated web under patch load.

$$
\begin{aligned}
& P_{R}=\gamma t_{f} t_{w} f_{y w}, \\
& \gamma=15,6 \gamma_{\alpha} \gamma_{c},
\end{aligned}
$$

where: $\gamma$-coefficient depending on geometrical parameters of the fold and load application width, 


$$
\gamma_{\alpha}=\left\{\begin{array}{ccc}
\frac{a_{1}+a_{3}}{a_{1}+a_{3} \cos (\alpha)} & \text { when } & \frac{t_{f}}{t_{w}} \geq 3,82 \\
1 & \text { when } & \frac{t_{f}}{t_{w}}<3,82
\end{array}\right.
$$

$a_{1}-$ length of the fold panel parallel to the web,

$a_{3}$ - length of fold oblique panel projection on girder axis,

$\alpha$-inclination angle of oblique panel of the fold,

$c$ - load application width [mm].

Formula (6) is valid for $\alpha \leq 75^{\circ}$.

In case of girders with sinusoidally corrugated web successfully attempt at solving problem of web patch load carrying capacity was taken in 1999 by Pasternak and Brańka [4]. They carried out a series of experimental tests and numerical analyses investigating the influence of geometrical parameters of girder with sinusoidally corrugated web on patch load carrying capacities. It was affirmed that load application width and load location in relation to characteristic points of the web wave (crest, zero point) have no significant influence on patch load carrying capacity of corrugated web. It was also shown that web and flange thickness have great influence on studied carrying capacity.

The following formula of corrugated web patch load carrying capacity was proposed

$$
P_{R d}=10 \cdot\left(\frac{W_{x f}}{I_{y w} / t_{w}}\right)^{0,4} \cdot 2 \cdot f \cdot t_{w} \cdot f_{d}
$$

where: $W_{x f}-$ loaded flange section modulus,

$I_{y w}$ - single wave moment of inertia in relation to beam axis,

$f$ - wave amplitude (height).

Equation (10) does not take into consideration load application width which, in case of relatively large widths, may lead to underestimating of patch load carrying capacity. This conclusion was confirmed by the results of author's experimental tests (Kuchta [5]).

According to Pasternak and Brańka [4] if patch load is acting in place of large bending moment, interaction of patch load and bending moment should be taken into consideration. This case occurs if the following conditions are fulfilled.

$$
\left\{\begin{array}{l}
0,5 \leq \frac{M}{M_{R}} \leq 1,0 \\
0,75 \leq \frac{P}{P_{R c}} \leq 1,0
\end{array}\right.
$$


Carrying capacity of the web is then described as below:

$$
0,4 \cdot \frac{M}{\varphi \cdot M_{R y}}+0,8 \cdot \frac{P}{P_{R}} \leq 1,0
$$

where: $\varphi$ - loaded flange instability factor.

Máchaček and Novák [14] investigated the possibility of girders with corrugated web application for crane beams. On the basis of numerical analyses confirmed by experimental tests they proposed formula for corrugated web carrying capacity under patch load transferred by crane rail

$$
P_{R d}=\left(78.9 t_{w}+3.2 t_{f}-14.7\right) \sqrt[3]{\frac{I_{f}+I_{r}}{I_{f}+I_{b}}} \gamma_{M},
$$

where: $\gamma_{M}=1,15$ - safety factor for material,

$I_{r}$ - crane rail moment of inertia $\left[\mathrm{mm}^{4}\right]$,

$I_{b}=112500 \mathrm{~mm}^{4}-$ moment of inertia of block $50 \times 30 \mathrm{~mm}$,

$t_{w}-$ web thickness in [mm],

$t_{f}$ - flange thickness in $[\mathrm{mm}]$.

Equation (13) is correct if eccentricity between a rail axis and a girder one is in the range of \pm 20 $\mathrm{mm}$ and because of that Máchaček and Novák [14] recommend the following limitation of calculated carrying capacity

$$
P_{R d} \leq 270 \sqrt[3]{\frac{I_{f}+I_{r}}{I_{f}+I_{b}}}
$$

Formula (13) may also serve to determine the carrying capacity of girders directly loaded (without crane rail) if the width of loading element is greater than $150 \mathrm{~mm}$. In case of load without eccentricity web carrying capacity $P_{R d}$ may be increased by $10 \%$.

\section{EXPERIMENTAL TESTS}

In order to describe quantitative and qualitative effects of corrugated web patch load carrying capacity lost a series of experimental test have been carried out.

Two girders ("A" and "B") with span about $2000 \mathrm{~mm}$ and $500 \mathrm{~mm}$ web height have been tested. They have the same nominal web thickness $(2,5 \mathrm{~mm})$ and steel yield point but their load application width $c$ differs (for "A" beam it was $75 \mathrm{~mm}$, for "B" beam - $203 \mathrm{~mm}$ ).

Research programme included measurement of the following quantities:

- vertical deflections (at the level of bottom flange - 1 measuring point),

- top and bottom flanges lateral (horizontal) displacements in the middle of span (2 measuring points),

- loading force and piston displacements (2 measuring points),

- $\quad$ support reactions (2 measuring points), 
- web strains in direction parallel to web generator line in stresses due to patch load acting influence area (9 measuring points),

- $\quad$ supports vertical displacements (2 measuring points).

The girders had "fork" supports against rotation on the bearings, patch load was applied in the middle of the span with load application width $c$. For ease of construction reason the places where the forces were put to girders, were not restrained against the horizontal displacements, but the increase of these displacements was continuously controlled. In the whole range of load, before the limit point on experimental equilibrium path was reached, only quite small horizontal displacements with linear dependence on load were observed. It means that during the whole experiment pure form of bending was maintained. Small span girder allows almost complete elimination of bending moment influence on web in support of patch load.

The main element of the test stand was a frame with SCHENCK hydraulic jack. The loads were controlled by displacements, what allows very accurate determination of ultimate carrying capacity and observation of post-limit states girder behaviour. Load was increased in steps, the length of step was lessened along with approaching predicted girder carrying capacity. Periods of stabilization, as well as periods of changes in acting load, were increased with girder deflection. During the tests cycles of "loading-unloading", the values of permanent deflections are in control.

Experimental equilibrium paths of tested girders are presented in Figures 7 and 8.

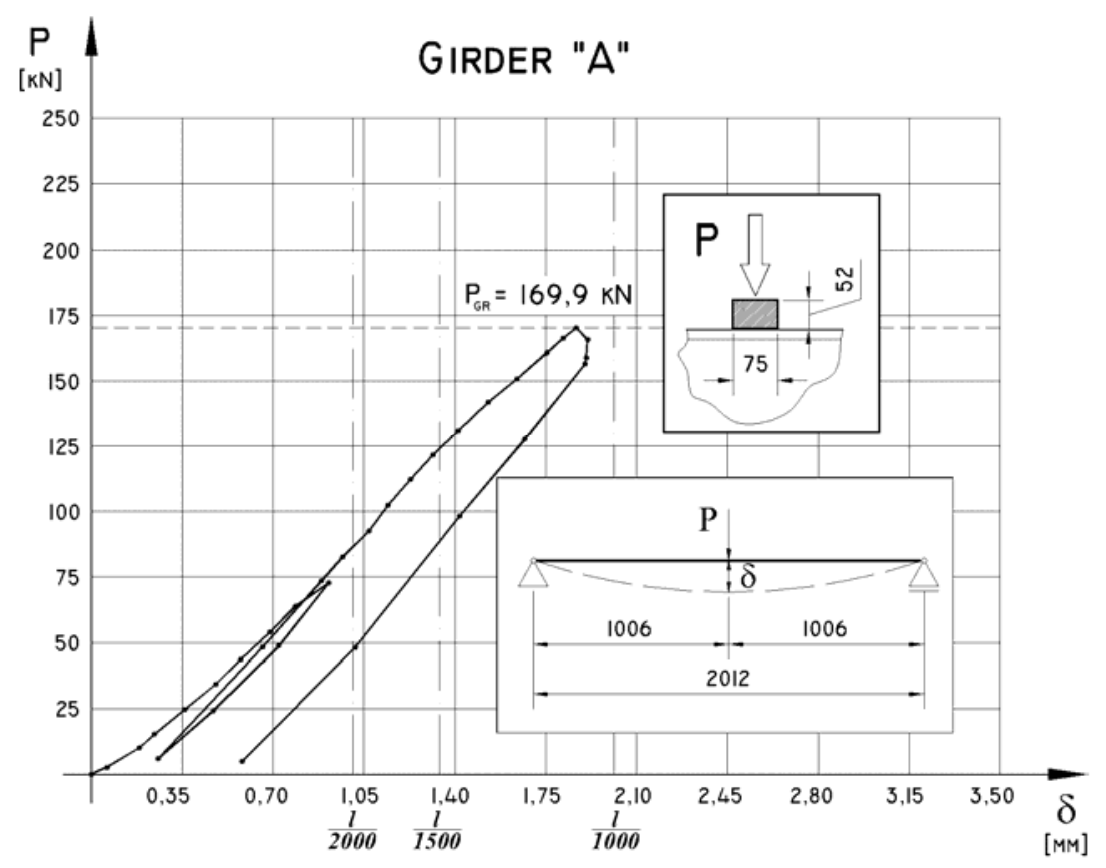

Figure 7 Experimental Equilibrium Path of Girder "A" 


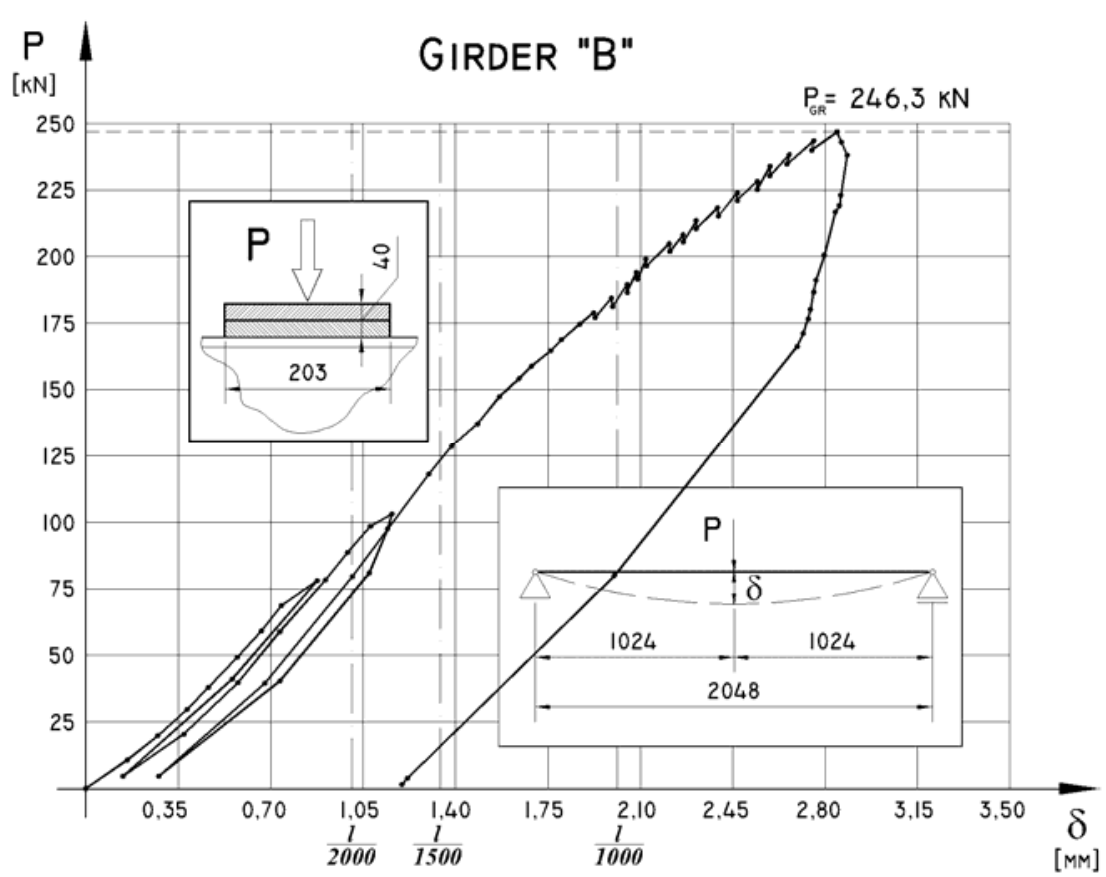

Figure 8 Experimental Equilibrium Path of Girder "B"

Because of girder small span its deflections (without supports settlement) were not large and in the range of 1,78 to $2,50 \mathrm{~mm}$ for force equal to limit point $P_{g r}$. For this reason, in range of loading force about $0-0,4 P_{g r}$, strong influence of test stand mechanical elements with unavoidable imperfections on the course of equilibrium path was observed (see Figures 7 and 8). Flexibility of supports, deformability of dynamometers measurement system, bearing and clamping clearances caused some irregularities, and it even increases stiffness in the girder resistance at early stages. When applied load exceeded the value around $0,7 P_{g r}$ nonlinearity of equilibrium paths occurred. Further loading to $P_{g r}$, there occurred a sudden loss of stability due to web plastic line, parallel to flanges axis but not exceeding web wave length. In each case propagation of web plastic line was limited to the nearest crest of wave.

In Figures 9 and 10 forms of failure for web and flange of girders " $\mathrm{A}$ " and "B" are presented.

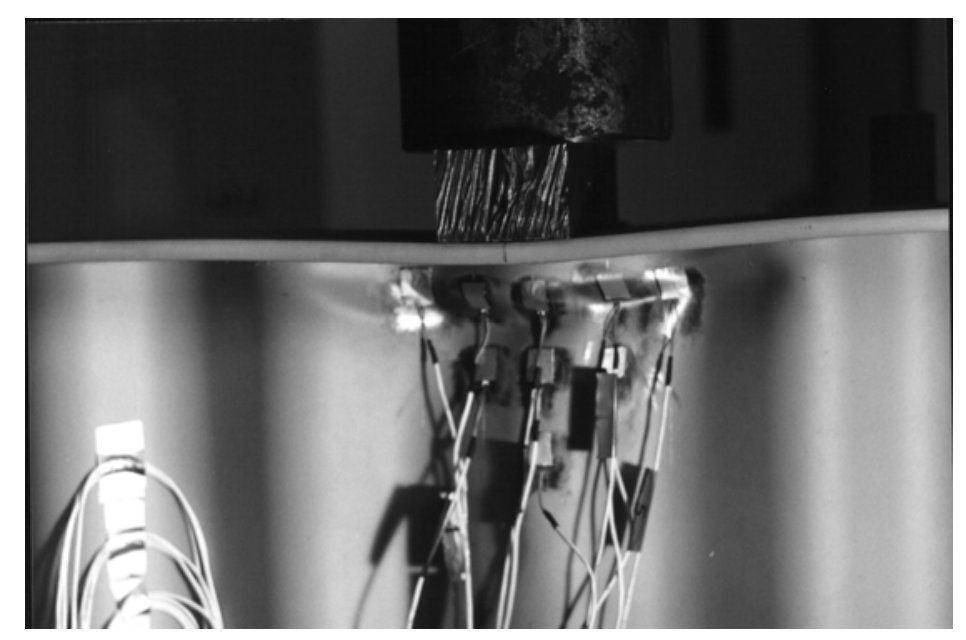

Figure 9 Form of Failure for Web and Flange of Girder "A" 


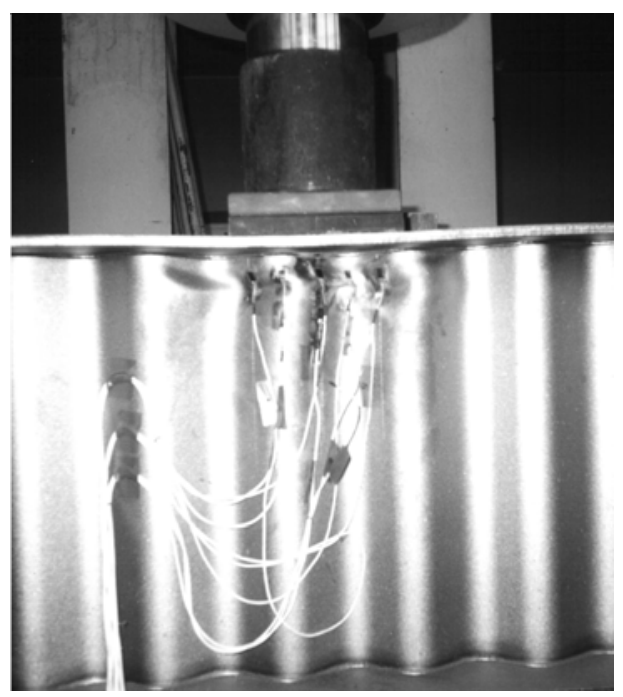

Figure 10 Form of Failure for Web and Flange of Girder "B"

It should be noticed that girders "A" and "B", differing from each other only in load application width $c$, reached significantly different values of load corresponding to limit point on equilibrium path (for girder "A" $P_{g r}=169,9 \mathrm{kN}$, for girder "B" $P_{g r}=246,3 \mathrm{kN}$ ).

Results of conducted experimental test showed that, similarly as for girders with plate web, patch load carrying capacity of girders with corrugated web is strongly dependent on load application width.

\section{NUMERICAL SIMULATIONS}

Ultimate strength of steel girders with corrugated web under patch loading was studied using a non-linear finite element method. Throughout the studies girders were described by shell model with geometry given in Figure 11.

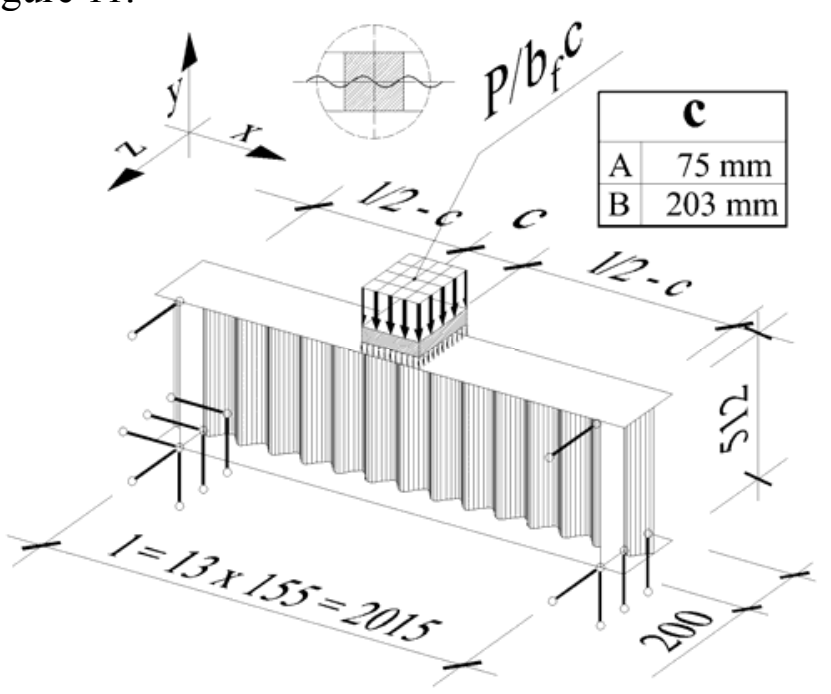

Figure 11 Static System of Shell Model of Tested Girders

Component shells of the model were located at flanges and web central surface. Web surface was modeled as waved surface with generating line perpendicular to flanges surface and direction described by sinusoid equation. 


$$
z(x)=f \cdot \sin \left(\frac{\pi \cdot x}{0,5 \cdot q}\right)
$$

For the numerical studies a finite element program ANSYS 8.0 was used. Effect of large deflections was taken into account and elastic-plastic model of material with strain hardening coefficient $(1 / 10000) E(E=205 \mathrm{GPa})$ was assumed. Throughout the simulations, a 4-node quadrilateral shell element SHELL43 was utilized to mesh both web and flanges. In place of support reactions acting $10 \mathrm{~mm}$ thick stiffeners were inserted. In order to achieve the best conformity between experimental tests conditions and numerical simulations, the model of the girder was supplemented with the model of distance piece meshed by 8-node brick elements SOLID45. Inserting this distance piece allowed to eliminate loaded flange bending in plane perpendicular to its axis. A layer of contact elements CONTAC52 was placed between flange and distance piece surfaces what enables local "unsticking" of contact surfaces and redistribution of contact stresses.

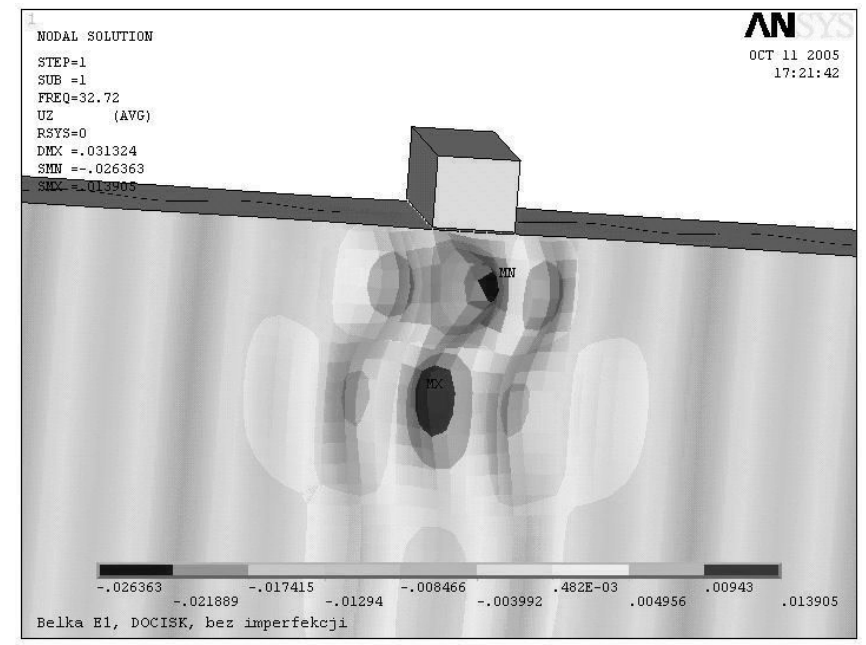

Figure 12 First Eigenvector Displacements $u_{z}[\mathrm{~m}]$ for Model of Girder "A"

The influence of geometric imperfections and fields of residual stresses were taken into consideration by means of introducing equivalent effective geometric imperfection in the form of $1^{\text {st }}$ eigenvector obtained as a result of solving linear stability eigenproblem by the linearized stability equation (Figure 12).

On the basis of a series of numerical simulations it was established that, in considered case, effective imperfection amplitude may be equal to thickness of the web.

Nonlinear static analysis which took into consideration large strains, large deflections and their gradients was performed for the above mentioned girder model. Arc-length method was used for solving nonlinear equations system, which allowed the attainment of the limit point in tracing of equilibrium path and allowed the studies of the behaviour of deflection in post-limit states. Numerical equilibrium paths of girders " $A$ " and " $B$ " are presented in Figures 13 and 14, respectively. 


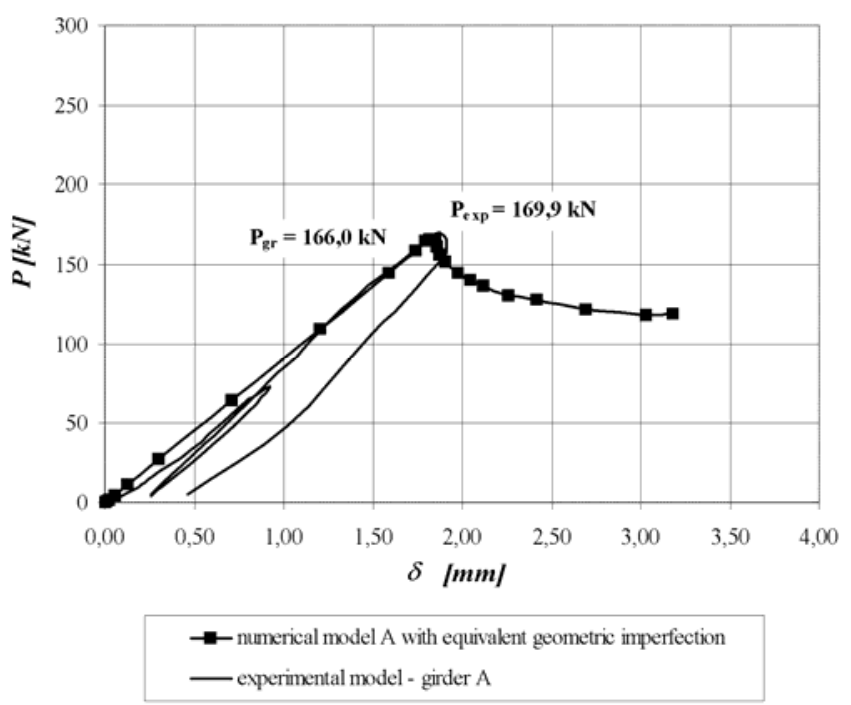

Figure 13 Comparison of Experimental and Numerical Equilibrium Paths of Girder "A"

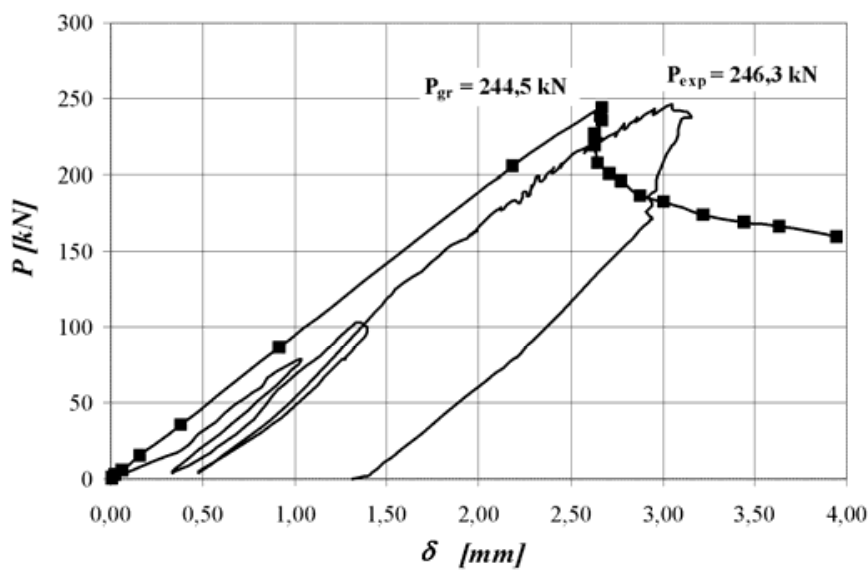

--numerical model B with equivalent geometric imperfection

- experimental model - girder B

Figure 14 Comparison of Experimental and Numerical Equilibrium Paths of Girder "B"

In both cases good conformity between experimental and numerical equilibrium paths was obtained.

In Table 1 values of load patch carrying capacity determined from theoretical formulae, obtained from experimental tests and numerical simulations are compared. It should be noticed that among theoretical formulae surprisingly good conformity with test results for both girders shows formula (1) with effective width of patch load distribution on the web $c_{0}$ according to (3). 
Table 1 Experimental and Theoretical Patch Load Carrying Capacities of Tested Girders

\begin{tabular}{|c|c|c|c|}
\hline \multicolumn{2}{|c|}{ Parameter/Girder } & "A" & "B" \\
\hline$c$ & {$[\mathrm{~mm}]$} & 75 & 203 \\
\hline$t_{w}$ & {$[\mathrm{~mm}]$} & 2,5 & 2,7 \\
\hline$R_{e w}$ & {$[\mathrm{MPa}]$} & 266,6 & 256,6 \\
\hline$R_{e f}$ & {$[\mathrm{MPa}]$} & 321,6 & 305,7 \\
\hline$E$ & {$[\mathrm{GPa}]$} & 205 & 205 \\
\hline$P_{\exp }$ & {$[\mathrm{kN}]$} & 169,9 & 246,3 \\
\hline$P_{T}$ & {$[\mathrm{kN}]$} & 73,9 & 181,1 \\
\hline$P_{\exp } / P_{T}$ & {$[-]$} & 2,299 & 1,360 \\
\hline$P_{P B}$ & {$[\mathrm{kN}]$} & 122,7 & 127,6 \\
\hline$P_{\exp } / P_{P B}$ & {$[-]$} & 1,385 & 1,930 \\
\hline$P_{B}$ & {$[\mathrm{kN}]$} & 122,6 & 225,1 \\
\hline$P_{\exp } / P_{B}$ & {$[-]$} & 1,386 & 1,094 \\
\hline$P_{M N}$ & {$[\mathrm{kN}]$} & - & 260,4 \\
\hline$P_{\exp } / P_{M N}$ & {$[-]$} & - & 1,057 \\
\hline$P_{F E M}$ & {$[\mathrm{kN}]$} & 166,0 & 244,5 \\
\hline$P_{\exp } / P_{F E M}$ & {$[-]$} & 1,023 & 1,007 \\
\hline
\end{tabular}

where: $P_{\exp }$ - experimental patch load carrying capacity,

$P_{T}$ - patch load carrying capacity according to (1) and (2) (as for plate web),

$P_{P B}$ - patch load carrying capacity according to Pasternak-Brańka formula (10),

$P_{B}$ - patch load carrying capacity according to (1) and (3),

$P_{M N}$ - patch load carrying capacity according to Máchaček-Novák formula (13),

$P_{F E M}-$ patch load carrying capacity according to FEM analysis.

Making use of numerical model described above, influence of patch load application width on patch load carrying capacity for different web thickness was investigated on the example of girder shown in Figure 7. Values of yield point were assumed as for steel commonly used as $R_{e w}=215$ $\mathrm{MPa}$ for web and $R_{e f}=235 \mathrm{MPa}$ for flanges.

Results obtained from this analysis are presented in Figure 15. 


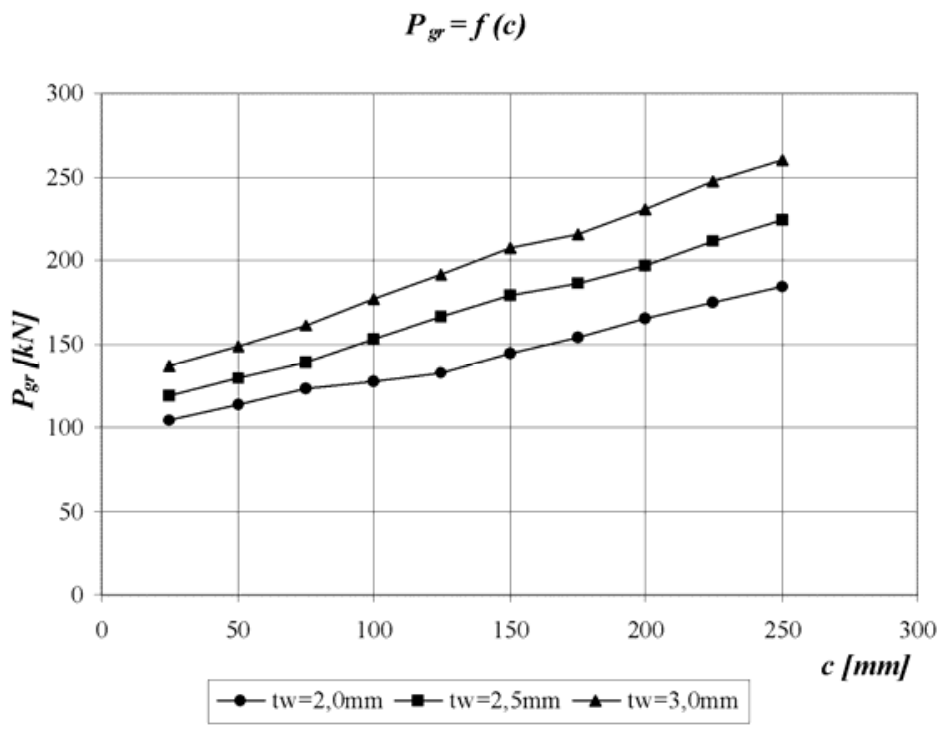

Figure 15 Influence of Patch Load Application Width on Ultimate Strength of Corrugated Web

\section{CONCLUSIONS}

The results of experimental tests and numerical studies are presented and it can be seen that, for girders with plane web, patch load capacity for girders with corrugated web depends heavily on patch load application width. From the numerical results, the girder ultimate strength depends linearly on patch load application width. Increase in girder ultimate strength due to larger patch load application width is more significant for thicker webs.

Problems of patch load carrying capacity of corrugated web need further investigations in order to realize its dependence on other design variables such as girder geometrical dimensions and internal forces distribution.

\section{REFERENCES}

[1] Eurocode No. 3, Design of Steel Structure. Part 1.1. General rules and rules for buildings (European Prestandard ENV-1993-1-1).

[2] Siokola, W., "Wellstegträger. Herstellung und Anwendung von Trägern mit profiliertem Steg“, Stahlbau 9/1997, pp. 596-605.

[3] Ramberger, G., "Gutachten über die Berechnung von Geschweissten I-Trägern Mit Stegen Aus Gewellten Blechen“, O. Univ., Wien 1989 - not published.

[4] Pasternak, H. and Brańka, P., “Tragverhalten von Wellstegträgern unter lokaler Lasteinleitung“, Bauingenieur 5/1999, pp. 219-224.

[5] Kuchta, K.R., "Nośność i Sztywność Blachownic o Falistych środnikach”, Politechnika Krakowska, Kraków 2004.

[6] Broude, B.M., "Raspriedielienie Sosriedotocziennowo Dawlienia W Mietaliczeskich Bałkach", Strojizdat, Moskwa - Leningrad 1950.

[7] Bergfelt, A., "Studies and Tests on Slender Plate Girders without Stiffeners", IABSE Coll. Des. Plate Box Girders Ultimate Strenght, London 1971.

[8] Roberts, T.M. and Rockey, K.C., "A Mechanism Solution for Predicting the Collapse Loads of Slender Plate Girders when Subjected to In-Plane Patch Loading", Proceedings of Institution of Civil Engineers, Part 2, 1979, pp. 155-175. 
[9] Oxfort, J. and Gauger, H.U., "Beultraglast von Vollwandträgern unter Einzellasten“, Stahlbau, 11/1989, pp. 331-339.

[10] DASt-Richtlinie 015. Träger mit Schlanken Stegen, Deutsches Ausschuss für Stahlbau, DASt, Köln, 1990.

[11] Kähönen A., "Zur Einleitung von Einzellasten in I-Träger mit trapezförmig profilierten Stegen“, Stahlbau, 57/1988, pp. 250-252.

[12] Luo, R. and Edlund, B., "Strength of Plate Girders with Trapezoidally Corrugated Webs in Shear or under Patch Loading", Proceedings of Nordic Steel Construction Conference, Malmö, 1995, pp. 79-86.

[13] Luo, R. and Edlund, B., "Shear Capacity of Plate Girders with Trapezoidally Corrugated Webs", Thin-Walled Structures, 1996, Vol. 26, No. 1, pp. 19-44.

[14] Macháček, J. and Novák, R., "Design Resistance of Undulating Webs under Patch Loading", Proceedings of the 3rd International Conference Coupled Instabilities in Metal Structures CISM'2000, Lisbon 2000, pp. 371-378. 


\title{
STRUCTURE, DESIGN AND CONSTRUCTION OF A STEEL ORTHOTROPIC BRIDGE IN SOFIA
}

\author{
D. Partov ${ }^{1, *}$ and D. Dinev ${ }^{2, \#}$ \\ ${ }^{1}$ Assoc. Professor, Higher School of Construction Engineering "L. Karavelov", Bulgaria \\ * (Corresponding author: E-mail: partov@vsu.bg) \\ ${ }^{2}$ Assist. Professor, Univ. of Architecture, Civil Engineering and Geodesy, Bulgaria \\ ${ }^{\#}$ This paper is dedicated to assoc. prof. B. Bankov for his numerous contributions \\ to the bridge design and construction in Bulgaria
}

Received: 30 August 2006; Revised: 5 April 2007; Accepted: 22 June 2007

\begin{abstract}
In this paper the conceptual design and technology of construction of a steel orthotropic $90 \mathrm{~m}$ long bridge in Sofia, Bulgaria is presented. The steel bridge is part of a multi-span reinforced concrete $(\mathrm{R} / \mathrm{C})$ bridge with a total length of $2114 \mathrm{~m}$, a total width of $21.5 \mathrm{~m}$ and an average height above the ground of about $10 \mathrm{~m}$. In transverse direction the orthotropic bridge is built with two individual parallel triple-box decks for two-way traffic. Each deck has a $7.5 \mathrm{~m}$ wide roadway with two lanes. The bridge is analysed as a frame structure using the finite element method. The design parameters of the bridge are verified by static and dynamic tests.
\end{abstract}

Keywords: Steel bridge, orthotropic plate, box girder

\section{INTRODUCTION}

In the beginning of the 90's, in Sofia, the capital of Bulgaria arose the necessity for a long bridge connecting the center of the city to the airport. For this purpose a steel-reinforced concrete bridge was designed and constructed with a total length of $2114 \mathrm{~m}$, a width of $21.5 \mathrm{~m}$ and a height above ground of about $10 \mathrm{~m}$. The bridge is located in a densely populated urban environment.

This important, effective and aesthetic bridge serves as a connection between the busiest input-output highway and the airport of Sofia. It ensures a convenient access to some highways, railways, streets and the airport. As a result of this requirement, the erection of the reinforced concrete bridge is not allowed to cross the railway between Sofia and Varna. So, a $90 \mathrm{~m}$ long middle steel part was designed to cover two spans of $45 \mathrm{~m}$ each in the multi-span bridge structure (see Figure 1).

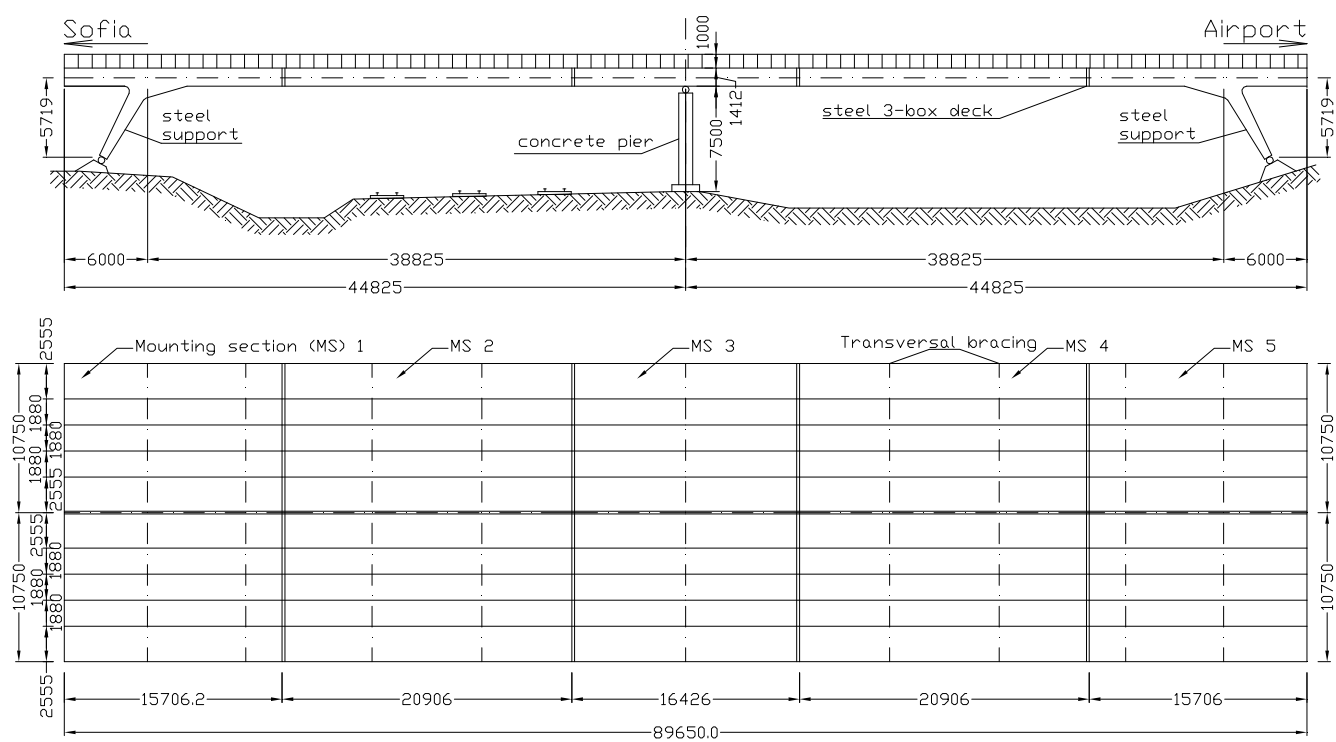

Figure 1. Longitudinal Cross-section and Top View of the Separate Sections 


\section{GENERAL DESCRIPTION OF THE BRIDGE STRUCTURE}

In longitudinal direction the bridge consists of two separate parallel steel structures with a total length of $89.650 \mathrm{~m}$. Each of the structures is $10.75 \mathrm{~m}$ wide and has a $7.5 \mathrm{~m}$ wide roadway with two lanes. The steel part of the bridge is placed in a horizontal curve with a radius of $1000 \mathrm{~m}$. In transverse direction the west deck of the bridge has a bilateral slope to vertical of $2 \%$ and the east deck has variable slopes between $0.319 \%$ and $2 \%$. The deck has a slightly descending slope of $0.10 \%$ along its length in the direction of the Airport because of the vertical profile of the road. The maximum distance from the upper level of the deck to the ground is about $7.5 \mathrm{~m}$. There is a longitudinal gap between adjacent decks.

The cross-section of each of these parallel parts is formed by triple-box structures with four vertical main girders. The girders are required by the longitudinal load distribution and the distances between them are $1880 \mathrm{~mm}$ (see Figure 2).

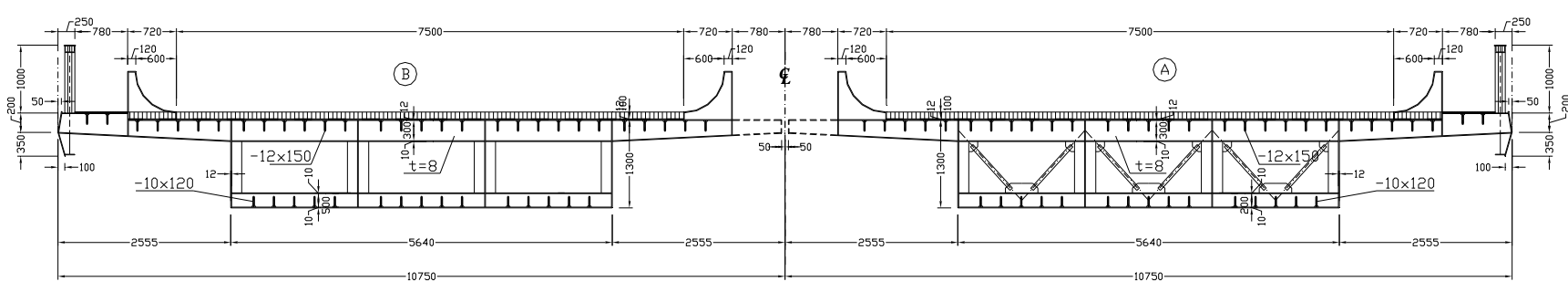

Figure 2. Cross-section of the Bridge

In the area of the transition ramp the bottom plate of the box cross-section is formed as a 3-D surface parallel to the upper deck. This solution keeps a constant height of $1300 \mathrm{~mm}$ of the main girders. These details showed the complexity of the structural problems during the design and the construction of the bridge.

The box has a constant cross-section with height of $1300 \mathrm{~mm}$ along the total length of the span. These dimensions were required and limited by aesthetic considerations, because the steel part should fully follow the silhouette of the concrete part with the same height. This is a pioneer example of how a steel structure follows the dimensional requirements of the adjacent concrete structure.

The system of the bridge structure is a classical orthogonal anisotropic plate (orthotropic plate) (Cornelius [1], Hawranek and Steinhardt [2], Pelikan and Esslinger [3]).

In longitudinal direction the main girders are connected to each other by upper and lower transversal steel beams at intervals of $1493.3 \mathrm{~mm}$. The upper transversal steel beams are connected at the top by a $12 \mathrm{~mm}$ thick steel plate. The lower transversal beams are connected at the bottom by a $10 \mathrm{~mm}$ thick steel plate.

The upper steel orthotropic plate, with a constant thickness of $12 \mathrm{~mm}$, is stiffened with longitudinal flat ribs: - $12 \times 150 \mathrm{~mm}$, which went through the webs of the transversal beams. All flat stiffening ribs were welded under the carriageway and footway plate, as well as to the webs of the transversal beams. The distance between the axes of the longitudinal ribs is $313 \mathrm{~mm}$. All these components form the orthotropic deck of the bridge (see Figure 3). 


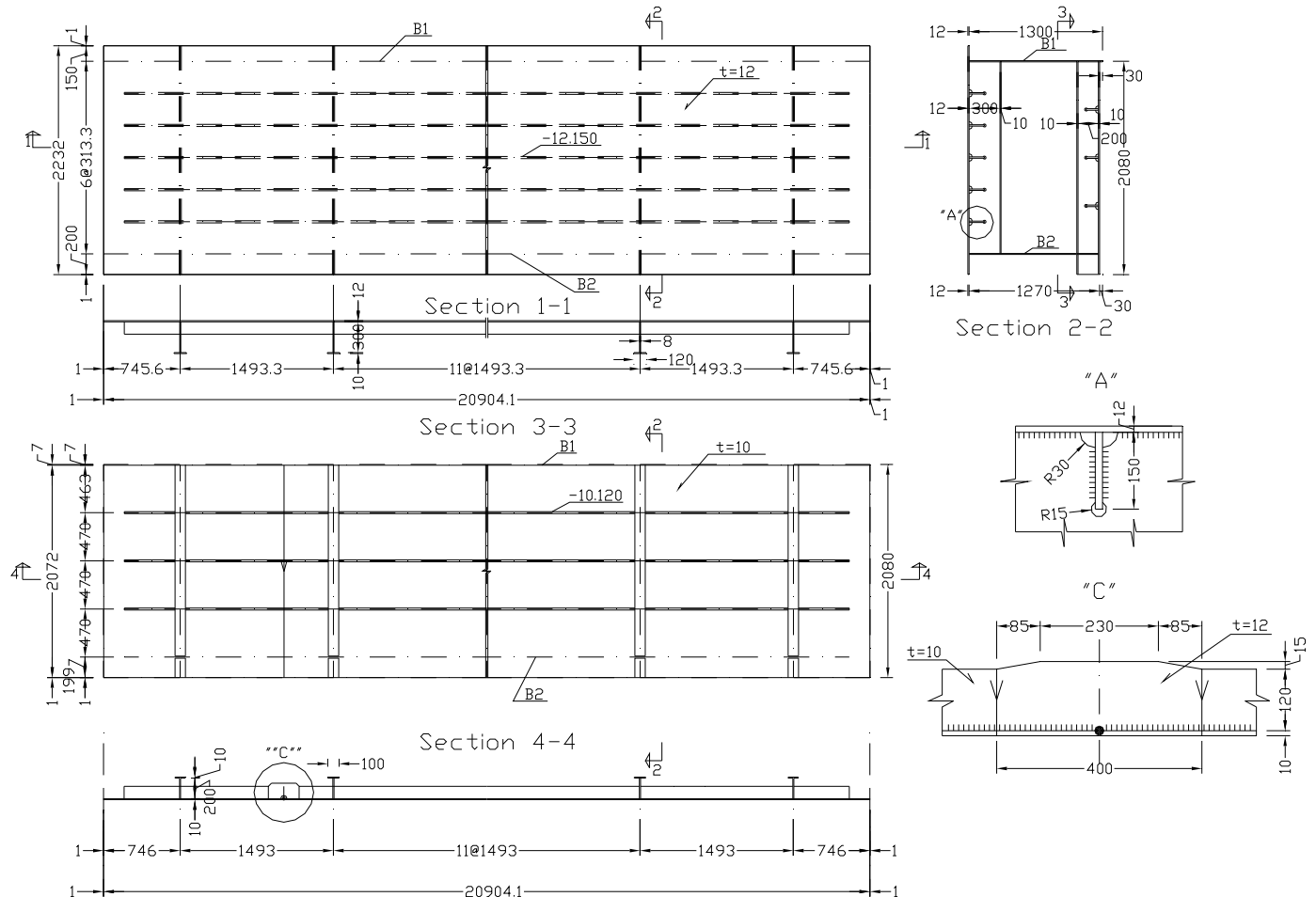

Figure 3. Steel Separate Deck Section - Orthotropic Plate Type

The upper transversal beams have " $\perp$ " cross-sections with web dimensions of $8 \times 300 \mathrm{~mm}$ and flange dimensions of $10 \times 120 \mathrm{~mm}$. The lower beams have " $T$ " cross-sections with web dimensions of $8 \times 200 \mathrm{~mm}$ and flange dimensions of $10 \times 100 \mathrm{~mm}$. The transversal beams ensure stability of the box cross-section.

The flat stiffening longitudinal ribs with dimensions of $10 \times 120 \mathrm{~mm}$ were welded to the bottom plate in order to achieve stability of the compressed bottom plate in the area of the middle support. The distances between them are $470 \mathrm{~mm}$.

The vertical webs of the triple-box girders with thickness of $12 \mathrm{~mm}$ are stiffened at every $1493 \mathrm{~mm}$ with vertical ribs of $10 \times 100 \mathrm{~mm}$ without flanges, which followed the results of structural analysis. These form the closed inner frame which stiffens the box cross-section.

For buckling analysis the vertical webs have dimensions of $12 \times 1300 \times 1493 \mathrm{~mm}$. Diagonal transverse bracings ( $\mathrm{L} 100 \times 100 \times 10 \mathrm{~mm}$ ) are placed at every $7.465 \mathrm{~m}$ into the plane frames in order to stiffen the structure against in-plane deformation. Transverse diaphragms are also placed at support regions.

The footway is designed as an orthotropic plate with a thickness of $6 \mathrm{~mm}$, stiffened with longitudinal flat ribs of $6 \times 60 \mathrm{~mm}$. The cross-sections of the transversal footway beams are “ $\perp$ ” shaped with webs $-8 \times 200 \mathrm{~mm}$ and flange of $10 \times 160 \mathrm{~mm}$. They were connected to the cantilevers of the transversal bridge beams by welding. The transversal slope of the footway was $1.5 \%$. The longitudinal board beam with a height of $350 \mathrm{~mm}$ connects the footway transversal beams. The footway has a $1000 \mathrm{~mm}$ high parapet.

The carriageway is equipped with safety borders, which have a concave surface with radius equal to $600 \mathrm{~mm}$. The two decks of the bridge are separated from each other by a $1560 \mathrm{~mm}$ wide gap. The space between the structures, at the level of the safety borders, is covered with a steel plate for security reasons. The steel plate is designed to carry the load of a car clash. The cantilevers of the 
transversal beams at the ends are extended to the longitudinal axis of the bridge to ensure the assembling of the dilatation joint.

In order to meet the requirement that the steel bridge should look like the concrete bridge, two "V"-shaped supports of varying cross-section were built (see Figures 4a and 4b).
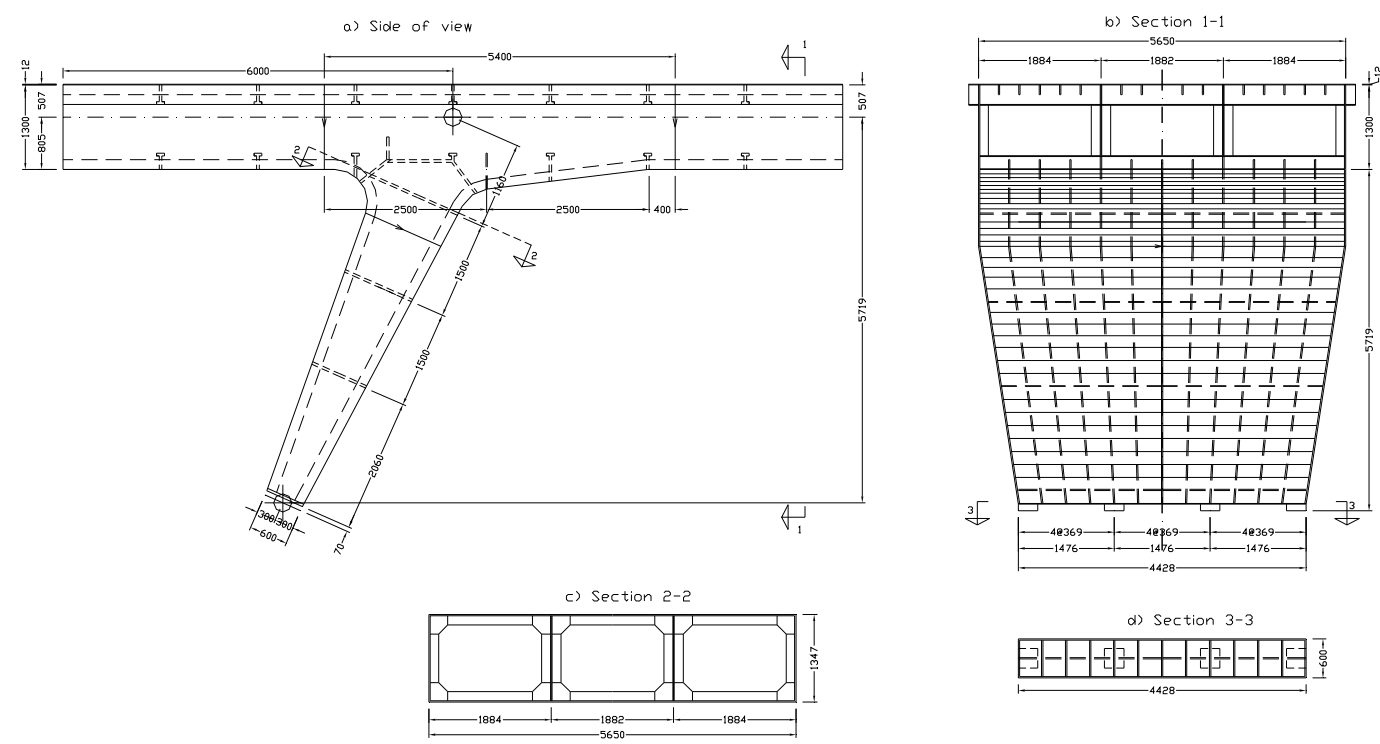

Figure 4. "V”- Shaped Steel Support

The steel supports of this part have triple-box cross-sections shown in Figure 4c. The "V"-shaped supports are rigidly connected to the decks and have rectangular cross-sections with dimensions $1347 \times 5650 \mathrm{~mm}$. The thickness of the steel sheets is $12 \mathrm{~mm}$. The other end of the supports is tied to the bases by cylindrical hinges. The cross-section at this level has dimensions $600 \times 4428 \mathrm{~mm}$ and is strengthened by four additional steel plates with dimensions $40 \times 400 \times 400 \mathrm{~mm}$ (Figure $4 \mathrm{~d}$ ). The supports were stiffened by transversal diaphragms placed at every $1500 \mathrm{~mm}$. The ribs of the lower deck were extended into the supports and form another orthotropic structure. The thickness of the steel sheets used for producing the ribs and the diaphragms was $10 \mathrm{~mm}$.

The two middle vertical R/C columns supporting the steel part of the bridge have varying rectangular cross-sections. They are bounded by elastomeric bearings to the steel bridge and by rigid joints to the foundations.

The adjacent "V"-shaped supports as well as the R/C columns of the two bridge structures are connected to separate R/C fundaments.

\section{METHOD OF CONSTRUCTION}

The steel superstructure in the form of an open steel cross-sections (or boxes, alternatively) were prefabricated in the shipbuilding plant "Stoyan Pavlov" in Varna.

The parts of the steel structure were cut out by a CAD/CAM system according to the final detailed drawings.

Full corrosion protection was provided at the construction site. The structure of the bridge was divided into separate sections (Figure 5) with such dimensions and weight that they could be transported by trucks about $500 \mathrm{~km}$ from Varna on the Black Sea coast to Sofia. 


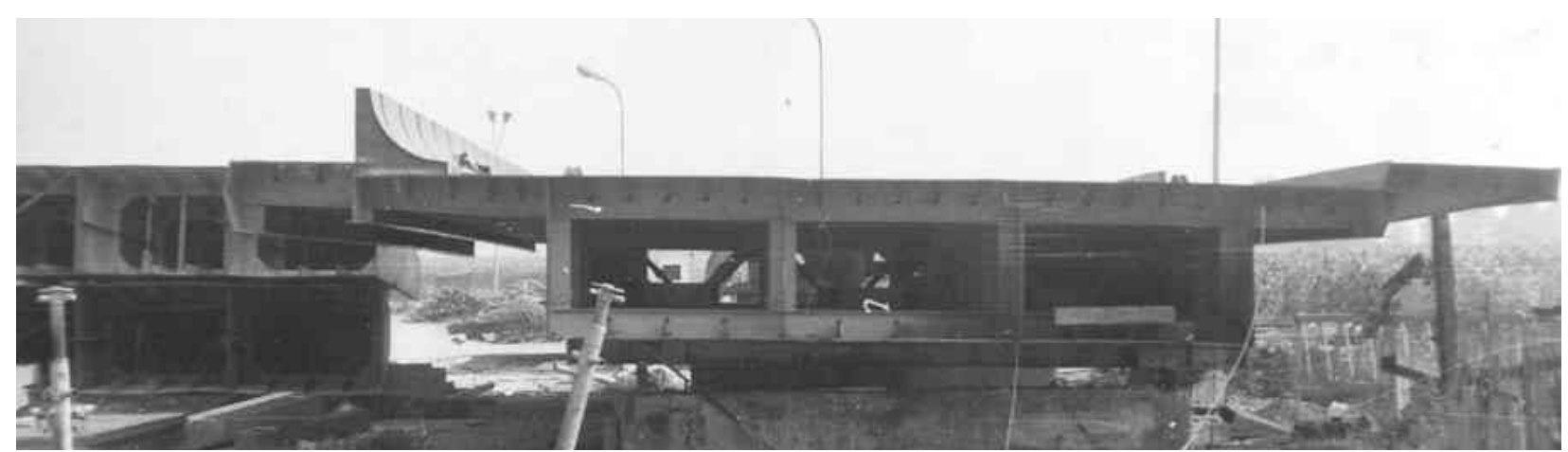

Figure 5. Triple-Box Section of the Bridge Deck

In longitudinal direction five separate sections formed the curvilinear shape of the bridge following the geometry of the road. In transversal direction each of the two decks was also assembled from five separate sections. The "V"-supports were delivered to the site as block elements built in their design dimensions (Figure 6).

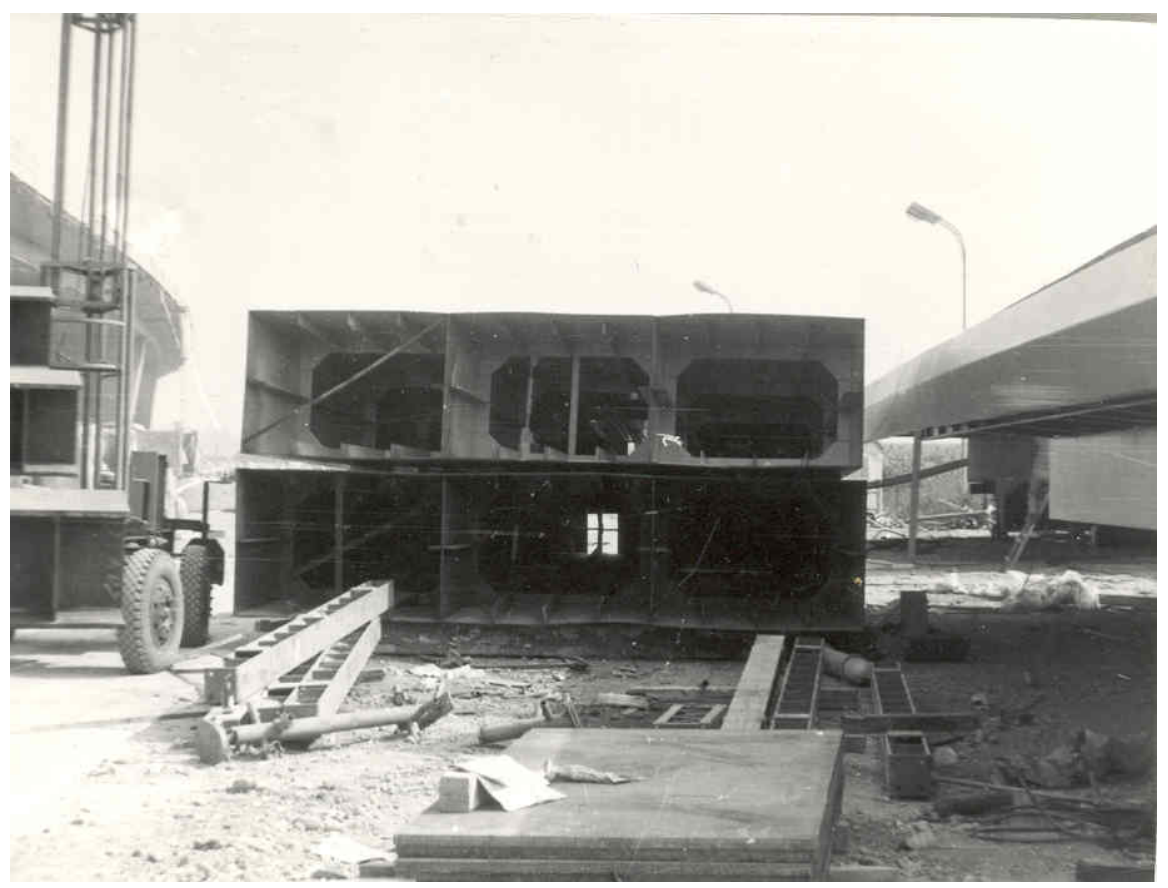

Figure 6. "V"- Supports at the Construction Site

The construction of the bridge started from the middle and continued to both ends simultaneously. The middle sections of the two carriageways with a length of $16.426 \mathrm{~m}$ were placed over the previously erected middle R/C columns and a temporary steel structure as shown in Figure 7. 


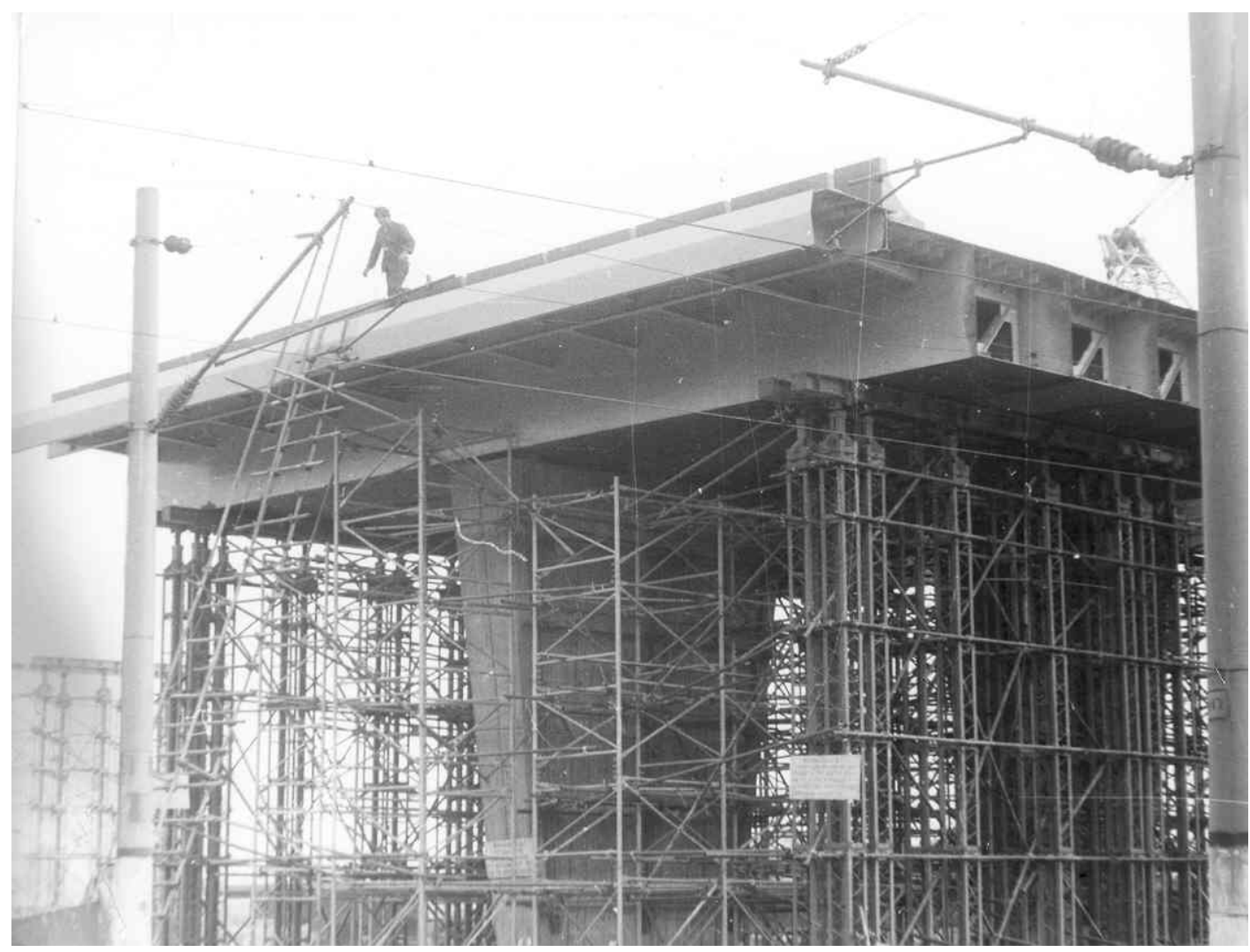

Figure 7. Assembly of the Central Section on the Middle Column and the Temporary Steel Structure

The girders were taken to the construction site (see Figure 8) where they were lifted into their final position with a mobile crane "Demag" shown in Figures 9 and 10.

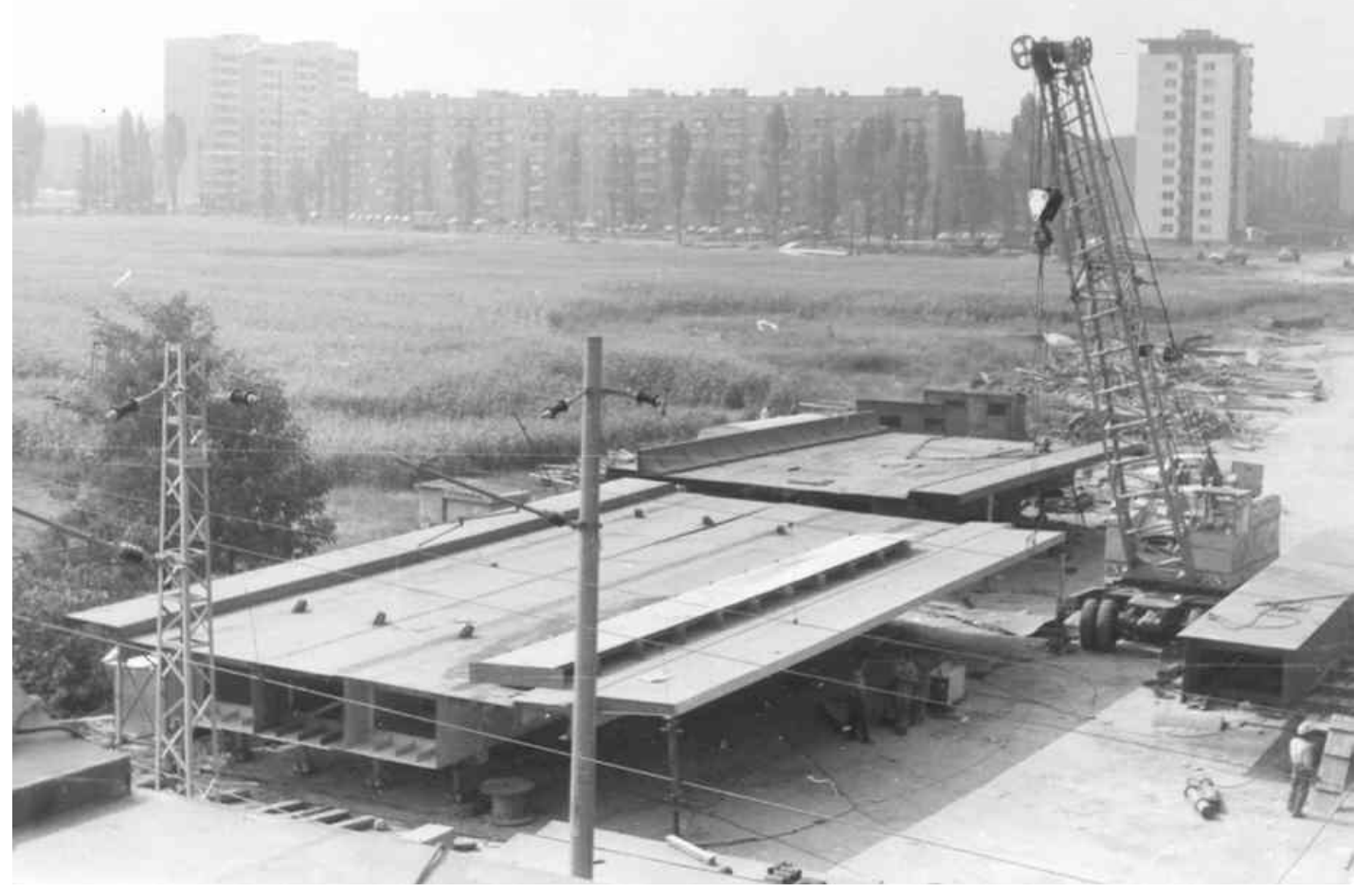

Figure 8. Orthotropic Bridge Storage Yard 


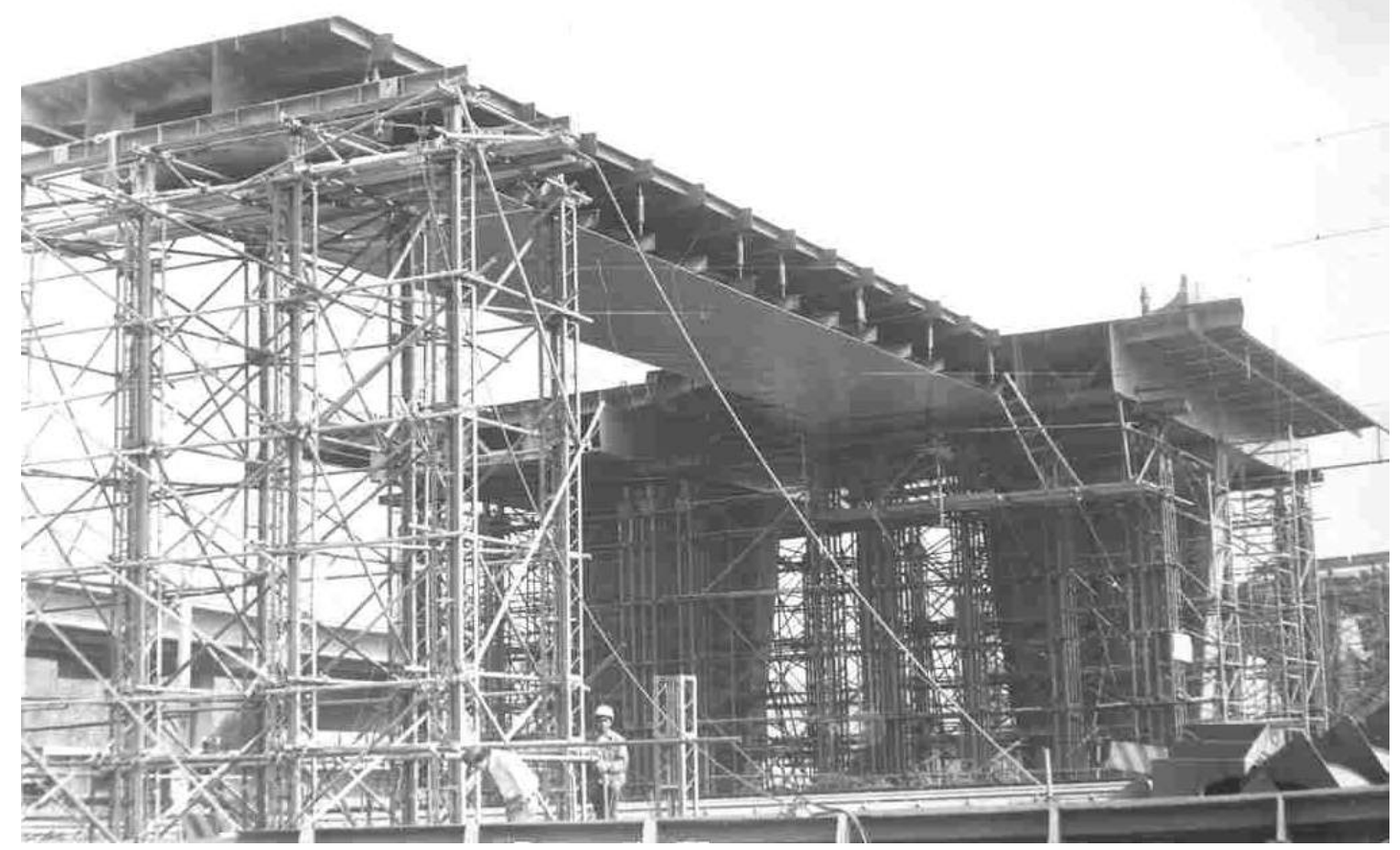

Figure 9. Assembly of the Box Girders

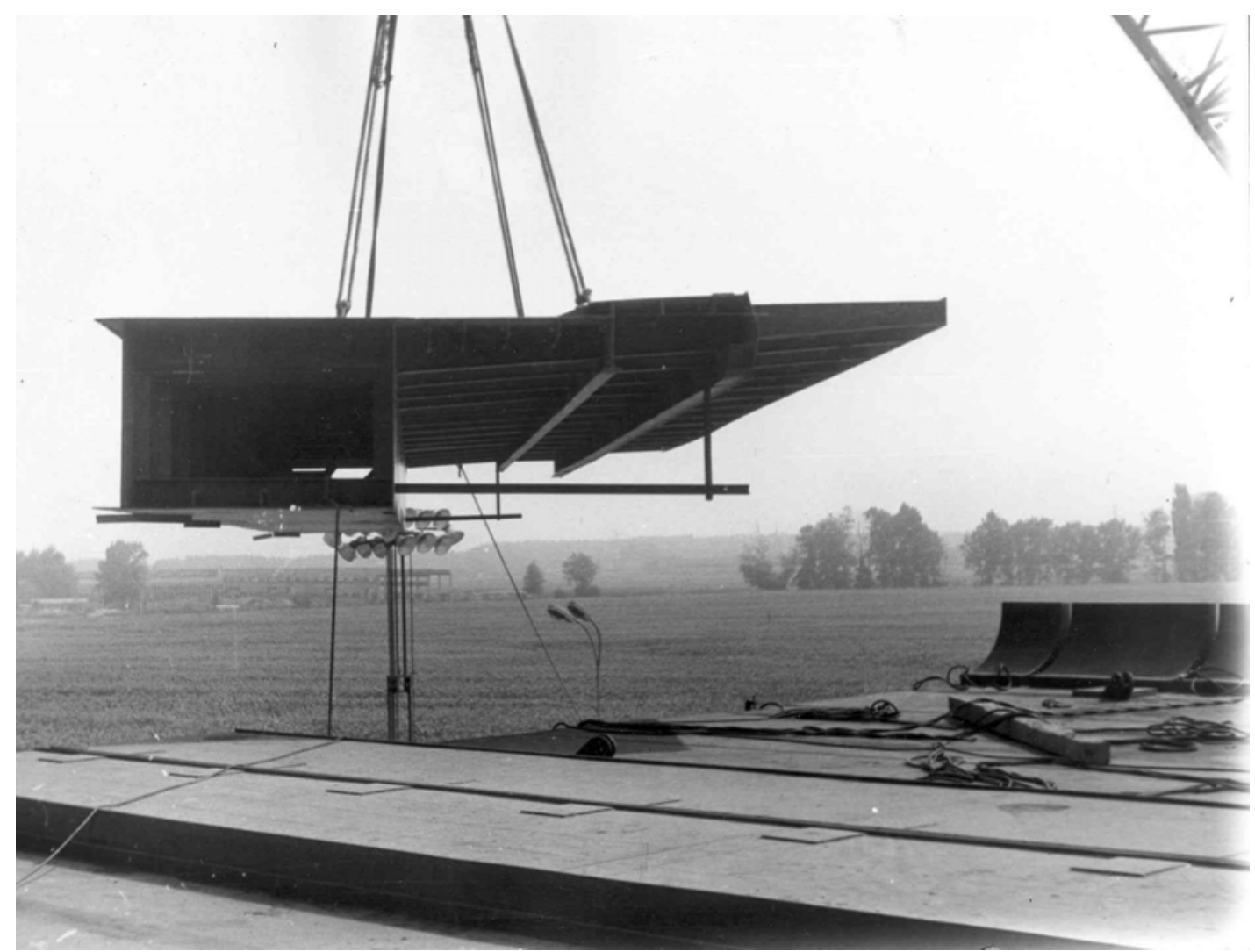

Figure 10. Composition of a Separate Section

The "V"-supports were erected using a temporary tubular scaffolding (Figure 11). 


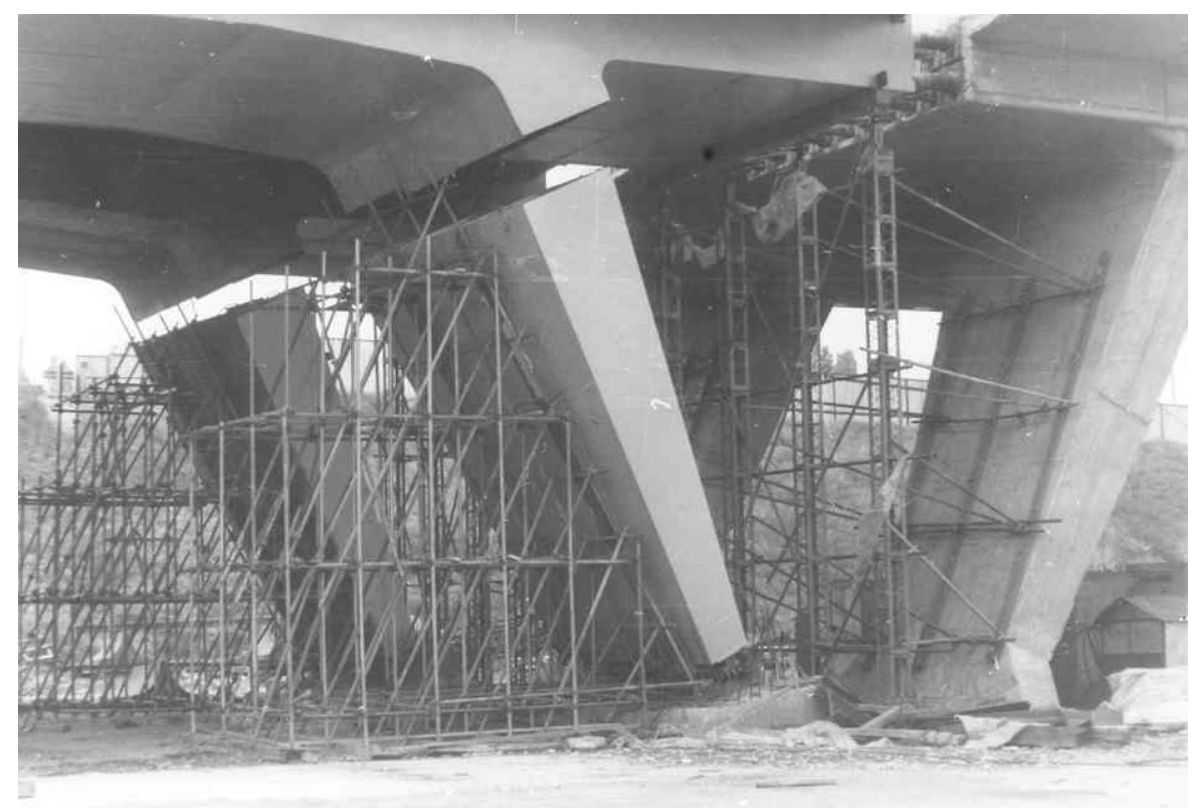

Figure 11. Assembling of the Steel "V”- Supports

In this position, the "V"-shaped supports were mounted onto the concrete bases by means of steel bearings and connected with precision to the lower orthotropic steel deck of the bridge (see Figure 12).

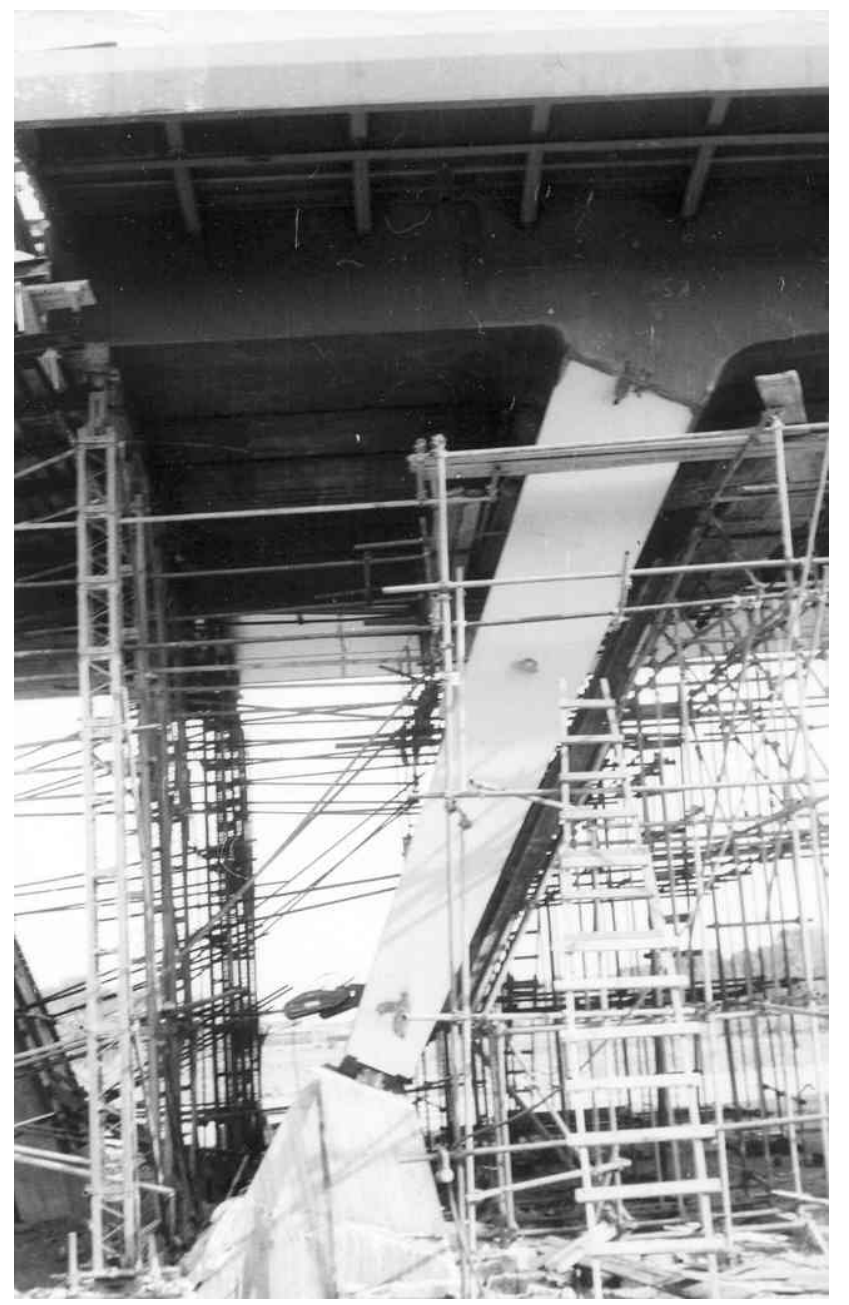

Figure 12. Connection of the "V"- Support to the Lower Orthotropic Steel Deck 
The concrete foundation was completed up to the level of the steel bearings after connecting the steel supports to the bridge deck (see Figure 13).

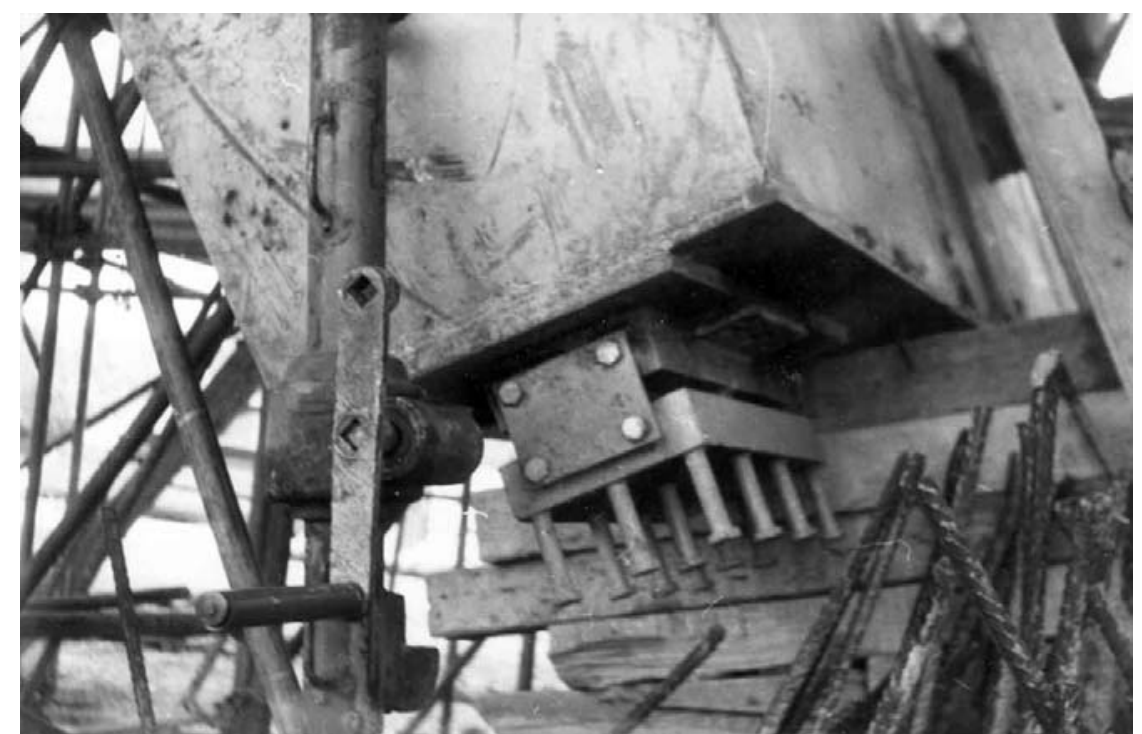

Figure 13. Cylindrical Steel Bearing of the "V”- Supports before Concrete Casting

The separated sections were connected to each other by welding. The adjustments between sections are realized by special steel cantilevers and hydraulic jacks (Figure 14).

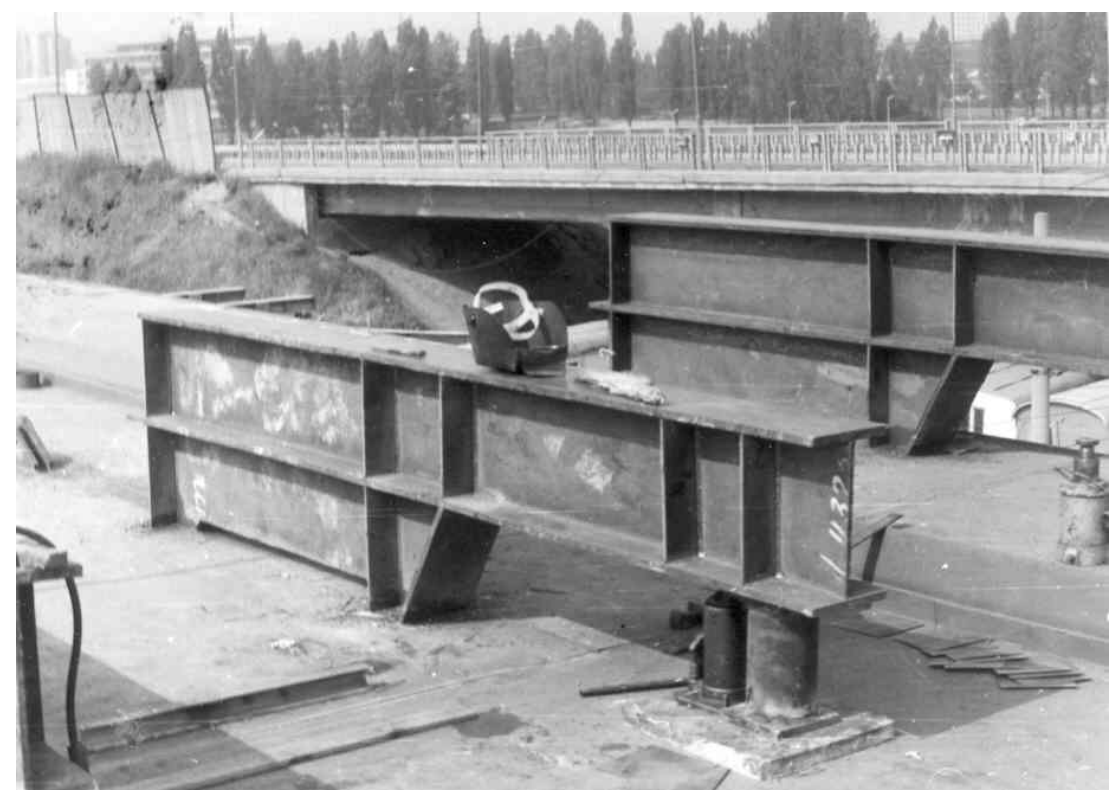

Figure 14. The Fitting Process by Steel Cantilevers and Hydraulic Jacks

A trial assembly of the separate sections was made at the construction site in order to ensure precise connections between them (Figure 8).

The total weight of all structural elements was 630 tons. All adjustments and connections were carefully supervised by chief designer Dr. eng. B. Bankov and the assembly process was completed in 12 days (Figure 15).

The railway had to be blocked during the night when the prefabricated steel elements were being installed. 


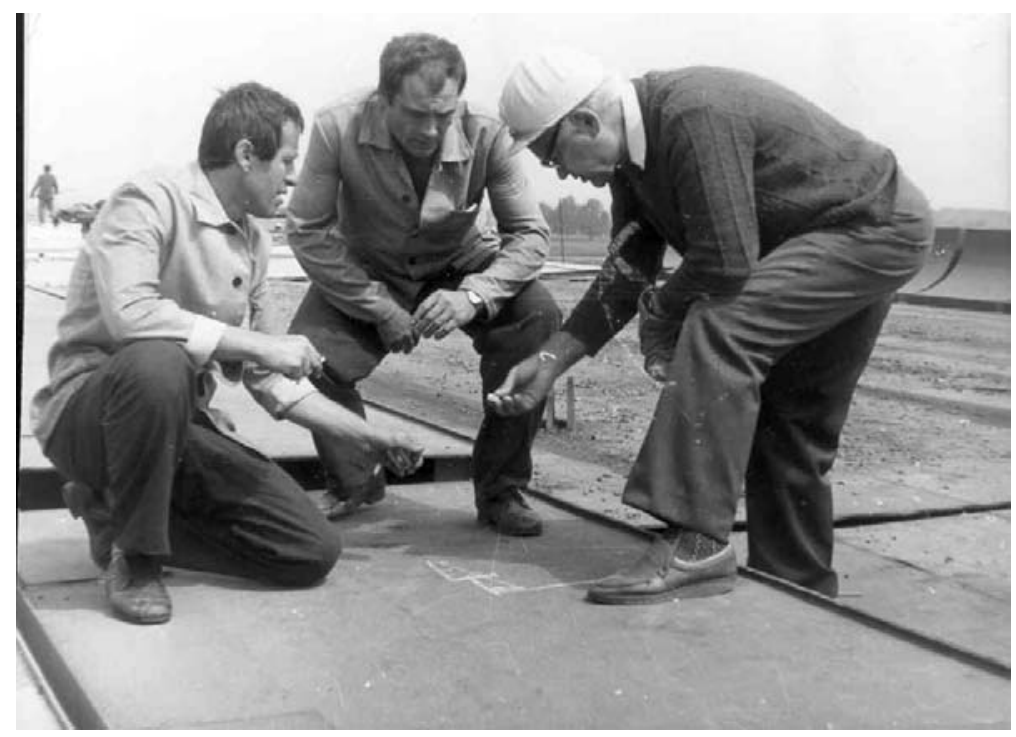

Figure 15. Supervision of the Assembly Process

\section{LOADS, ANALYSIS AND DESIGN}

In the preliminary design the structure was analyzed and designed manually as an orthotropic plate carried by a two-bay frame with hinged supports (Cornelius [1], Hawranek and Steinhardt [2], Pelikan and Esslinger [3]). The frame can be treated as a "Gazelle"-type structure with two spans, $38.825 \mathrm{~m}$ each, and two cantilevers of $6 \mathrm{~m}$ long. The calculations include all actions of:

- dead loads - self-weight of structural components;

- live loads - uniformly distributed $3.0 \mathrm{kN} / \mathrm{m}^{2}$ on the footway;

- $\quad$ snow loads $-1.0 \mathrm{kN} / \mathrm{m}^{2}$;

- moving loads - N30, NK80 according to DIN 1072;

- break forces - obtained from two columns of trucks N30 and equal to $540.0 \mathrm{kN}$;

- wind loads - by unloaded bridge $-2.5 \mathrm{kN} / \mathrm{m}^{2}$; by loaded bridge $-1.25 \mathrm{kN} / \mathrm{m}^{2}$;

- temperature loads $- \pm 40^{\circ} \mathrm{C}$;

- $\quad$ earthquake loads - according to Bulgarian code 1972;

NK80 was presented by four concentrated forces of $200 \mathrm{kN}$ each with a distance between them of $1.20 \mathrm{~m}$.

The moving loads were transmitted to the transversal beams by longitudinal ribs. The loads on the transversal beams were obtained from the influence lines for vertical support reactions and bending moments of multi-span continuous beams with rigid supports.

The bending moments of the transversal beams and the longitudinal ribs were obtained as moments in an orthotropic plate according to the Cornelius theory (Cornelius [1]) and verified by the theory of Pelikan and Esslinger (Pelikan and Esslinger [3]). The maximum bending moments in the middle of the beams and ribs were obtained by influence surfaces (Hawranek and Steinhardt [2]).

The total stresses in the upper deck were the sum of the stresses obtained from the analysis of the top flanges of the transversal beams, the longitudinal ribs and the main girders.

For the purpose of the detailed design, the bridge structure was modelled as a 3D frame and analyzed by the computer program STRUDL (Manuals of STRUDL-II [4]), based on the finite element method. 
The structure was designed in accordance with German Codes (DIN 1073 [5], DIN 1079 [6], DIN 4101 [7]) for all loads (DIN 1072 [8]) acting on the bridge during the assembly process and exploitation. Additionally, design checks were manually performed for some structural elements, taking into account several important characteristics (Bankov et al. [9]). The effect of the horizontal curvature on strains and internal forces was analyzed. The pure torsion and the restricted torsion of the thin-walled box steel girder were considered. The inclined "V"-shaped supports with variable cross-sections were analyzed according to the second order theory. The axial force, the shear force and the bending moments obtained from the analysis were taken into account in the design of the structure. It is assumed that the constitutive Prandtl's law holds for steel. The stability of the critical sections in all phases is ensured using DIN 4114 (DIN 4114 [10]) and Kloeppel design tables (Kloeppel [11]).

\section{USED MATERIALS, MANUFACTURE AND ERECTION OF THE BRIDGE}

The upper and the lower deck of the box structure, the transversal beams and the longitudinal ribs of the orthotropic plates, the webs and the stiffeners of the main girders, the "V"-shaped supports were made from high-strength steel 09G2BM ( $\left.\mathrm{f}_{\mathrm{y}}=330 \mathrm{MPa}\right)$, produced in Bulgaria. The footway structure, the structure between two carriageways, the safety borders and the parapets were made from steel V St3 $\left(\mathrm{f}_{\mathrm{y}}=210 \mathrm{MPa}\right)$. All components and joints of the bridge structures were welded (Figure 8). The construction work on the bridge was completed in a short period of time. The design process started on 05/10/1982 and finished on 30/03/1983. The delivery of steel for the structure began on $05 / 05 / 1983$. The erection and assembly of the bridge took only six months. The bridge was opened for traffic on October 4th, 1983.

\section{PAVEMENT AND WATERPROOFING}

The pavement consists of a $3 \mathrm{~mm}$ waterproofing, which is a polymer epoxy resin layer, one layer of medium grained mastic asphalt carpet made of modified $45 \mathrm{~mm}$ thick asphalt and a final layer of 45 mm thick asphalt. The effectiveness of the connection between the steel structure and the epoxy resin was guaranteed by sand blasting the steel deck. Surfaces needed to be sanded in order to remove rust and any other debris and impurities. An additional steel reinforcement ensured the composite action between the steel deck and the pavement (Figure 16)

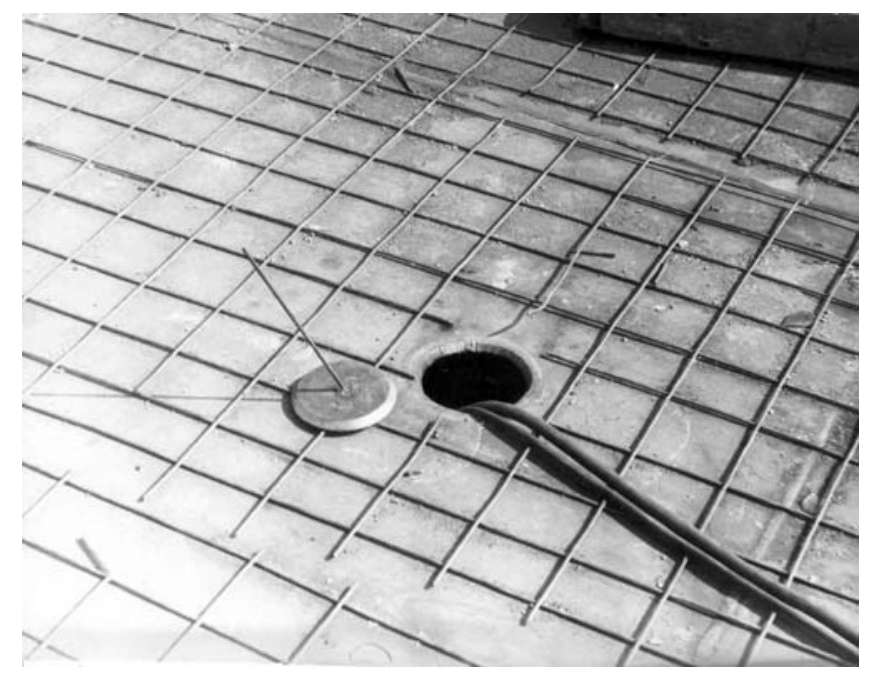

Figure 16. A Steel Reinforcement Welded to the Bridge Deck 


\section{NONDESTRUCTIVE TESTING OF MATERIALS AND WELDS}

The materials used for the structural elements were subject to non-destructive testing by means of an ultrasonic device before cutting the steel sheets. The predominant defect in structural steel is delamination of the sheet edges. $100 \%$ of the welds between the separate sections are tested "in situ” by X-rays.

\section{STRUCTURAL TESTING}

The static and dynamic tests were performed during the process of assembly of the bridge steel structure.

The testing load consisted of lorries loaded with military tanks, which provided $100 \%$ of the design load. The response of the structure was controlled by measuring deflection and strains in the middle of the span. The dynamic response of the bridge in longitudinal direction was measured by simulation of an impulse, caused by the motion of a particular vehicle along the bridge at various speeds.

The maximum value of deflection in the middle of span was $28 \mathrm{~mm}$. The series of measurements of the local strains (stresses) showed an acceptable uniform distribution of the stress field over the cross-section for both symmetrical and asymmetrical positions of the test load.

After unloading the structure it was established that the stress response and the deformation response of the bridge were elastic. The tests showed that the roadway orthotropic bridge in Sofia was able to bear traffic loading in compliance with design codes [4], [5].

\section{SUMMARY}

The steel orthotropic bridge over the railway Sofia-Varna is an example of an effective structural method for medium span bridges. It is applicable for spans of 20-60 m considering that the prefabricated steel components are transported by road. To achieve of design versatility with the use of steel as a building material, a visually attractive structure could also be created.

Since the region of Sofia is an active earthquake area, seismic codes had to be considered. However, the structure was proven to be ideal for earthquake regions. The superstructure with small mass, together with the inclined supports and columns formed a structure with excellent stiffness.

A high level of precision was required during the process of construction, since much of the work had to be carried out in advance under the factory conditions. The technical tests proved the high quality of the structure. This important and complex bridge has been operating successfully for more than 20 years (see Figures 17, 18). 


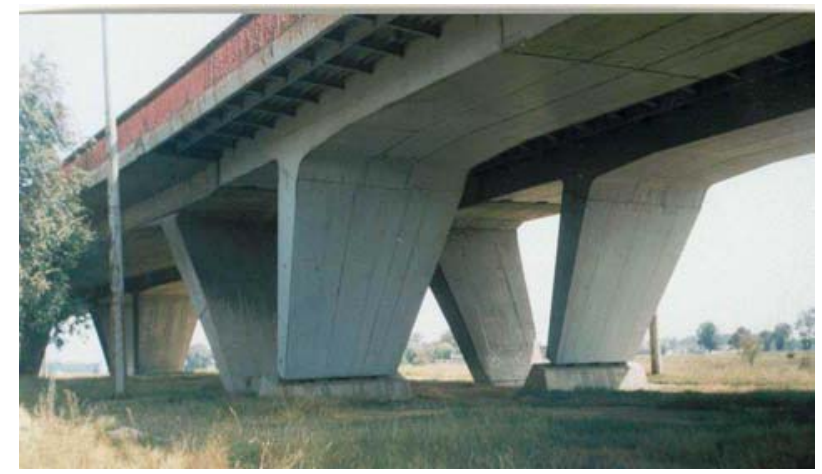

Figure 17. A View of the Steel and Concrete Parts of the Bridge

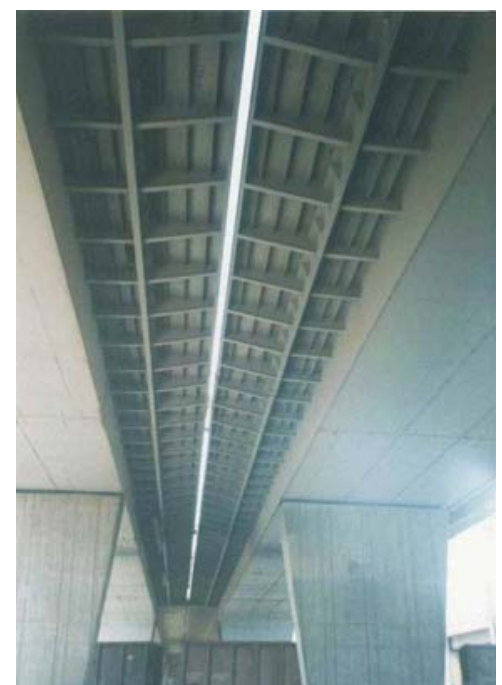

Figure 18. A View from Beneath the Orthotropic Bridge

\section{REFERENCES}

[1] Cornelius, W., "Die Berechnung der ebenen Flaechentragwerke mit Hilfe der Theorie der orthogonal-anisotropen Platte”, Der Stahlbau, 1952, Vol. 21, pp. 21-24; 43-48; 60-64.

[2] Hawranek, A. and Steinhardt, O., “Theorie und Berechnung der Stahlbruecken”, Berlin-Goettingen-Heidelberg, Springer Verlag, 1958.

[3] Pelikan, W. and Esslinger, M., "Die Stahlfahrbahn, Berechnung und Konstruktion", Ausburg-Nuernberg, MAN-Forschungsheft No 7, 1957.

[4] “Manuals of the Computer Program STRUDL-II”, Massachusetts Institute of Technology, Massachusetts, 1982.

[5] DIN 1073, "Staehlerne Strassenbruecken, (Berechnungsgrundlagen)”, 1973.

[6] DIN 1079, "Staehlerne Strassenbruecken, (Grundsaetze fuer Bauliche Dirchbildung)", 1979.

[7] DIN 4101, “Geschweisste staehlerne Strassenbruecken, (Berechnung, Bauliche Durchbildung und Ausfuerung)”, 1970.

[8] DIN 1072, "Strassen und Wegbruecken, (Lastannahmen)", 1967.

[9] Bankov, B., Partov, D., Hristov, H., Tsvetkov, V., Bankova, I., Hristov, V., Hadjinikolov, L. and Bankov, L., "Detailed Structural Design Project of the Orthotropic Bridge to the Airport in Sofia”, 1983, (in BG).

[10] DIN 4114, "Stabilitaetsfaelle”, 1961.

[11] Kloeppel, K., “Beulwerte ausgesteifer Rechteckplatten”, W. Ernst, I-1960, II-1968. 


\title{
DUCTILITY OF HIGH PERFORMANCE STEEL MOMENT CONNECTIONS
}

\author{
Ana M. Girão Coelho ${ }^{1,2, *}$ and Frans S. K. Bijlaard ${ }^{2}$ \\ ${ }^{1}$ Department of Civil Engineering, Polytechnic Institute of Coimbra \\ Rua Pedro Nunes, 3030-199 Coimbra, Portugal \\ ${ }^{2}$ Structural and Building Engineering, Faculty of Civil Engineering, Delft University of Technology \\ PO Box 5048, 2600 GA Delft, The Netherlands \\ *(Corresponding author: Phone: +351 239790312 / +351 964837 943; Fax: +351 239790 311; \\ E-mail:a.m.girao@clix.pt)
}

Received: 23 April 2007; Revised: 2 July 2007; Accepted: 23 July 2007

\begin{abstract}
Recent developments in high performance construction materials have made them attractive for the design of buildings, as light weight and thin elements are desirable for architectural reasons and for the reduction of environmental impacts of construction. Steel framework is a typical structural system in modern buildings. Current analysis and design of steel-framed buildings are usually carried out under the semi-continuous/partially-restrained philosophy. This type of structural modelling is only feasible if the structural joints are designed for rotation capacity and ductility. Members and joints made up of high performance steel exhibit improved strength but limited deformation capacity compared to mild steel grades. Connections between members, in particular, are the regions where the material is exposed to higher deformations demands. The designer then has to ensure that they undergo large inelastic deformations. To address this topic, an experimental investigation was undertaken on moment connections with end plates made from high strength steel grades S460, S690 and S960 (yield stress of $460 \mathrm{MPa}, 690$ $\mathrm{MPa}$ and $960 \mathrm{MPa}$, respectively) to provide insight into the nonlinear behaviour of this joint type. The major contributions of this study are (i) the validation of current Eurocode 3 specifications for the design of joints and (ii) the ductility analysis of high performance steel joints to verify whether they have large plastic deformations.
\end{abstract}

Keywords: Ductility; end plate connections; experimental testing; high-strength steel; resistance; rotation capacity; stiffness

\section{INTRODUCTION}

Steel framework is a typical structural system in modern building construction. In this type of construction, beam-column joints have to transfer the beam and floor loads to the columns. Generally, the forces transmitted through the joints can be axial and shear forces, bending and torsion moments. The bending deformations are predominant in most cases, when compared to axial and shear deformations that are hence neglected. The effect of torsion is also negligible in planar frames. Typical beam-column moment-resisting joints in steel-framed structures include bolted end plate connections, bolted connections with angle cleats and welded connections. The behaviour of these joints is intrinsically nonlinear. This nonlinearity arises because a joint is an assemblage of several components that interact differently at distinct levels of applied loads. The interaction between the elemental parts includes elastoplastic deformations, contact, slip and separation phenomena. The analysis of this complex behaviour is usually approximate in nature with drastic simplifications. Tests (both experimental and numerical) are frequently carried out to obtain the actual response, which is then modelled approximately by mathematical expressions that relate the main structural joint properties. In the case of moment-resisting joints, three properties are usually sufficient for characterization of their behaviour (Figure 1): (i) moment resistance, (ii) rotational stiffness and (iii) rotation capacity. Research work on this subject has been intensive over the past years [1-7]. Emphasis was mainly placed on full strength joints and, therefore, only the resistance and stiffness properties were fully characterized. Rules for prediction of strength and stiffness of this joint type were thus included in modern design codes as the European code of practice for the design of structural steel joints in buildings, part 1-8 of Eurocode 3 [8] (EN 1993-1-8), and the specification for structural steel buildings from the American Institute of Steel Construction [9]. 


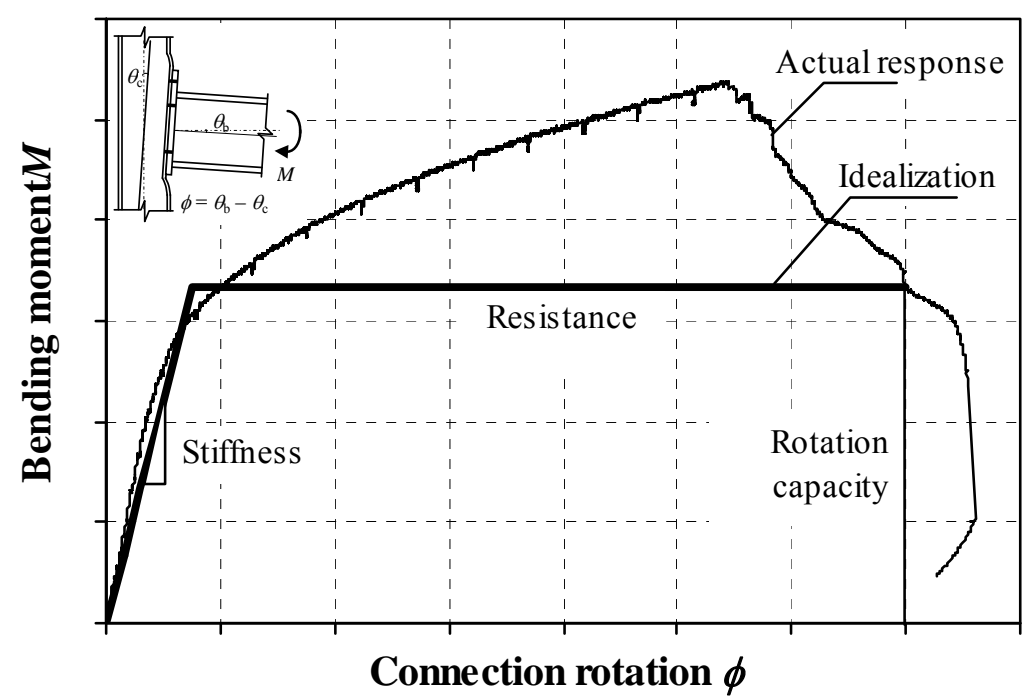

Figure 1. Moment-rotation Response of a Joint (Definitions)

Several authors have recently highlighted the importance of designing structural joints for rotation capacity and ductility [10-13]. The knowledge of the plastic deformation supply of members and joints is particularly important for steel frames that experience abnormal loading conditions, such as fire and seismic events. In these extreme events, very high demands for local and global deformation are imposed on structural elements, connections and details. Connections between members, in particular, are the regions where the material is exposed to higher deformations and, consequently, they influence local ductility requirements and framing performance. EN 1993-1-8 includes simple deemed-to-satisfy criteria to guarantee that the available deformation capacity is higher than the deformation demand of a specific joint. Derivation of such criteria can be found in References 14 and 15. In the context of the component method that considers a joint as an assembly of elemental parts (or components), some researchers have developed simplified approaches to quantify the overall rotation capacity of joints $[7,11,12,16,17]$.

Recent interest in high performance construction materials to produce innovative structures again draws attention to issues related to the deformation capacity of members and, specially, connections. High performance steels (HPS) in construction represent a family of steels with a yield stress above $460 \mathrm{MPa}$ and offer higher performance in tensile stress, toughness, weldability and corrosion compared to mild steel grades [18]. The mechanical characteristics of these steels are different from conventional steels. HPS are generally less ductile and have a smaller (i) yield plateau and (ii) yield stress-to-tensile stress ratio.

Traditionally, the design of structures fabricated from HPS is essentially based on an elastic concept as the service requirements usually govern the structural response. The limit states are then the attainment of the (i) yield stress or (ii) buckling stress at the critical locations. Structural strength and stiffness of members and connections can be derived relatively easily in this case. Designers have however recognized the need to account for inelastic effects directly in structural analysis. Advanced analysis that includes material plasticity, geometric nonlinearities and connection behaviour is then required. Part 1-12 of Eurocode 3 [19] (prEN 1993-1-12) presently forbids elastic-plastic global structural analysis with plastified sections and/or joints acting as plastic hinges. This standard states that the rules for semi-rigid joints are not applicable to HPS and that the resistance of joints should always be based on elastic distribution of forces over the components [19].

Whether or not HPS can be used for plastic design will depend on the outcome of intensive 
research. This motivated an experimental and numerical comprehensive investigation on "HPS in Civil Engineering Structures" that is being carried out at the Department of Structural and Building Engineering of the Delft University of Technology. The research work presented in this paper mainly focus on moment connections employing HPS. Experiments on statically loaded bolted end plate connections were undertaken to provide insight into the behaviour of this connection type. Since an end plate connection comprises several critical components, it was decided to focus this study on the single contribution of the assembly end plate-bolts in the tension zone. These components are modelled as equivalent T-stubs [2,4] (Figure 2). Previous work on similar connection details has shown that the deformation characteristics primarily depends on (i) the connection geometry, particularly the ratio between the end plate thickness $t_{\mathrm{ep}}$, and the bolt diameter $\phi_{b}$, (ii) the assurance of a good material ductility for plate and bolts, (iii) the ratio between the resistance of the plate and the bolt and (iv) the welding quality [7,12,14]. Test results were used to (i) validate current specifications for the design of joints in EN 1993-1-8, within the semi-continuous/partially-restrained concept, (ii) to examine the connection response from a strength and deformation point of view and (iii) to verify whether HPS moment connections develop sufficient rotation capacity for global plastic analysis.

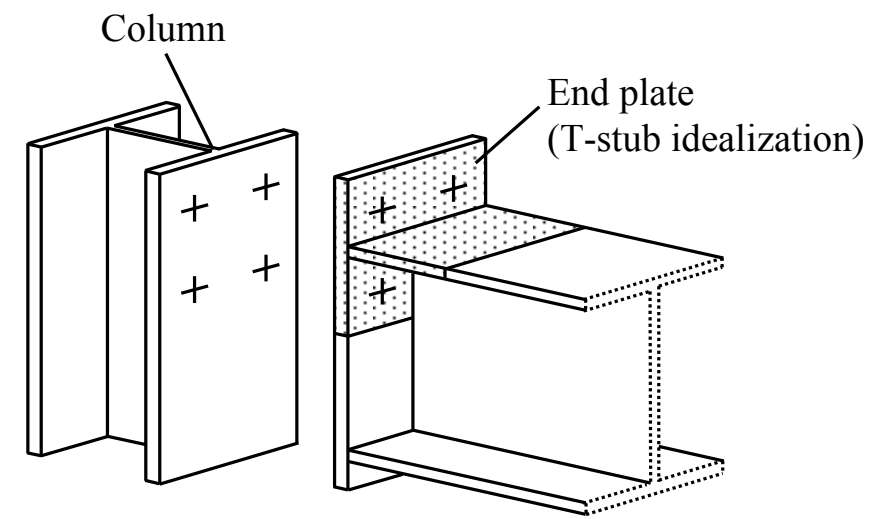

Figure 2. Extended End Plate Connection: T-stub Idealization

This paper specifically deals with the latter topic. A brief description of the experimental programme and results is given. Comparisons with code predictions are also drawn. The paper opens the way for the establishment of requirements for sufficient rotation capacity as well as ductility requirements to avoid brittle failures and concludes by outlining future research that is still required.

\section{EXPERIMENTAL PROGRAMME}

\section{$2.1 \quad$ Test Details}

The experimental programme consisted of seventeen beam-column bolted end plate connections. The specimens were designed to trigger failure in the assembly end plate-bolts in the tension zone without development of the full plastic moment capacity of the beam (partial-strength joint). Beam and column sections are of class 1 [20].

Extended end plate (EEP) and two different flush end plate configurations (F1EP and F2EP) were tested (Figure 3a). For the second flush end plate configuration (F2EP), a detail of the welding to the beam is also given in Figure 3b. A general review and description of the test programme is given elsewhere [21,22]. The relevant details of the test specimens are given in Figure 3c and Table 1. Bolts were hand-tightened to give a snug fit in all sets. 


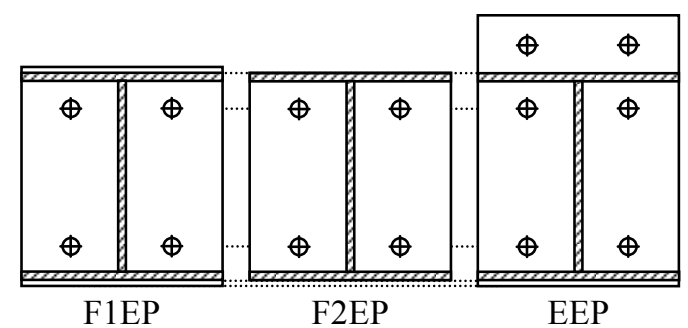

(a) Configurations

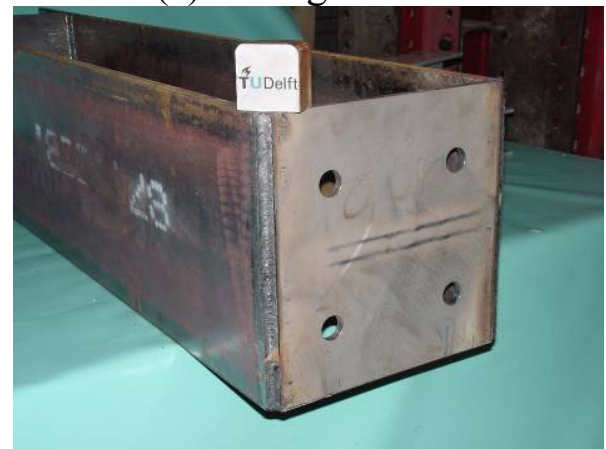

(b) Detail of the Welding of the End Plate to Beam Flange (Outside) for Flush Configuration 2

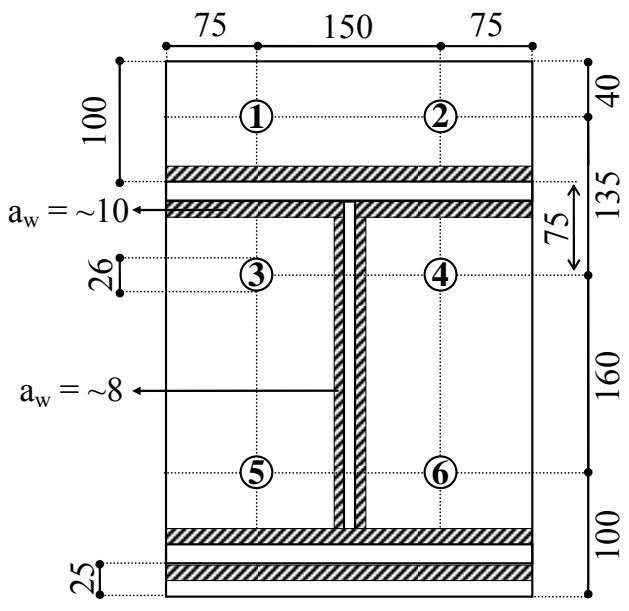

(c) End Plate Dimensions

Figure 3. End Plate Configurations and Dimensions

Table 1. Details of Test Specimens

\begin{tabular}{|c|c|c|c|c|c|c|c|c|c|c|c|c|}
\hline \multirow[t]{2}{*}{ Test ID } & \multicolumn{2}{|c|}{ Column } & \multicolumn{2}{|c|}{ Beam } & \multicolumn{5}{|c|}{ End plate } & \multicolumn{3}{|c|}{ Bolt } \\
\hline & Section & Grade & Section & Grade & $\begin{array}{c}t_{\mathrm{ep}} \\
(\mathrm{mm})\end{array}$ & Grade & $\begin{array}{c}f_{\text {y.ep }} \\
(\mathrm{MPa})\end{array}$ & $\rho_{\mathrm{y}}$ & $\varepsilon_{\mathrm{f}}$ & $\begin{array}{c}\phi_{b} \\
(\mathrm{~mm})\end{array}$ & Grade & $\begin{array}{c}f_{\text {u.b }} \\
(\mathrm{MPa})\end{array}$ \\
\hline F1EP_15_1 & HE300M & S355 & HE320A & S355 & 15.30 & $\mathrm{~S} 460$ & 483 & 0.84 & 0.175 & 24 & 12.9 & 1413 \\
\hline F2EP_15_1 & HE300M & S355 & HE320A & S355 & 15.30 & S460 & 483 & 0.84 & 0.175 & 24 & 12.9 & 1413 \\
\hline EEP $15 \overline{1}$ & HE300M & S355 & HE320A & S355 & 15.25 & $\mathrm{~S} 460$ & 483 & 0.84 & 0.175 & 24 & 8.8 & 940 \\
\hline F1EP $15 \quad 2$ & HE300M & S355 & HE320A & S355 & 14.75 & S690 & 774 & 0.95 & 0.186 & 24 & 12.9 & 1413 \\
\hline F2EP 152 & HE300M & S355 & HE320A & S355 & 14.64 & S690 & 774 & 0.95 & 0.186 & 24 & 12.9 & 1413 \\
\hline EEP $15 \_2$ & HE300M & S355 & HE320A & S355 & 14.62 & S690 & 774 & 0.95 & 0.186 & 24 & 12.9 & 1413 \\
\hline $\begin{array}{llll}\text { F1EP } & 10 & 2\end{array}$ & HE300M & S355 & HE320A & S355 & 10.15 & S690 & 698 & 0.93 & 0.175 & 24 & 12.9 & 1413 \\
\hline F2EP $10-2$ & HE300M & S355 & HE320A & S355 & 10.25 & S690 & 698 & 0.93 & 0.175 & 24 & 12.9 & 1413 \\
\hline EEP_10_- $\mathrm{a}$ & HE300M & S355 & HE320A & S355 & 10.10 & S690 & 698 & 0.93 & 0.175 & 24 & 12.9 & 1413 \\
\hline EEP_10_2b & HE300M & S355 & HE320A & S355 & 10.10 & S690 & 698 & 0.93 & 0.175 & 24 & 8.8 & 940 \\
\hline F1EP_10_3 & HE300M & S355 & HE320A & S355 & 10.00 & S960 & 952 & 0.91 & 0.154 & 24 & 12.9 & 1413 \\
\hline F2EP 103 & HE300M & S355 & HE320A & S355 & 10.00 & S960 & 952 & 0.91 & 0.154 & 24 & 12.9 & 1413 \\
\hline EEP $10 \overline{3}$ & HE300M & S355 & HE320A & S355 & 10.00 & S960 & 952 & 0.91 & 0.154 & 24 & 12.9 & 1413 \\
\hline F2EP_10_2(M27) & HE300M & S355 & HE320A & S355 & 10.05 & S690 & 698 & 0.93 & 0.175 & 27 & 8.8 & 1013 \\
\hline EEP_10_2(M27) & HE300M & S355 & HE320A & S355 & 10.10 & S690 & 698 & 0.93 & 0.175 & 27 & 8.8 & 1013 \\
\hline F2EP_10_3(M27) & HE300M & S355 & HE320A & S355 & 10.00 & S960 & 952 & 0.91 & 0.154 & 27 & 8.8 & 1013 \\
\hline EEP $\overline{10} \overline{3}$ (M27) & HE300M & S355 & HE320A & S355 & 10.03 & S960 & 952 & 0.91 & 0.154 & 27 & 8.8 & 1013 \\
\hline
\end{tabular}


The actual mechanical properties for the end plates and bolts are also given in Table $1\left(f_{\mathrm{y}}\right.$ : yield stress; $f_{\mathrm{u}}$ : tensile stress; $\rho_{\mathrm{y}}=f_{\mathrm{y}} / f_{\mathrm{u}}$ : yield ratio; $\varepsilon_{\mathrm{f}}$ : strain at rupture load). The constitutive law of the several classes of HPS is plotted in Figure 4.

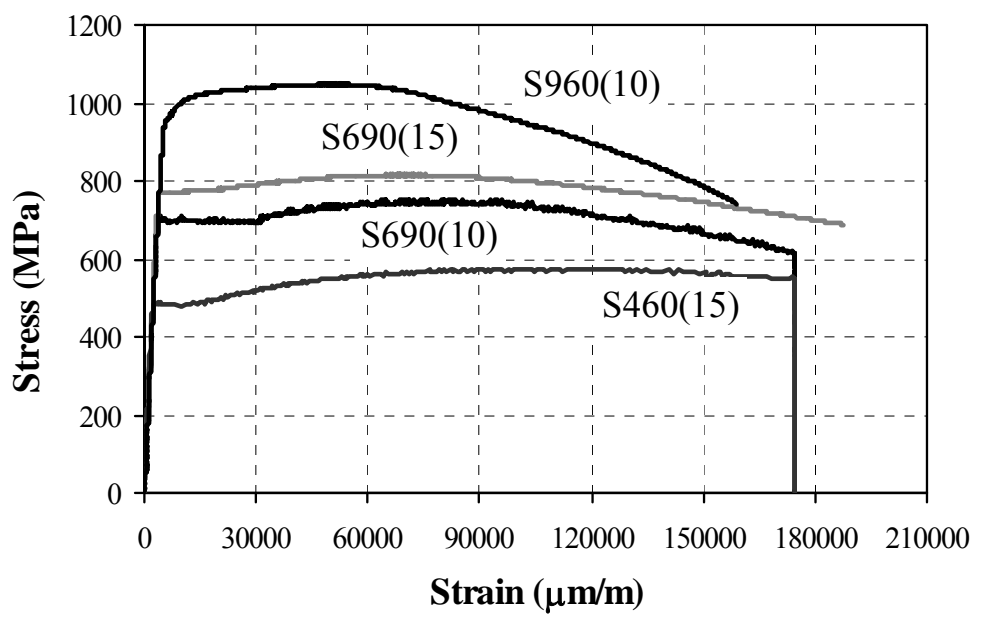

Figure 4. Stress-strain Behaviour of the End Plate Material

\section{$2.2 \quad$ Moment-rotation Curves and Failure Modes}

The behaviour of moment connections is typically represented by a moment-rotation curve that describes the relationship between the applied bending moment, $M$ and the corresponding rotation between the members, $\phi$. Figure 5 illustrates a typical moment-rotation response of the connections tested. This curve defines three main structural properties: (i) (plastic and ultimate) moment resistance, $M_{\mathrm{j} . \mathrm{R}}$ and $M_{\mathrm{j} . \mathrm{max}}$, (ii) (initial and post-yield) rotational stiffness, $S_{\mathrm{j} . \mathrm{ini}}$ and $S_{\mathrm{j} . \mathrm{p}-1}$ and (iii) rotation capacity, $\phi_{\mathrm{C}}$. The characteristics of these curves for the several test details are set out in Table 2. The failure modes of the specimens are also indicated in the table: (i) mode A: cracking of the end plate in the heat affected zone, (ii) mode B: bolt-thread stripping and (iii) mode C: bolts in tension. Illustration of these modes of failure is given in Figure 6.

The $M-\phi$ response for representative test specimens is given in Figure 7. Several conclusions can be drawn from the analysis of these graphs and the curves properties in Table 2:

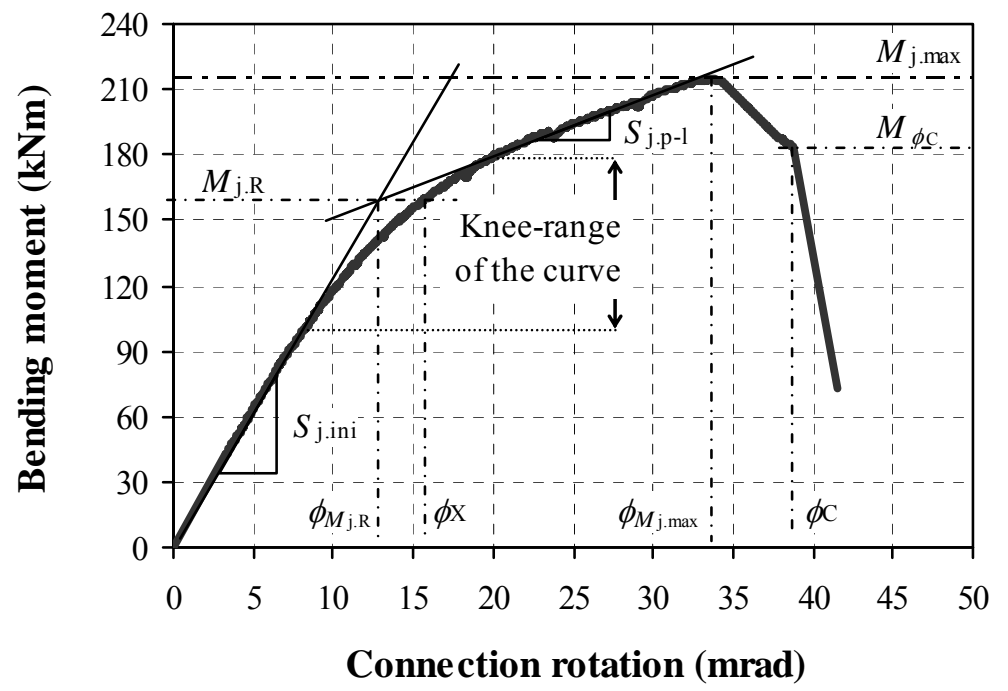

Figure 5. Typical Moment-rotation Response (e.g. F2EP_15_2) 
Table 2. Main (Experimental) Characteristics of the Moment-rotation Curves

\begin{tabular}{|c|c|c|c|c|c|c|c|}
\hline \multirow[t]{2}{*}{ Test ID } & \multicolumn{2}{|c|}{ Stiffness $(\mathrm{kNm} / \mathrm{mrad})$} & \multicolumn{2}{|c|}{ Resistance (kNm) } & \multicolumn{2}{|c|}{ Rotation capacity (mrad) } & \multirow[t]{2}{*}{ Failure mode } \\
\hline & $S_{\mathrm{j} . \mathrm{ini}}$ & $S_{\text {j.p-1 }}$ & $M_{\mathrm{j} . \mathrm{R}}$ & $M_{\mathrm{j} \text {.max }}$ & $\phi_{M_{j \max }}$ & $\phi_{\mathrm{C}}$ & \\
\hline F1EP_15_1 & 18.4 & 0.18 & 192 & 198 & 33 & 33 & Mode A \\
\hline F2EP_15_1 & 12.7 & 2.1 & 128 & 172 & 32 & 40 & Mode A \\
\hline EEP $15 \overline{1}$ & 30.0 & 3.3 & 270 & 326 & 28 & 28 & Mode B \\
\hline $\begin{array}{lll}\text { F1EP } & 15 & 2\end{array}$ & 14.1 & 2.6 & 175 & 231 & 34 & 37 & Mode $\mathrm{C}$ \\
\hline F2EP 152 & 12.3 & 2.6 & 160 & 215 & 33 & 39 & Mode C \\
\hline EEP $15 \overline{2}$ & 35.3 & 9.7 & 245 & 366 & 20 & 20 & Mode C \\
\hline $\begin{array}{llll}\text { F1EP } & 10 & 2\end{array}$ & 7.8 & 1.9 & 95 & 142 & 39 & 46 & Mode A \\
\hline $\mathrm{F} 2 \mathrm{EP}^{-} 10^{-} 2$ & 7.2 & 1.4 & 89 & 117 & 35 & 41 & Mode A \\
\hline EEP $\overline{1} 0 \overline{2} \mathrm{a}$ & 17.2 & 3.2 & 173 & 244 & 36 & 45 & Mode A \\
\hline EEP_10_2b & 19.9 & 5.4 & 188 & 252 & 37 & 46 & Mode A \\
\hline F1EP_10_3 & 9.3 & - & 171 & 201 & 46 & 46 & Mode C \\
\hline F2EP_10_3 & 8.0 & 0.8 & 155 & 176 & 52 & - & Mode C \\
\hline EEP $10 \overline{3}$ & 20.7 & 4.0 & 235 & 326 & 38 & 38 & Mode C \\
\hline F2EP_10_2(M27) & 7.2 & 1.3 & 98 & 130 & 38 & 38 & Mode A \\
\hline EEP 102 (M27) & 23.2 & 3.4 & 195 & 266 & 30 & 52 & Mode A \\
\hline F2EP_10_3(M27) & 10.9 & 1.9 & 123 & 173 & 42 & 67 & Modes A\&C \\
\hline EEP 10 3(M27) & 23.0 & 3.7 & 253 & 314 & 31 & 44 & Mode A \\
\hline
\end{tabular}
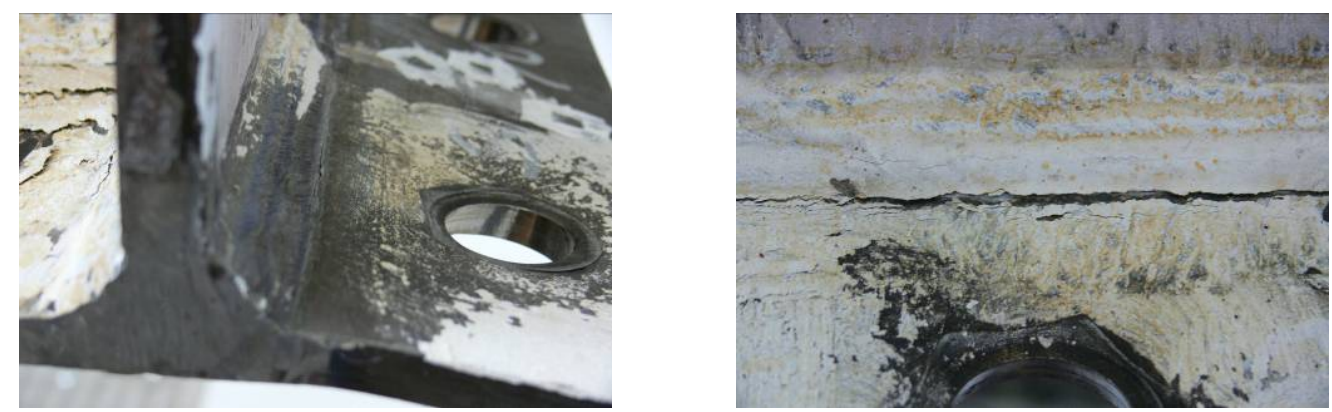

(a) Mode A: Cracking of the End Plate in the Heat Affected Zone (Specimen EEP_10_2(M27))
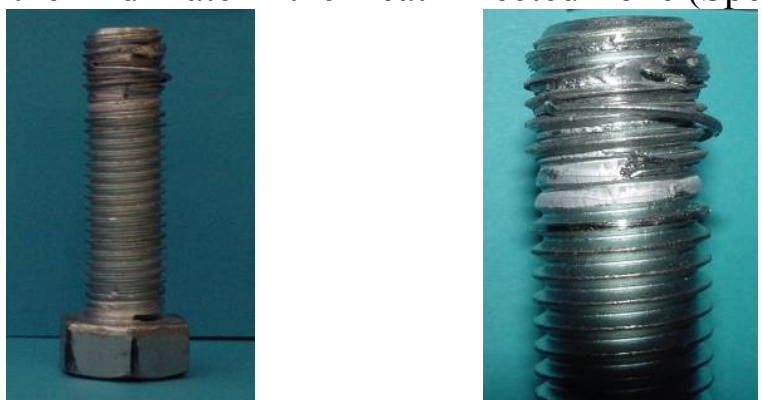

(b) Mode B: Bolt-thread Stripping (Specimen EEP 15_1, bolt \#3)

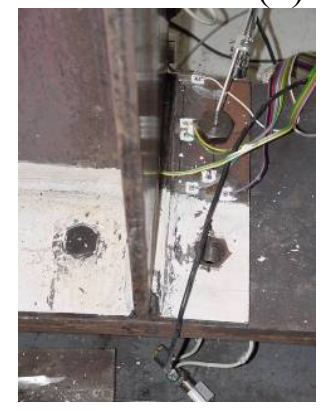

Specimen F1EP_15_2

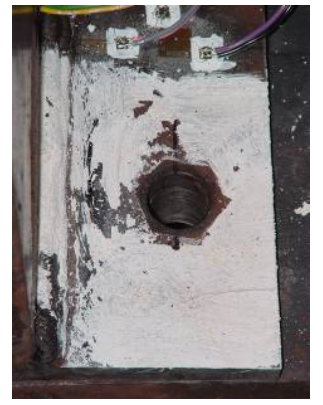

(c) Mode C: Bolts in Tension

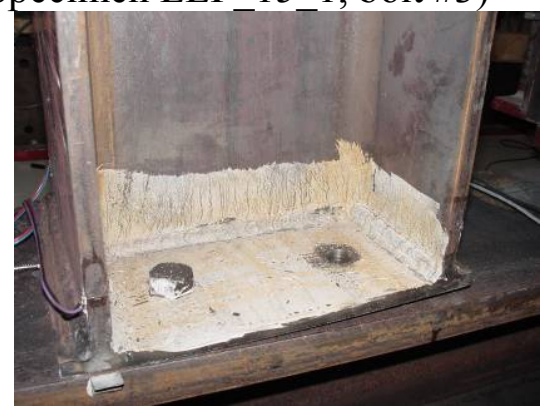

Specimen EEP_15_2 (general view and detail)

Figure 6. Illustration of the Failure Modes 

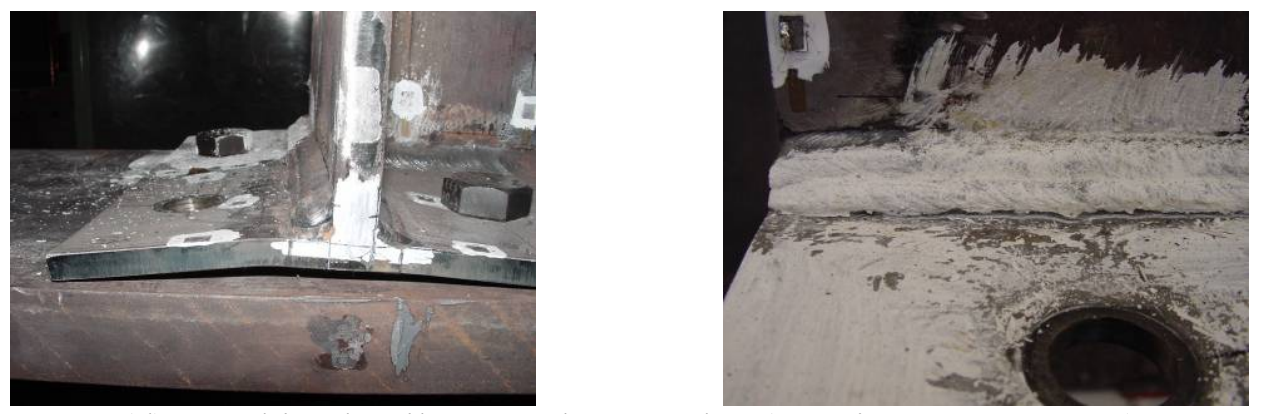

(d) Combined Failure Modes A and C (Specimen EEP_10_3)

Figure 6. Illustration of the Failure Modes (cont.)

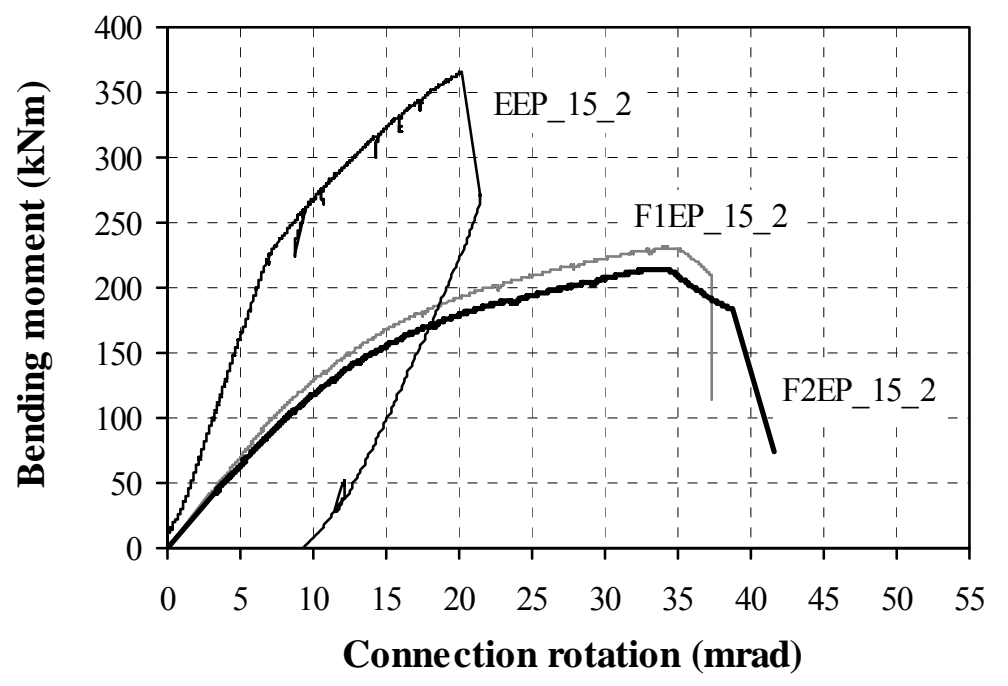

(a) $15 \mathrm{~mm}$ End Plates, S690

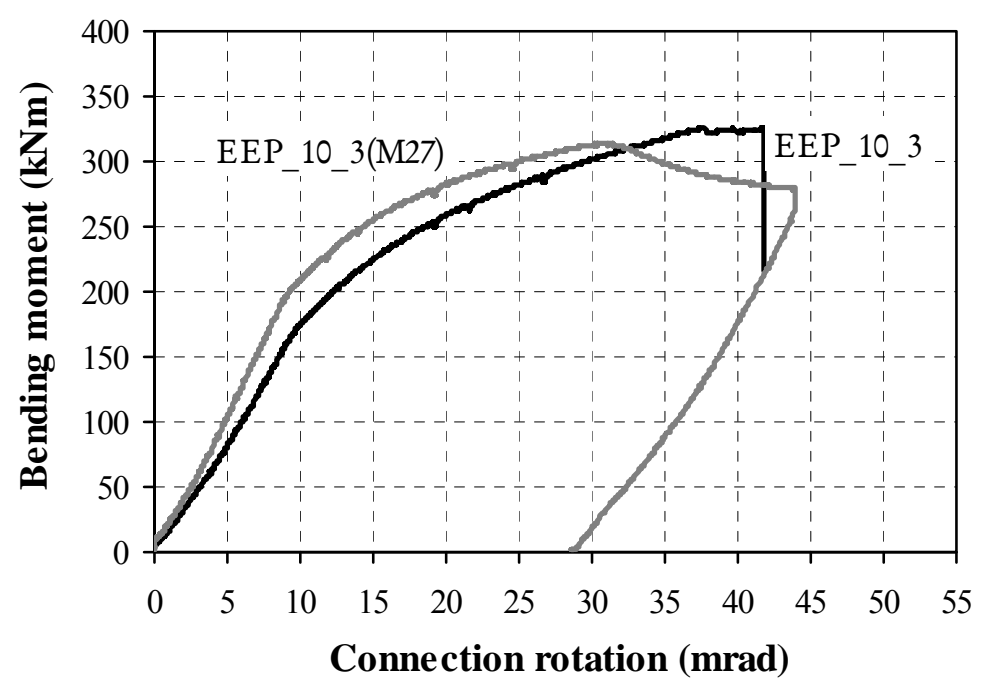

(b) $10 \mathrm{~mm}$ Extended End Plates, S960

Figure 7. Moment-rotation Curves for Specimens Employing S690 and S960

1. The rotational stiffness of the joints increases with the end plate thickness; because this property mainly depends on the Young modulus, there are no relevant variations with the plate steel grade.

2. The moment resistance enhances with the end plate thickness and the plate steel grade.

3. The rotation capacity decreases with the thickness of the plate; in general, it also decreases with the plate steel grade, though this variation is also linked to the governing failure mode. 
4. The behaviour of the two flush end plate configurations is identical over the entire elastoplastic range (Figure 7a).

5. The behaviour of extended end plate joints is much stiffer than "parent" flush end plate configurations; moment resistance is also larger but the deformation capacity is smaller (Figure 7a).

6. The joint performance, in terms of resistance and stiffness, with bolts M24 grade 12.9 and bolts M27 grade 8.8 is equivalent; however, from a ductility point of view, bolt grade 8.8 should be taken (Figure 7b). Bolts 12.9 exhibited very limited ductility and hardly any deformation in bending. In fact, in some cases (e.g. specimens with extended end plates) failure of the bolt occurred due to excessive rotation near the bolt head. Therefore, a strong recommendation against the use of this class of bolts is made.

The usual bolt diameter/end plate thickness combination for mild steel grades (e.g. bolts M24 in 15 $\mathrm{mm}$ plates) was checked for cases where HPS was present. Alternatively, the test programme included M27 8.8 bolts in $10 \mathrm{~mm}$ end plates, to check whether the overall ductility improved. In the latter case, very strong bolts were used in relatively thin end plates. The results however were rather disappointing since the rotation capacity did not increase as expected. The overall behaviour was dominated by cracking of the plate in the heat affected zone.

\section{VERIFICATION OF EUROCODE 3 PREDICTIONS ON TEST RESULTS}

The design of joints made up of HPS up to S700 is covered in prEN 1993-1-12, as mentioned above. This pre-norm does not allow the design of HPS joints within the semi-continuous/partially-restrained concept [19]. Experiments have however shown that yielding of the end plate also occurs with HPS S690 or S960. Still, the adoption of this type of structural modelling for global analysis is only adequate if the joint develops sufficient rotation capacity so that a ductile failure mechanism of the whole structure can be formed prior to fracture of the joint. Literature shows that end plate connections can achieve rotation capacity provided that the end plate is a "weak link" relative to the bolts $[12,14,23]$. The conclusions however were validated for mild steel grades. Current tests employ end plates and bolts with similar mechanical properties, in terms of yield stress and yield ratio. It has to be investigated whether this influences the above premises.

In this section, a comparison between test results and current EN 1993-1-8 design provisions is undertaken. The code gives quantitative rules for the prediction of the joint flexural plastic resistance and initial stiffness. These structural properties are evaluated below by using the actual geometrical and mechanical properties [21]. The recommendations on rotation capacity are also verified to investigate if there is enough rotation capacity according to EN 1993-1-8. The provisions are compared with the test results below. The partial safety factors were taken as unitary.

The initial stiffness is evaluated in the framework of the component method. The method is illustrated in Figure 8 for the case of bolted extended end plate connections (with two bolt rows in tension). For the computation of the joint rotational stiffness, the active joint components for this configuration, according to EN 1993-1-8 are: column web in shear (cws), column web in compression (cwc), column web in tension (cwt), column flange in bending (cfb), end plate in bending (epb), and bolts in tension (bt). The welds connecting the end plate and the beam are not taken into account for computation of the rotational stiffness, as well as components beam web and flange in compression (bfc) and beam web in tension (bwt). The basic joint components are modelled by means of extensional springs characterized by an elastic stiffness $k_{\mathrm{e}}$. These components are grouped according to their type of loading (tension, compression or shear) and are 
then assembled into a mechanical model in order to evaluate the $M-\phi$ response of the whole joint. Mechanical (component) models use a set of rigid and flexible parts (springs) to simulate the interaction between the various sources of joint deformation. The springs are combined in series or in parallel depending on the way they interplay with each other. Springs in series are subjected to the same force whilst parallel springs undergo the same deformation.

The following expression can be readily derived from the code [8]:

$S_{\mathrm{j} . \mathrm{ini}}=\frac{z^{2}}{1 / k_{\mathrm{ec}}+1 / k_{\mathrm{et}}}$

whereby $z$ : lever arm; $k_{\text {ec }}$ and $k_{\text {et: }}$ stiffness of the assembly of components in the compression/shear zone and in the tension zone, respectively (Figure 8).
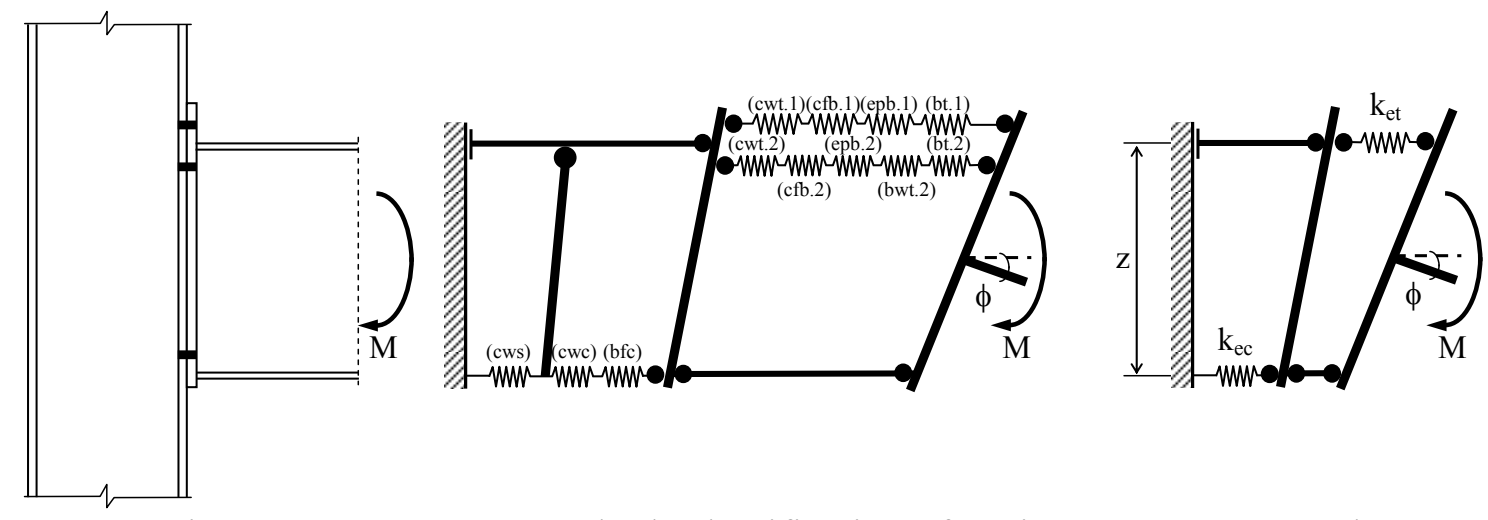

Figure 8. Component Method: Identification of Active Components and Mechanical Model Adopted in EN 1993-1-8

End plate moment connections transmit moment by coupling tension force(s) in the bolts with compression at the opposite flange. The joint design flexural resistance, $M_{\mathrm{j} . \mathrm{R}}$, in the absence of an axial force, is then calculated from simple equilibrium considerations:

$M_{\mathrm{j} . \mathrm{Rd}}=\sum_{i=1}^{n} F_{\mathrm{ti} . \mathrm{Rd}} h_{i}$

where $F_{\text {ti.R }}$ : resistance of bolt row $i$ in the tension zone [8] and $h_{i}$ : distance of the $i$-th bolt row from the centre of compression (subscript "d" indicates "design value").

Table 3 compares the code predictions with the experiments (subscripts "EC3" and "exp", respectively). The code overestimates structural stiffness properties. This is in line with experimental evidence from connections made up of mild steels [12]. The predictions for resistance compare well with test results.

The code recommendations on rotation capacity are also verified (Table 3). EN 1993-1-8 simply gives some guidelines on the subject: a bolted end plate joint may be assumed to have sufficient rotation capacity for global plastic analysis, provided that both of the following criteria are satisfied: (i) the moment resistance of the joint is governed by the resistance of either the column flange or the end plate in bending and (ii) the maximum (subscript "max") thickness $t$ of either the column flange or end plate - not necessarily the same component as (i) - fulfils:

$t_{\max }=0.36 \phi_{\mathrm{b}} \sqrt{f_{\mathrm{u} . \mathrm{b}} / f_{\mathrm{y}}}$ 
where $\phi_{\mathrm{b}}$ : bolt diameter; $f_{\mathrm{u} . \mathrm{b}}$ : tensile strength of the bolt and $f_{\mathrm{y}}$ : yield stress of the relevant basic component. These guidelines are yet insufficient to ensure adequate ductility in partial-strength joints.

Table 3. EN 1993-1-8 Predictions of the Structural Properties of the Joints Tested and Ratio to the Experiments

\begin{tabular}{lrrrrrrrl}
\hline \multicolumn{1}{c}{ Test ID } & \multicolumn{2}{c}{ Stiffness $(\mathrm{kNm} / \mathrm{mrad})$} & \multicolumn{3}{c}{ Resistance $(\mathrm{kNm})$} & \multicolumn{2}{c}{ Rotation capacity } \\
& $S_{\text {j.ini.EC3 }}$ & $S_{\text {j.ini.exp }}$ & Ratio & $M_{\mathrm{j} \text {.R.EC3 }}$ & $M_{\mathrm{j} \text {.R.exp }}$ & Ratio & $t_{\text {ep.max }}$ & Eq. $(3)$ verifies? \\
& & & & & & & $(\mathrm{mm})$ & \\
\hline F1EP_15_1 & 23.3 & 18.4 & 1.27 & 149 & 192 & 0.78 & 14.78 & No. $\left(t_{\mathrm{ep}}=15.30 \mathrm{~mm}\right)$ \\
F2EP_15_1 & 23.9 & 12.7 & 1.88 & 152 & 128 & 1.19 & 14.78 & No. $\left(t_{\mathrm{ep}}=15.30 \mathrm{~mm}\right)$ \\
EEP_15_1 & 58.7 & 30.0 & 1.96 & 244 & 270 & 0.90 & 12.05 & No. $\left(t_{\mathrm{ep}}=15.25 \mathrm{~mm}\right)$ \\
\hline F1EP_15_2 & 22.6 & 14.1 & 1.60 & 167 & 175 & 0.95 & 11.67 & No. $\left(t_{\mathrm{ep}}=14.75 \mathrm{~mm}\right)$ \\
F2EP_15_2 & 21.5 & 12.3 & 1.75 & 164 & 160 & 1.03 & 11.67 & No. $\left(t_{\mathrm{ep}}=14.64 \mathrm{~mm}\right)$ \\
EEP_15_2 & 58.0 & 35.3 & 1.64 & 369 & 245 & 1.51 & 11.67 & No. $\left(t_{\mathrm{ep}}=14.62 \mathrm{~mm}\right)$ \\
\hline F1EP_10_2 & 12.4 & 7.8 & 1.59 & 104 & 95 & 1.09 & 12.29 & Yes. $\left(t_{\mathrm{ep}}=10.15 \mathrm{~mm}\right)$ \\
F2EP_10_2 & 12.4 & 7.2 & 1.72 & 104 & 89 & 117 & 12.29 & Yes. $\left(t_{\mathrm{ep}}=10.25 \mathrm{~mm}\right)$ \\
EEP_10_2a & 31.9 & 17.2 & 1.85 & 184 & 173 & 1.06 & 12.29 & Yes. $\left(t_{\mathrm{ep}}=10.10 \mathrm{~mm}\right)$ \\
EEP_10_2b & 34.3 & 19.9 & 1.72 & 184 & 188 & 0.98 & 10.03 & No. $\left(t_{\mathrm{ep}}=10.10 \mathrm{~mm}\right)$ \\
\hline F1EP_10_3 & 11.8 & 9.3 & 1.27 & 138 & 171 & 0.81 & 10.53 & Yes. $\left(t_{\mathrm{ep}}=10.00 \mathrm{~mm}\right)$ \\
F2EP_10_3 & 12.3 & 8.0 & 1.54 & 140 & 155 & 0.90 & 10.53 & Yes. $\left(t_{\mathrm{ep}}=10.00 \mathrm{~mm}\right)$ \\
EEP_10_3 & 31.9 & 20.7 & 1.54 & 247 & 235 & 1.05 & 10.53 & Yes. $\left(t_{\mathrm{ep}}=10.00 \mathrm{~mm}\right)$ \\
\hline F2EP_10_2(M27) & 12.1 & 7.2 & 1.68 & 101 & 98 & 1.03 & 11.71 & Yes. $\left(t_{\mathrm{ep}}=10.05 \mathrm{~mm}\right)$ \\
EEP_10_2(M27) & 32.8 & 23.2 & 1.41 & 184 & 195 & 0.94 & 11.71 & Yes. $\left(t_{\mathrm{ep}}=10.10 \mathrm{~mm}\right)$ \\
\hline F2EP_10_3(M27) & 12.1 & 10.9 & 1.11 & 137 & 123 & 1.11 & 10.03 & Yes. $\left(t_{\mathrm{ep}}=10.00 \mathrm{~mm}\right)$ \\
EEP_10_3(M27) & 32.8 & 23.0 & 1.43 & 247 & 253 & 0.98 & 10.03 & Yes. $\left(t_{\mathrm{ep}}=10.03 \mathrm{~mm}\right)$ \\
\hline
\end{tabular}

\section{CONSIDERATIONS ON THE JOINT DUCTILITY}

Analysis and design of steel frameworks are usually carried out under the semi-continuous/partially-restrained philosophy. The consistency of this type of structural modelling requires the establishment of accurate criteria regarding (i) the rotation capacity and (ii) the ductility of the joints. The rotation capacity is the angle through which the joint can rotate for a given resistance level without failing [8]. The ductility properties of a joint reflect the length of the yield plateau of the moment-rotation response. Both criteria should be based on the mechanical and geometrical characteristics of the joint components.

To meet the criterion for rotation capacity, the available joint rotation must be higher than the required joint rotation. For mild steel grades, it is generally accepted that a minimum of 35-40 mrad ensures "sufficient rotation capacity" of a bolted joint in a partial-strength scenario. Wilkinson et al. suggest that a moment connection in steel moment resisting frames in a seismic area must develop a minimum plastic rotation, $\phi_{\mathrm{p}}$, of $30 \mathrm{mrad}$ [24]. The validation of this criterion for HPS however requires further investigation. Table 4 computes the experimental values of joint plastic rotation, which corresponds to the difference between the ultimate joint rotation, $\phi_{\mathrm{C}}$, and the first yielding rotation, $\phi_{\mathrm{y}}[7]$ :

$\phi_{\mathrm{y}}=\frac{2 / 3 M_{\mathrm{j} . \mathrm{R}}}{S_{\mathrm{j} . \mathrm{nin}}}$

Previous experimental results from tests carried out by the authors [12,26,27] are also included in this table. Tests FS1 and FS4 correspond to a bolted end plate connection between a beam IPE300, 
steel grade S355, and a rigid column. The test configuration is similar to the extended end plate specimens reported herein. The end plates had a $10 \mathrm{~mm}$ thickness and employed steel S355 in test FS1 and S690 in test FS4.

In general, thinner end plates meet the above criterion.

The requirements for ductility ensure that brittle failures are avoided, i.e. the inelastic deformations are sufficiently large. The joint ductility strongly depends on the material performance (for plates and bolts). Nowadays, the quality of HPS meets similar standards to mild steel grades. Uniaxial tension tests on HPS coupons have shown that these steels can achieve elongations at fracture up to $20 \%$, which is considered excellent $[18,25]$. However, the assurance of a good material ductility does not necessarily imply that the whole structure will behave ductile. The behaviour of steel is strongly dependent on the load history and the presence of residual strains due to prior occurrence of large deformations.

The ductility can be quantified by means of the joint ductility index $\vartheta_{\mathrm{j}}$ that relates the rotation capacity of the joint, $\phi_{\mathrm{C}}$ to the rotation value corresponding to the joint plastic resistance, $\phi_{M \mathrm{j} . \mathrm{R}}$ $[12,26]$ :

$\vartheta_{\mathrm{j}}=\frac{\phi_{\mathrm{C}}}{\phi_{M_{\mathrm{j} . \mathrm{R}}}}$

Table 4 evaluates the joint ductility index $\vartheta_{\mathrm{j}}$ for the several specimens. Experimentally, the rotation capacity was defined at the rotation level for which failure of one or more components occurred.

Table 4 also includes the rotation values at maximum load and the corresponding ductility levels, $\vartheta_{\text {j.max load: }}$

$\vartheta_{\mathrm{j} . \text { max load }}=\frac{\phi_{M_{\mathrm{j} \text { max }}}}{\phi_{M_{\mathrm{j}, \mathrm{R}}}}$

Some conclusions can be drawn from the analysis of the values in Table 4:

1. Within the same test series, the ductility indexes are similar for both flush end plate configurations; this means that the welding detail did not play an important role in the joint behaviour.

2. The extended end plate configuration yields higher ductility indexes but lower rotation capacity, except for specimens with $15 \mathrm{~mm}$ end plates.

3. Bolts 8.8 ensure a more ductile behaviour when compared to bolts 12.9 (see results for specimens EEP_10_2a and EEP_10_2b.

In order to investigate the influence of HPS grades in the deformation demand of a joint when inserted into a braced frame, a simple beam model is analysed (Figure 9a). Beam length, $L_{\mathrm{b}}$, is taken as $20 h_{\mathrm{b}}$ and $50 h_{\mathrm{b}}\left(h_{\mathrm{b}}\right.$ : beam section height). Rotational springs at the beam ends simulate the connection to the column. The beam is subjected to a uniformly distributed load, $q$. With partial-strength joints, the beam flange remains elastic and the first plastic hinges are formed in the joints. The third plastic hinge is formed in the mid-span, provided that the joint delivers enough rotation. 
Table 4. Experimental Evaluation of the Joint Ductility Indices $\vartheta_{\mathrm{j} \text {.max load }}$ and $\vartheta_{\mathrm{j}}$ and the Plastic Rotation Supply $\phi_{\text {p.u }}$

\begin{tabular}{|c|c|c|c|c|c|c|c|}
\hline Test ID & $\begin{array}{c}\phi_{y \cdot \exp } \\
(\mathrm{mrad})\end{array}$ & $\begin{array}{l}\phi_{M j . R . e x p} \\
(\mathrm{mrad})\end{array}$ & $\begin{array}{l}\phi_{\mathrm{Mj} . \max } \\
(\mathrm{mrad})\end{array}$ & $\begin{array}{c}\phi_{\text {C.exp }} \\
(\mathrm{mrad})\end{array}$ & $\begin{array}{c}\phi_{\text {p.u.exp }} \\
(\mathrm{mrad})\end{array}$ & $\vartheta_{j . \max \text { load }}$ & $\vartheta_{j}$ \\
\hline F1EP_15_1 & 7 & 12 & 33 & 33 & 26 & 2.75 & 2.75 \\
\hline F2EP 15 & 7 & 10 & 32 & 40 & 33 & 3.20 & 4.00 \\
\hline EEP $15 \overline{1}$ & 6 & 9 & 28 & 28 & 22 & 3.11 & 3.11 \\
\hline F1EP $15 \quad 2$ & 8 & 12 & 34 & 37 & 29 & 2.83 & 3.08 \\
\hline F2EP 152 & 9 & 13 & 33 & 39 & 30 & 2.54 & 3.00 \\
\hline EEP_15_2 & 5 & 7 & 20 & 20 & 15 & 2.86 & 2.86 \\
\hline F1EP_10_2 & 8 & 12 & 39 & 46 & 38 & 3.25 & 3.83 \\
\hline F2EP 102 & 8 & 12 & 35 & 41 & 33 & 2.92 & 3.42 \\
\hline EEP $10 \_\overline{2} \mathrm{a}$ & 7 & 10 & 36 & 45 & 38 & 3.60 & 4.50 \\
\hline $\mathrm{EEP} 10 \_2 \mathrm{~b}$ & 6 & 9 & 37 & 46 & 40 & 4.11 & 5.11 \\
\hline F1EP 103 & 12 & * & 46 & 46 & 34 & - & - \\
\hline F2EP_10_3 & 13 & * & 52 & - & - & - & - \\
\hline EEP_10_3 & 8 & 11 & 38 & 38 & 30 & 3.45 & 3.45 \\
\hline F2EP_10_2(M27) & 9 & 14 & 38 & 38 & 29 & 2.71 & 2.71 \\
\hline EEP $10 \_2(\mathrm{M} 27)$ & 6 & 9 & 30 & 52 & 46 & 3.33 & 5.78 \\
\hline F2EP 10 3(M27) & 8 & 14 & 42 & 67 & 59 & 3.00 & 4.79 \\
\hline EEP_10_3(M27) & 7 & 12 & 31 & 44 & 37 & 2.58 & 3.67 \\
\hline FS1 & 5 & 7 & 77 & 111 & 106 & 11.9 & 17.1 \\
\hline FS4 & 7 & 10 & 44 & 64 & 57 & 4.6 & 6.8 \\
\hline
\end{tabular}

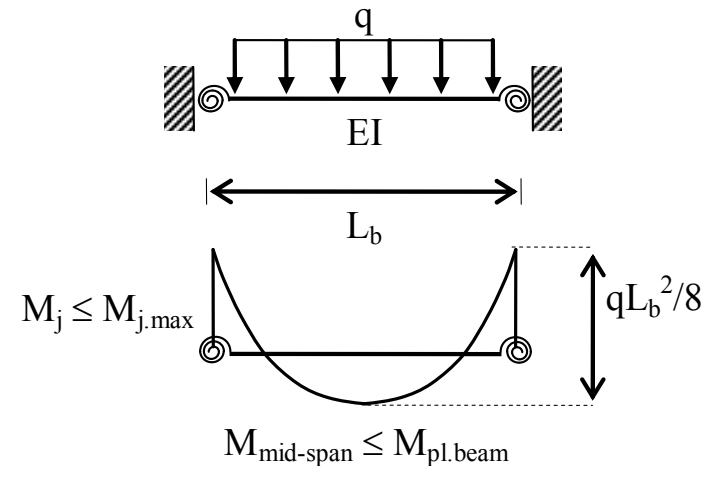

(a) Beam: Parameters

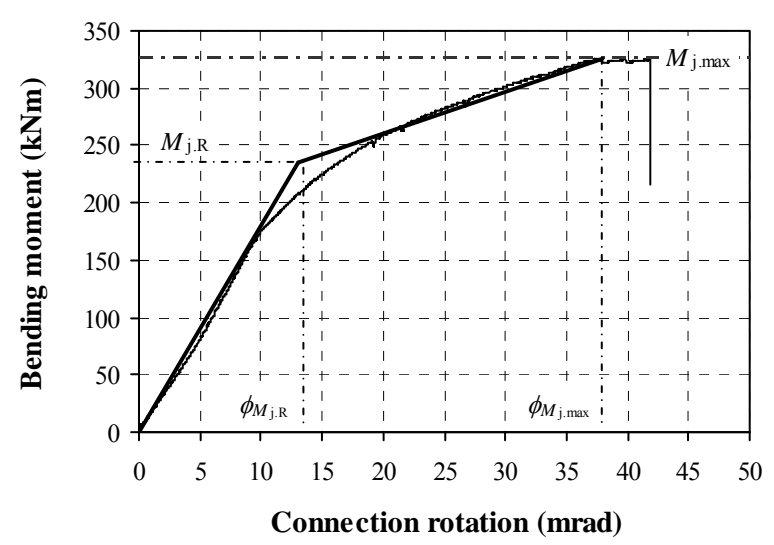

(i) e.g. EEP_10_3

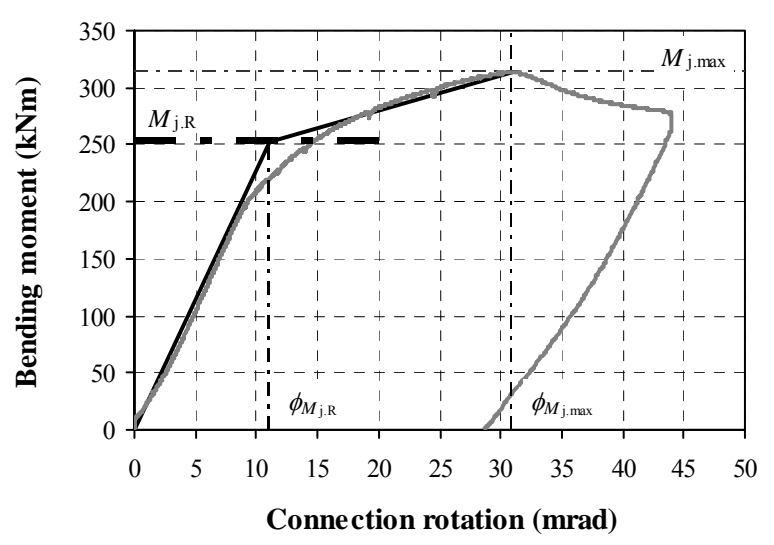

(ii) e.g. EEP_10_3(M27)

(b) Moment-rotation Characteristics of the Joints: Actual Behaviour and Bilinear Approximation Figure 9. Beam Model 
The actual profiles from the tested specimens are adopted in the analysis. For good comparison of results, a modification to the actual beam mechanical behaviour is introduced. All the above connections use a beam of grade S355. An actual frame however would employ beams and end plates of similar steel grade, i.e. end plates S690 and beams S690, for instance. In this analysis, the steel grade of the beam and the end plate is identical. This solution was not adopted in the tests because rolled profiles of steel grades S690 and S960 are hardly economically available for research purposes. For this beam-end plate steel grades combination, the degree of partial-strength reduces considerably.

The actual behaviour of the various joints is approximated by a simplified bilinear relationship (Figures 5 and 9b). Joints F2EP_15_1, F2EP_15_2, EEP_10_2a, EEP_10_3, EEP_10_2(M27), EEP_10_3(M27), FS1 and FS4 are used for further comparisons.

The results of this analysis are set out in Tables 5-6 and plotted in the graphs from Figures $10\left(L_{\mathrm{b}}=\right.$ $50 h_{\mathrm{b}}$ in all graphs) and 11 , in terms of connection rotation vs. ratio $\varsigma=q L_{\mathrm{b}}{ }^{2} / M_{\text {pl.beam. }}$. Figure 11 , in particular, shows that the beam span length mainly influences the results in the post-yield behaviour domain of the joints. Load $q$ is incremented from zero until (i) a plastic hinge is formed in the mid-span $\left(M_{\text {mid-sp }}=M_{\text {pl.beam }}\right)$ or (ii) the maximum rotation of the joints is reached. In all cases, the second condition governs (Tables 5 and 6, sixth column). For each test, the plastic moment of the beam section is computed as follows:

$M_{\text {pl.beam }}=W_{\text {pl.b }} f_{\text {y.ep.nom }}$

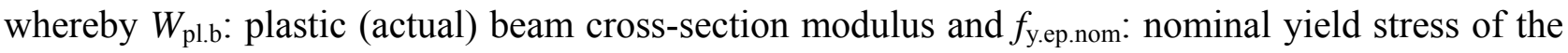
corresponding end plate (Table 7, second and third columns).

Table 5: Results from the Beam Analysis for $L_{\mathrm{b}}=20 h_{\mathrm{b}}$

\begin{tabular}{|c|c|c|c|c|c|}
\hline \multirow[t]{2}{*}{ Test ID } & \multirow{2}{*}{$\begin{array}{l}\phi(\mathrm{mrad}) \\
(\varsigma=2.5)\end{array}$} & \multirow{2}{*}{$\begin{array}{c}\varsigma \\
(\phi=30 \mathrm{mrad})\end{array}$} & \multicolumn{3}{|c|}{ Failure conditions $\left(\phi=\phi_{M_{\mathrm{j} \text { max }}}\right)$} \\
\hline & & & $q_{\mathrm{u}}(\mathrm{kN} / \mathrm{m})$ & $M_{\mathrm{j}} / M_{\text {pl.beam }}$ & $M_{\text {mid-sp }} / M_{\text {pl.beam }}$ \\
\hline F2EP_15_1 & 8.9 & 4.9 & 98.0 & 0.23 & 0.41 \\
\hline F2EP 152 & 14.7 & 3.7 & 113.0 & 0.19 & 0.30 \\
\hline EEP_10_2a & 11.9 & 3.9 & 126.0 & 0.22 & 0.33 \\
\hline $\mathrm{EEP}_{-}^{-} 10 \_3$ & 15.9 & 3.4 & 154.0 & 0.21 & 0.28 \\
\hline EEP_10_2(M27) & 8.8 & 4.3 & 124.0 & 0.24 & 0.31 \\
\hline EEP_10_3(M27) & 14.1 & 3.5 & 140.0 & 0.20 & 0.24 \\
\hline FS1 & 2.9 & 7.5 & 65.0 & 0.72 & 0.59 \\
\hline FS4 & 5.4 & 5.3 & 69.0 & 0.44 & 0.28 \\
\hline
\end{tabular}

Table 6: Results from the Beam Analysis for $L_{\mathrm{b}}=50 h_{\mathrm{b}}$

\begin{tabular}{lrrrrr}
\hline \multicolumn{1}{c}{ Test ID } & $\phi(\mathrm{mrad})$ & \multicolumn{1}{c}{$\varsigma$} & \multicolumn{3}{c}{ Failure conditions $\left(\phi=\phi_{M_{\mathrm{j} \text { max }}}\right)$} \\
& $(\varsigma=2.5)$ & $(\phi=30 \mathrm{mrad})$ & $q_{\mathrm{u}}(\mathrm{kN} / \mathrm{m})$ & $M_{\mathrm{j}} / M_{\text {pl.beam }}$ & $M_{\text {mid-sp }} / M_{\text {pl.beam }}$ \\
\hline F2EP_15_1 & 12.3 & 3.6 & 11.3 & 0.23 & 0.23 \\
F2EP_15_2 & 23.7 & 2.8 & 13.5 & 0.19 & 0.18 \\
\hline EEP_10_2a & 19.6 & 3.1 & 15.3 & 0.22 & 0.20 \\
EEP_10_3 & 24.3 & 2.7 & 19.5 & 0.21 & 0.17 \\
EEP_10_2(M27) & 13.2 & 3.4 & 15.8 & 0.24 & 0.19 \\
EEP_10_3(M27) & 21.9 & 2.8 & 18.1 & 0.20 & 0.15 \\
\hline FS1 & 2.9 & 7.1 & 9.2 & 0.72 & 0.45 \\
FS4 & 5.4 & 5.1 & 10.5 & 0.44 & 0.25 \\
\hline
\end{tabular}




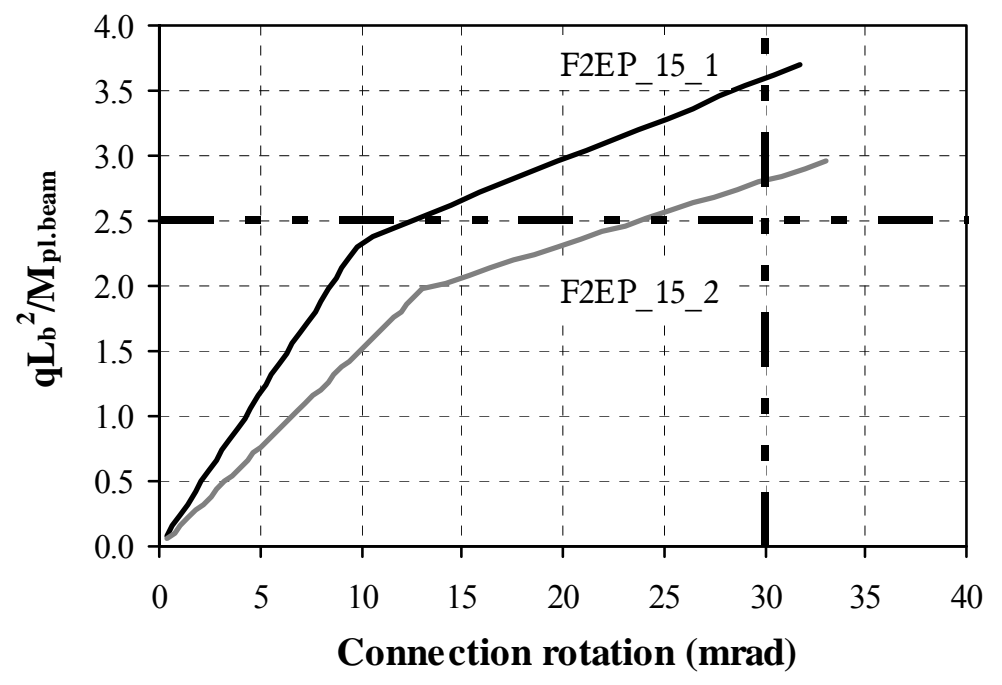

(a) Specimens F2EP

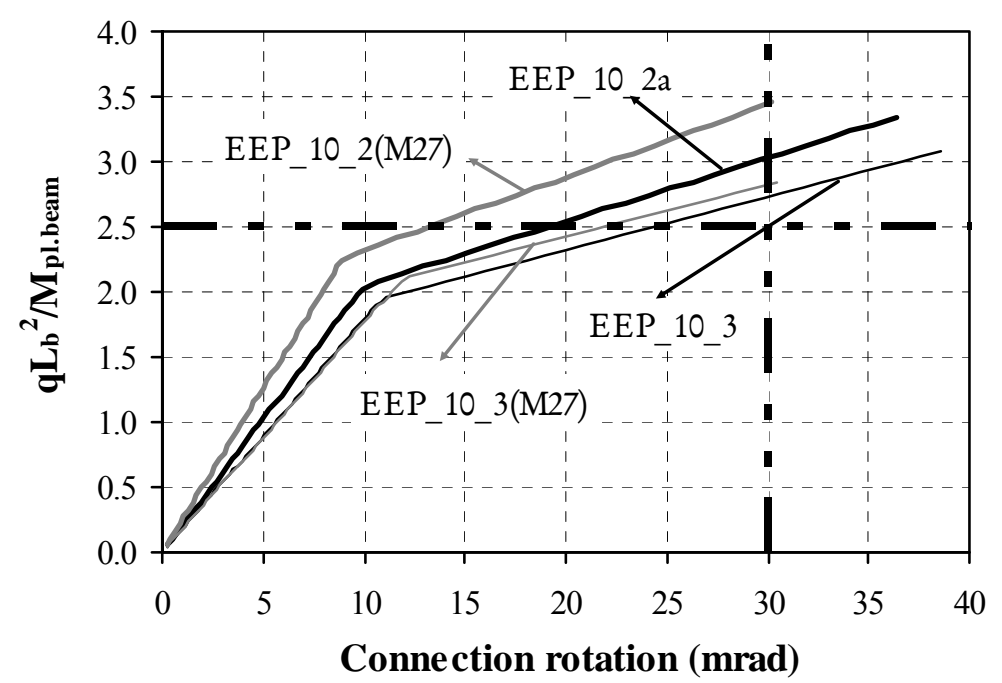

(b) Specimens EEP

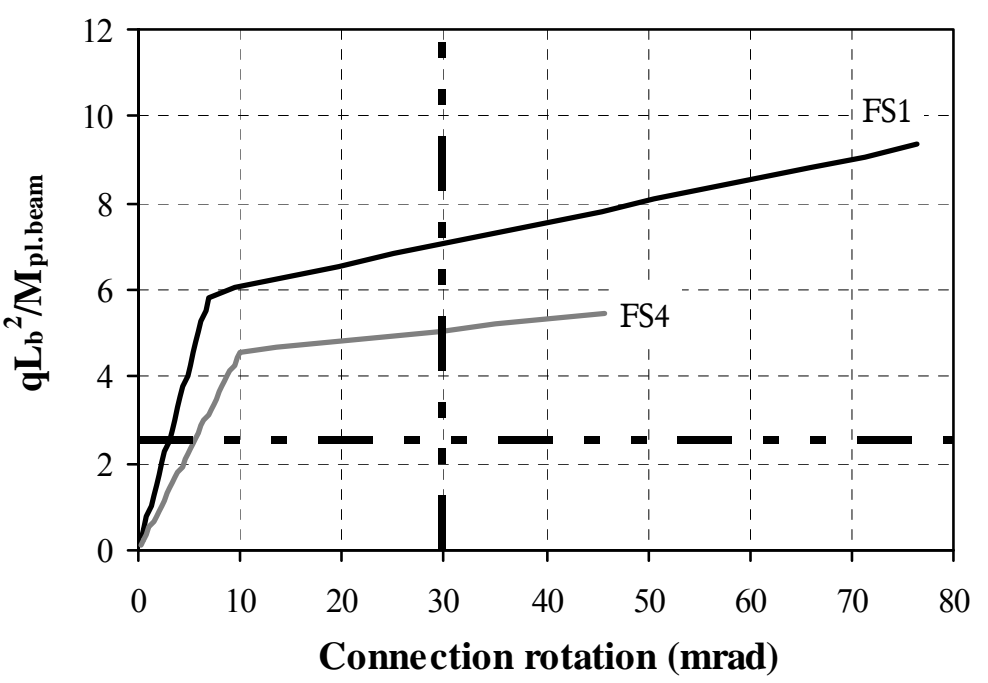

(c) Specimens FS1 and FS4

Figure 10. Behaviour "Available Rotation Capacity" vs. "Ratio $q L_{\mathrm{b}}{ }^{2} / M_{\text {pl.beam }}$ " $\left(L_{\mathrm{b}}=50 h_{\mathrm{b}}\right)$ 
The ratio $\varsigma=q L_{\mathrm{b}}{ }^{2} / M_{\text {pl.beam }}$ gives an idea of the degree of utilization of the beam. The graphs in Figure 10 highlight the demand for higher rotations in higher steel grades for the same value of $\varsigma$. Tables 5 and 6 that compare the joint rotation for such a ratio of 2.5 (second column) clearly show this tendency. If now the results are compared for a specific rotation of $30 \mathrm{mrad}$, for example (third column on Tables 5 and 6 ) the values of the above ratio decrease with the end plate yield stress. The failure conditions, for $\phi=\phi_{\mathrm{Mj} \text {.max }}$, are also characterized, in terms of maximum load, $q_{\mathrm{u}}$, the bending moment acting (i) at the joints $M_{\mathrm{j}}$ and (ii) at mid-span $M_{\text {mid-sp }}$, computed with reference to the plastic moment of the beam section. The ratio $M_{\mathrm{j}} / M_{\text {pl.beam }}$ corresponds to the degree of joint partial-strength. As expected, the maximum load increases when higher stress steel grades are employed. But, the degree of joint partial-strength decreases and the beam efficiency reduces. Finally, Table 7 compares the increase in steel grade for the various specimens and the corresponding increase in load capacity. This correspondence is not comparable. Taking specimen EEP_10_2(M27) (S690) and EEP_10_3(M27) (S960) as example, the improvement in steel grade is $40 \%$ whilst the maximum load only increases $10 \%$.

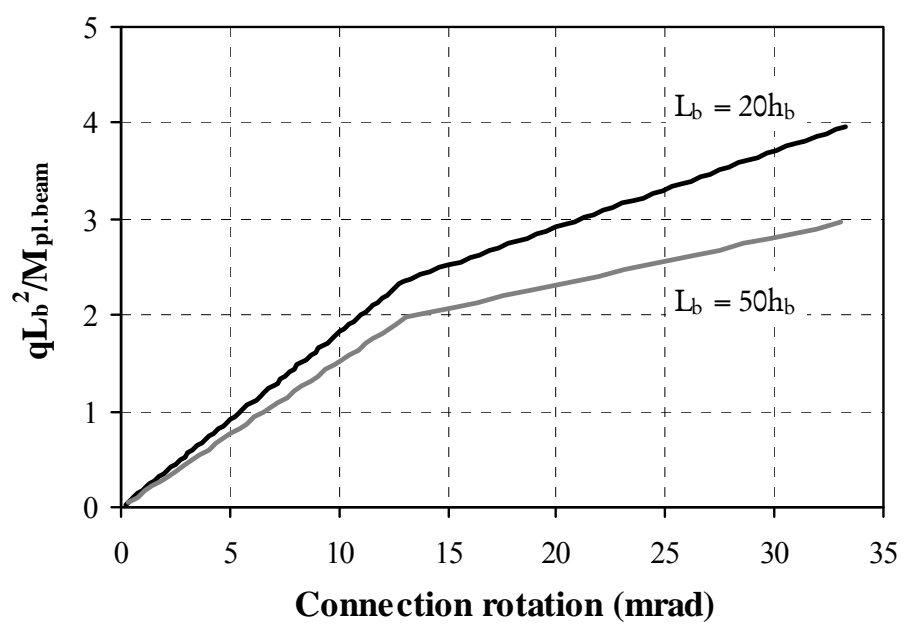

Figure 11. F2EP_15_2: "Behaviour Available Rotation Capacity" vs. "Ratio $q L_{\mathrm{b}}{ }^{2} / M_{\text {pl.beam }}$ " for Different Beam Spans

Table 7. Computation of the Increase in Stele Grade and Corresponding Increase in Maximum Load

\begin{tabular}{lrrrrr}
\hline \multicolumn{1}{c}{ Test ID } & $f_{\text {y.ep.nom }}(\mathrm{MPa})$ & $M_{\text {pl.beam }}(\mathrm{kNm})$ & $\begin{array}{c}\text { Increase } \\
\text { in steel grade }\end{array}$ & $q_{\mathrm{u}}(\mathrm{kN} / \mathrm{m})$ & \multicolumn{2}{c}{$\begin{array}{c}\text { Increase } \\
\text { in max. load }\end{array}$} \\
\hline F2EP_15_1 & 460 & 749 & 1.5 & 11.3 & 1.2 \\
F2EP_15_2 & 690 & 1123 & 13.5 & 1.3 \\
\hline EEP_10_2a & 690 & 1123 & 1.4 & 15.3 & 1.5 \\
EEP_10_3 & 960 & 1563 & 1.4 & 15.8 & 1.1 \\
\hline EEP_10_2(M27) & 690 & 1123 & 18.1 & 1.1 \\
EEP_10_3(M27) & 960 & 1563 & 1.9 & 9.2 & 10.5 \\
\hline FS1 & 355 & 223 & & & \\
FS4 & 690 & 433 & & &
\end{tabular}




\section{CONCLUSIONS}

The primary goals of this research work were (i) the experimental characterization, (ii) the validation of current Eurocode 3 specifications for mild steels and (iii) the deformation analysis of HPS moment connections.

Comparison of test results with EN 1993-1-8 procedures for the design of joints within the semi-continuous/partially-restrained concept shows that (i) the T-stub idealization of the tension zone of moment connections adopted in EN 1993-1-8 gives accurate results in terms of prediction of the design resistance even when HPS grades are employed, (ii) the stiffness properties are overestimated and (iii) the guidelines for verification of sufficient rotation capacity can be quite conservative in some cases (Tables 3 and 4).

It was found out that the rotation capacity of the connection specimens using HPS satisfy high deformation demands. Plastic rotation capacities of $30 \mathrm{mrad}$ (and above) were achieved with thinner end plates and $15 \mathrm{~mm}$ flush end plates. However, a simple beam analysis with actual joint behaviour has shown that (i) the efficiency of HPS moment connections has no correspondence to the improvement in steel quality and (ii) the deformation demands of these connections are higher than for mild steel grades. Both aspects must further be looked into in order to establish accurate ductility and deformation requirements that allow the designer to take full advantage in the use of this new family of constructional steels. The next logical step forward to this investigation is the numerical implementation of these joint configurations to propose simple expressions for evaluation of the rotation capacity based on geometrical and mechanical parameters.

\section{ACKNOWLEDGMENTS}

Financial support from Delft University of Technology is gratefully acknowledged. The assistance provided by the staff of the Stevin Laboratory, particularly Mr. Edwin Scharp, in preparing the test specimens and their support in conducting the tests, is most appreciated.

\section{REFERENCES}

[1] Douty, R.T. and McGuire, W., "High Strength Moment Connections", Journal of Structural Division, ASCE, 1965, Vol. 91, ST2, pp. 101-128.

[2] Zoetemeijer, P., "A Design Method for the Tension Zone of Statically Loaded Bolted Beam-to-Column Connections", Heron, 1974, Vol. 20, No. 1, pp. 1-59.

[3] Mann, A.P. and Morris, L.J., "Limit Design of Extended End Plate Connections", Journal of the Structural Division, ASCE, 1979, Vol. 105, ST3, pp. 511-526.

[4] Yee, Y.L. and Melchers, R.E., "Moment-rotation Curves for Bolted Connections", Journal of Structural Engineering, ASCE, 1985, Vol. 112, No. 3, pp. 615-635.

[5] Davison, J.B., Kirby, P.A. and Nethercot, D.A., "Rotational Stiffness Characteristics of Steel Beam-to-Column Connections", Journal of Constructional Steel Research, 1987, Vol. 8, pp. 17-54.

[6] Jaspart, J.P. and Maquoi, R., "Prediction of the Semi-rigid and Partial Strength Properties of Structural Joints", Proceedings of the Annual Technical Meeting on Structural Stability Research, Lehigh, 1994, pp. 177-191.

[7] Faella, C., Piluso, V. and Rizzano, G., "Structural Semi-rigid Connections - Theory, Design and Software", CRC Press, 2000. 
[8] European Committee for Standardization (CEN), EN 1993-1-8 - Eurocode 3: Design of Steel Structures - Part 1-8: Design of Joints, 2005.

[9] American Institute of Steel Construction (AISC), ANSI/AISC 360-05 - Specification for Structural Steel Buildings, 2005.

[10] Gioncu, V., Mateescu, G., Petcu, D. and Anastasiadis, A., "Prediction of Available Ductility by Means of Local Plastic Mechanism Method: DUCTROT Computer Program”, Chapter 2.1 in Moment Resistant Connections of Steel Frames in Seismic Areas (Ed.: F. Mazzolani), E\&FN Spon, pp. 95-146.

[11] Beg, D., Zupančič, E. and Vayas, I., "On the Rotation Capacity of Moment Connections”, Journal of Constructional Steel Research, 2004, Vol. 60, pp. 601-620.

[12] Girão Coelho, A.M., "Characterization of the Ductility of Bolted End Plate Beam-to-Column Steel Connections", PhD Thesis, University of Coimbra, 2004. Free download at: $\mathrm{http}: / / \mathrm{www} . \mathrm{cmm} . \mathrm{pt} / \mathrm{gcom} / \mathrm{publicacoes} / \mathrm{teses} / \mathrm{phd}$ thesis_ana_girao.pdf

[13] Bjorhovde, R., "Deformation Considerations for Connection Performance and Design", Proceedings of the Fifth International ECCS/AISC Workshop on Connections in Steel Structures: Innovative Steel Connections, Amsterdam, 2004, pp. 11-20.

[14] Zoetemeijer, P., "Summary of the Research on Bolted Beam-to-Column Connections", Report 25-6-90-2, Faculty of Civil Engineering, Stevin Laboratory - Steel Structures, Delft University of Technology, 1990.

[15] Jaspart, J.P., "Contributions to Recent Advances in the Field of Steel Joints - Column Bases and Further Configurations for Beam-to-Column Joints and Beam Splices", Aggregation Thesis, University of Liège, 1997.

[16] Swanson, J.A., "Characterization of the Strength, Stiffness and Ductility Behaviour of T-stub Connections", PhD Thesis, Georgia Institute of Technology, 1999.

[17] Kuhlmann, U. and Kühnemund, F., "Ductility of Semi-rigid Steel Joints", Proceedings of the International Colloquium on Stability and Ductility of Steel Structures (SDSS 2002), Budapest, 2002, pp. 363-370.

[18] Günther, H-P. (Ed.), "Use and Application of High-performance Steels for Steel Structures", International Association for Bridge and Structural Engineering (IABSE), Structural Engineering Documents, 2005, Vol. 8.

[19] European Committee for Standardization (CEN), prEN 1993-1-12 - Eurocode 3: Design of Steel Structures - Part 1-12: Additional Rules for the Extension of EN 1993 up to Steel Grades S700; 2005.

[20] European Committee for Standardization (CEN), EN 1993-1-1 - Eurocode 1: Design of Steel Structures - Part 1-1: General Rules and Rules for Buildings, 2005.

[21] Girão Coelho, A.M. and Bijlaard, F.S.K., "Experimental Behaviour of High Performance Steel Moment Connections", Report 6-06-5, Faculty of Civil Engineering, Stevin Laboratory - Steel Structures, Delft University of Technology, 2006.

[22] Girão Coelho, A.M. and Bijlaard, F.S.K., "Experimental Behaviour of High Strength Steel end Plate Connections", Journal of Constructional Steel Research, 2007, Vol. 63, pp. 1228-1240.

[23] Zandonini, R. and Zanon, P., "Experimental Analysis of End Plate Connections", Proceedings of the First International ECCS/AISC Workshop on Connections in Steel Structures: Behaviour, Strength and Design, Cachan, 1988, pp. 40-51.

[24] Wilkinson, S., Hurdman, G. and Crowther, A., "A Moment Resisting Connection for Earthquake Resistant Structures", Journal of Constructional Steel Research, 2006, Vol. 62, pp. 295-302.

[25] Bjorhovde, R., "Development and Use of High Performance Steel”, Journal of Constructional Steel Research, Vol. 60, 2004, pp. 393-400. 
[26] Girão Coelho, A.M., Simões da Silva, L. and Bijlaard, F.S.K., "Ductility Analysis of Bolted Extended End Plate Beam-to-Column Connections in the Framework of the Component Method", Steel and Composite Structures, 2006, Vol. 6, No. 1, pp. 33-53.

[27] Girão Coelho, A.M., Bijlaard, F.S.K. and Simões da Silva, L., "Experimental Assessment of the Ductility of Extended End Plate Connections", Engineering Structures, 2004, Vol. 26, pp. 1185-1206.

\section{NOMENCLATURE}

\section{Lower cases}

$a_{\mathrm{w}}$

$f_{\mathrm{u}}$

$f_{\mathrm{y}}$

$h$

$h_{i}$

$k_{\mathrm{e}}$

$k_{\mathrm{ec}}$

$k_{\text {et }}$

$n$

$q$

$t$

$Z$

\section{Upper cases}

\section{E}

$F_{\text {ti.R }}$

$L$

M

$M_{\mathrm{j} . \mathrm{R}}$

$M_{\text {j.max }}$

$M_{\not C}$

$S_{\text {j.ini }}$

$S_{\text {j.p-1 }}$

$W_{\mathrm{pl}}$

\section{$\underline{\text { Greek letters }}$}

$\varepsilon_{\mathrm{f}}$

$\phi$

$\phi_{\mathrm{b}}$

$\phi_{\mathrm{C}}$

$\phi_{\text {Mj.max }}$

$\phi_{\mathrm{Mj} . \mathrm{R}}$

$\phi_{\mathrm{p}}$

$\phi_{\mathrm{y}}$

$\vartheta_{j}$

$\vartheta_{\text {j.max load }}$

$\rho_{\mathrm{y}}$

$\varsigma$
Throat thickness of a fillet weld

Ultimate or tensile stress

Yield stress

Depth

Distance of bolt row $i$ to the centre of compression

Stiffness of an active joint component

Stiffness of the assembly of components in the compression/shear zone

Equivalent stiffness of the assembly of components in the tension zone

Number of bolt rows

Load

Thickness

Lever arm

Young modulus

Potential resistance of bolt row $i$ in the tension zone at plastic conditions

Length

Bending moment

Joint flexural plastic resistance

Maximum bending moment

Bending moment at fracture of the joint

Initial rotational stiffness of a joint

Post-yield rotational stiffness of a joint

Plastic cross-section modulus
Strain at rupture load

Connection rotational deformation

Bolt diameter

Rotation capacity of a connection

Rotation of the connection at maximum load

Connection rotation "analytical" value at which the moment resistance first reaches $M_{\mathrm{j} . \mathrm{R}}$

Plastic rotation of a connection

First yielding connection rotation

Joint ductility index

Joint ductility index evaluated for the rotation at maximum load

Yield ratio

Ratio $q L_{\mathrm{b}}^{2} / M_{\text {pl.beam }}$ 


\section{Subscripts}

\begin{tabular}{lll}
\hline $\mathrm{b}$ & & Beam; bolt \\
$\mathrm{d}$ & & Design value \\
$\mathrm{ep}$ & & End plate \\
$\mathrm{exp}$ & & Experimental \\
$\mathrm{EC} 3$ & Eurocode 3 \\
$\mathrm{j}$ & Joint \\
$\max$ & Maximum \\
$\operatorname{mid}-\mathrm{sp}$ & Mid-span \\
nom & Nominal value \\
$\mathrm{pl}$ & Pure plastic conditions \\
$\mathrm{u}$ & Ultimate conditions \\
$\mathrm{y}$ & Yield
\end{tabular}

